Karl MARX (1851)

\title{
Le 18 Brumaire \\ de Louis Bonaparte
}


Karl MARX (1813-1883)

\section{Le 18 Brumaire de Louis Bonaparte. \\ (1851)}

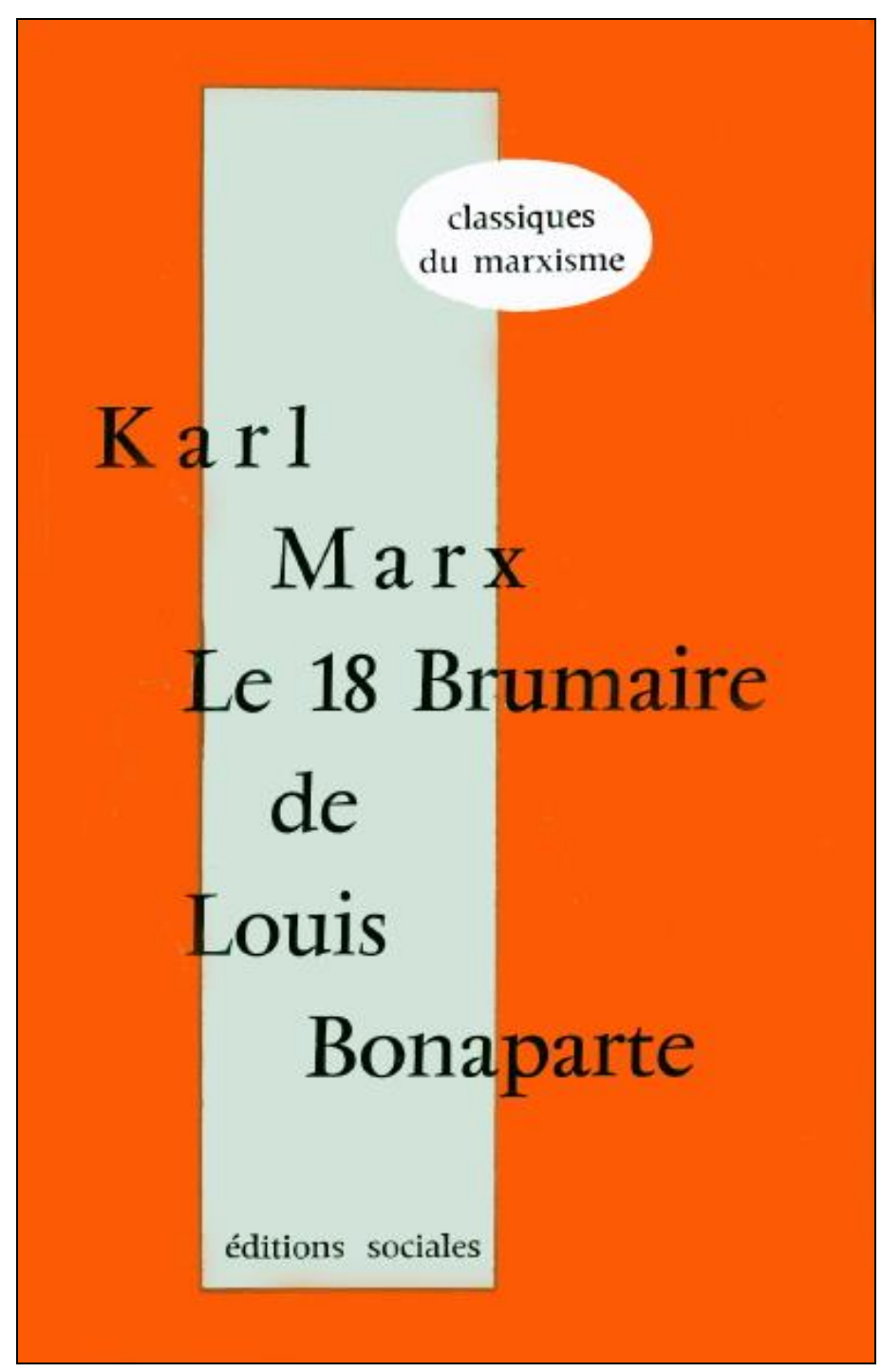

Paris : Les Éditions sociales, 1969, 162 pp.

Collection : Classiques du marxisme.

Traduction de la $3^{\mathrm{e}}$ édition allemande de 1885 . 


\section{Table des matières}

Note des éditeurs

Préface de l'auteur à la deuxième édition allemande, 1869.

Préface de Friedrich Engels à la troisième édition allemande, 1885.

$\underline{\text { Le } 18 \text { Brumaire de Louis Bonaparte }}$

$\underline{\mathbf{I}}$

II

$\underline{\text { III }}$

$\underline{\text { IV }}$

$\underline{\mathrm{V}}$

$\underline{\mathrm{VI}}$

$\underline{\text { VII }}$ 


\section{NOTE DES ÉDITEURS}

\section{Retour à la table des matières}

Marx était installé à Londres depuis près de deux ans et demi lorsque se produisit le coup d'État du 2 décembre qui venait donner une conclusion provisoire, mais logique, aux événements qui s'étaient déroulés en France depuis février 1848. Quelques jours après le « coup de théâtre » de Louis Bonaparte, Weydemeyer, qui venait de s'installer à New York, sollicitait Engels et Marx de lui adresser des articles pour un journal hebdomadaire dont il projetait la publication. Dès le 23 décembre, Marx lui répondait en lui annonçant une série d'articles sur le « 18 Brumaire ».

Malgré sa santé déficiente et des difficultés financières sans nombre, Marx se mit au travail, entre le $1^{\mathrm{er}}$ janvier et le 25 mars 1852, il expédie avec une régularité remarquable les sept articles qui constituent les chapitres de la brochure. Malheureusement, les projets de Weydemeyer avaient dû entre temps être abandonnés, et c'est grâce à un dévouement anonyme qu'il fut en mesure de publier une revue : La Révolution, dont le premier numéro, qui contenait le 18 Brumaire, parut à New York le 20 mai 1852.

Du vivant de Marx, l'ouvrage ne connaitra qu'une réédition en 1869. Et ce n'est que l'édition assurée en 1885 par Engels qui devait inaugurer la brillante carrière du 18 Brumaire de Louis Bonaparte. Après un certain nombre de tentatives infructueuses, la première traduction française paraissait enfin à Lille en 1891.

Bien que reprenant en grande partie les événements dont traitaient des Luttes de classes en France, le 18 Brumaire constitue une œuvre différente. En 1852, Marx jugeait avec beaucoup plus de recul les événements dont il venait d'être le témoin. Son «optique » a changé. Il se préoccupe essentiellement de tirer de la Révolution de 448 des conclusions pour la politique future du prolétariat. Aussi le 18 Brumaire se présente-t-il comme une œuvre en un sens plus théorique et plus abstraite que les Luttes de classes.

Mais cette brochure marque aussi un approfondissement de la pensée de Marx. Dans le Manifeste, la question de l'État n'était soulevée que d'une manière générale. A la lumière des événements de 48, Marx pose maintenant d'une façon nouvelle et concrète le problème du remplacement de l'État bourgeois par l'État prolétarien. On lira avec profit le commentaire que Lénine a donné au 18 Brumaire dans L'État et la révolution.

La présente édition a fait l'objet d'une révision approfondie de la traduction publiée antérieurement. Elle a été également pourvue de notes et l'index qui la termine a été refait et amélioré. 


\section{PRÉFACE}

\section{de l'auteur à de deuxième édition allemande,}

1869.

\section{$\underline{\text { Retour à la table des matières }}$}

Mon ami Joseph Weydemeyer, mort prématurément, se proposait de publier, à partir du $1^{\text {er }}$ janvier 1852, une revue politique hebdomadaire à New York. Il me demanda d'écrire pour cette publication l'histoire du coup d'état. Je lui fis parvenir toutes les semaines, jusqu'à la mi-février, des articles intitulés : «Le 18 Brumaire de Louis Bonaparte ». Entre temps, le plan primitif de Weydemeyer avait échoué. Mais il publia, au printemps de l'année 1852, une revue mensuelle intitulée La Révolution, dont le second ${ }^{1}$ numéro est constitué par le « 18 Brumaire ». Quelques centaines d'exemplaires en furent alors envoyés en Allemagne, mais sans pouvoir cependant être placés en librairie. Un libraire allemand, qui se donnait comme radical avancé et auquel j'en proposai la diffusion, répondit en manifestation son effroi vertueux d'une proposition aussi «inopportune ».

On voit, par ce qui précède, que l'ouvrage ci-dessous est né sous la pression des événements et que la matière historique qu'il traite ne dépasse pas le mois de février 1852 . Sa réédition actuelle est due, en partie, aux demandes de librairie et, en partie, aux instances de mes amis d'Allemagne.

Parmi les ouvrages qui, à peu près à la même époque, traitaient le même sujet, deux seulement méritent d'être mentionnés : Napoléon le Petit, de Victor Hugo, et Le Coup d'État, de Proudhon.

Victor Hugo se contente d'invectives amères et spirituelles contre l'auteur responsable du coup d'état. L'événement lui-même lui apparaît comme un éclair dans un ciel serein. Il n'y voit que le coup de force d'un individu. Il ne se rend pas compte qu'il le grandit ainsi, au lieu de le diminuer, en lui attribuant une force d'initiative personnelle sans exemple dans l'histoire. Proudhon, lui s'efforce de représenter le coup d'État comme le résultat d'un développement historique antérieur. Mais, sous sa plume, la construction historique du coup d'état se transforme en une apologie du héros du coup d'état. Il tombe ainsi dans l'erreur que commettent nos historiens soi-disant objectifs. Quant à moi, je montre, par contre, comment la

1 C'est en réalité dans le premier numéro de La Révolution que parut l'œuvre de Marx. 
lutte des classes en France créa des circonstances et une situation telles qu'elle permit à un personnage médiocre et grotesque de faire figue de héros.

Un remaniement de l'ouvrage ci-dessous lui aurait enlevé sa couleur particulière. Je me suis donc borné à corriger les fautes d'impression et à supprimer les allusions qui ne seraient plus comprises aujourd'hui.

Ce que je disais dans la phrase finale de mon ouvrage: "Mais lorsque le manteau impérial tombera finalement sur les épaules de Louis Bonaparte, la statue d'airain de Napoléon s'écroulera du haut de la colonne Vendôme », s'est déjà réalisé.

Le colonel Charras a, le premier, engagé l'offensive contre le culte de Napoléon dans son ouvrage sur la campagne de 1815. Depuis, et notamment au cours de ces dernières années, la littérature française, au moyen des armes de la recherche historique, de la critique, de la satire et de l'ironie, a donné le coup de grâce à la légende de Napoléon. Hors de France, cette rupture violente avec les croyances populaires traditionnelles, cette immense révolution intellectuelle, a été peu remarquée et encore moins comprise.

En fin de compte, j'espère que cet ouvrage contribuera à écarter le terme couramment employé aujourd'hui, particulièrement en Allemagne, de césarisme. Dans cette analogie historique superficielle, on oublie le principal, à savoir que, dans l'ancienne Rome, la lutte des classes ne se déroulait qu'à l'intérieur d'une minorité privilégiée, entre les libres citoyens riches et les libres citoyens pauvres, tandis que la grande masse productive de la population, les esclaves, ne servait que de piédestal passif aux combattants. On oublie la phrase célèbre de Sismondi : «Le prolétariat romain vivait au dépens de la société, tandis que la société moderne vit aux dépens du prolétariat. » Étant donné la différence complète entre les conditions matérielles, économiques de la lutte des classes dans l'antiquité et dans les temps modernes, les formes politiques qui en découlent ne peuvent pas avoir plus de ressemblance entre elles que l'archevêque de Canterbury avec le grand prêtre Samuel.

Londres, 23 juin 1869.

KARL MARX 


\section{PRÉFACE \\ de Friedrich Engels \\ à de troisième édition allemande, 1885.}

\section{$\underline{\text { Retour à la table des matières }}$}

Qu'une nouvelle édition du 18 Brumaire soit devenue nécessaire trente-trois ans après sa parution, cela prouve que cette brochure n'a encore aujourd'hui rien perdu de sa valeur.

En effet, c'était un travail génial. Immédiatement après l'événement qui surprit tout le monde politique comme un éclair dans le ciel serein, qui fut maudit par les uns avec des cris d'indignation vertueuse, et accueilli par les autres comme l'acte apportant le salut hors de la révolution et comme le châtiment du trouble provoque par elle, mais fut un objet d'étonnement et d'incompréhension pour tous, Marx en fit un exposé court, épigrammatique. Il y expliquait toute la marche des événements survenus en France depuis les Journées de février dans leurs rapports internes, montrait comment le miracle du 2 Décembre n'était que le résultat naturel, nécessaire de ces rapports, sans avoir besoin de traiter le héros du coup d'état autrement qu'avec un mépris bien mérité. Et le tableau était brossé avec une telle maîtrise que toutes les révélations faites depuis n'ont fait qu'apporter de nouvelles preuves de la fidélité avec laquelle il reflète la réalité. Cette compréhension remarquable de l'histoire quotidienne vivante, cette intelligence claire des événements, au moment même où ils se déroulaient, est, en effet, sans exemple.

Mais, pour cela, il fallait la connaissance profonde de l'histoire de France qu'avait Marx. La France est le pays où les luttes de classes ont été menées chaque fois, plus que partout ailleurs, jusqu'à la décision complète, et où, par conséquent, les formes politiques changeantes, à l'intérieur desquelles elles se meuvent et dans lesquelles se résument leurs résultats, prennent les contours les plus nets. Centre du féodalisme au moyen âge, pays classique, depuis la Renaissance, de la monarchie héréditaire, la France a, dans sa grande Révolution, détruit le féodalisme et donné à la domination de la bourgeoisie un caractère de pureté classique qu'aucun autre pays n'a atteint en Europe. De même, la lutte du prolétariat révolutionnaire contre la bourgeoisie régnante y revêt des formes aiguës, inconnues ailleurs. 
Telle est la raison pour laquelle Marx non seulement étudiait avec une prédilection spéciale l'histoire du passé français, mais encore suivait dans tous ses détails l'histoire courante, rassemblait les matériaux destinés à être utilisés plus tard, et ne fut, par conséquent, jamais surpris par les événements.

Mais à cela vint s'ajouter encore une autre circonstance. Ce fut précisément Marx qui découvrit le premier la loi d'après laquelle toutes les luttes historiques, qu'elles soient menées sur le terrain politique, religieux, philosophique ou dans tout autre domaine idéologique, ne sont, en fait, que l'expression plus ou moins nette des luttes des classes sociales, loi en vertu de laquelle l'existence de ces classes, et par conséquent aussi leurs collisions sont, à leur tour, conditionnées par le degré de développement de leur situation économique, par leur mode de production et leur mode d'échange, qui dérive lui-même du précédent. Cette loi, qui a pour l'histoire la même importance que la loi de la transformation de l'histoire de la II ${ }^{\mathrm{e}}$ République française. C'est cette histoire qui lui a servi à mettre sa loi à l'épreuve et, trente-trois ans après, il nous faut encore reconnaître qu'elle a subi brillamment cette épreuve.

\section{FRIEDRICH ENGELS.}




\section{I}

\section{$\underline{\text { Retour à la table des matières }}$}

Hegel fait quelque part cette remarque que tous les grands événements et personnages historiques se répètent pour ainsi dire deux fois. Il a oublié d'ajouter : la première fois comme tragédie, la seconde fois comme farce Causidière pour Danton, Louis Blanc pour Robespierre, la Montagne de 1848 à 1951 pour la Montagne de 1793 à 1795, le neveu pour l'oncle. Et nous constatons la même caricature dans les circonstances où parut la deuxième édition du 18 Brumaire.

Les hommes font leur propre histoire, mais ils ne la font pas arbitrairement, dans les conditions choisies par eux, mais dans des conditions directement données et héritées du passé. La tradition de toutes les générations mortes pèse d'un poids très lourd sur le cerveau des vivants. Et même quand ils semblent occupés à se transformer, eux et les choses, à créer quelque chose de tout à fait nouveau, c'est précisément à ces époques de crise révolutionnaire qu'ils évoquent craintivement les esprits du passé, qu'ils leur empruntent leurs noms, leurs mots d'ordre, leurs costumes, pour apparaître sur la nouvelle scène de l'histoire sous ce déguisement respectable et avec ce langage emprunté. C'est ainsi que Luther prit le masque de l'apôtre Paul, que la révolution de 1789 à 1814 se drapa successivement dans le costume de la République romaine, puis dans celui de l'Empire romain, et que la révolution de 1848 ne sut rien faire de mieux que de parodier tantôt 1789, tantôt la tradition révolutionnaire de 1793 à 1795. C'est ainsi que le débutant qui apprend une nouvelle langue la retraduit toujours dans sa langue maternelle, mais il ne réussit à s'assimiler l'esprit de cette nouvelle langue et à s'en servir librement que quand il arrive à la manier sans se rappeler sa langue maternelle, et qu'il parvient même à oublier complètement cette dernière.

L'examen de ces conjurations des morts de l'histoire révèle immédiatement une différence éclatante. Camille Desmoulins, Danton, Robespierre, Saint-Just, Napoléon, les héros, de même que les partis et la masse de la première révolution française accomplirent dans le costume romain, et en se servant d'une phraséologie romaine, la tâche de leur époque, à savoir l'éclosion et l'instauration de la société bourgeoise moderne. Si els premiers brisèrent en morceaux les institutions féodales et coupèrent les têtes féodales qui avaient poussé sur ces institutions, Napoléon, lui, créa à l'intérieur de la France les conditions grâce auxquelles on pouvait désormais développer la libre concurrence, exploiter la propriété parcellaire du sol et utiliser les forces productives industrielles libérées de la nation, tandis qu'à l'extérieur il 
balaya partout les institutions féodales dans al mesure où cela était nécessaire pour créer à la société bourgeoise en France l'entourage dont elle avait besoin sur le continent européen. La nouvelle forme de société une fois établie, disparurent les colosses antédiluviens, et, avec eux, la Rome ressuscitée : les Brutus, les Gracchus, les Publicola, les tribuns, les sénateurs et César lui-même. La société bourgeoise, dans la sobre réalité s'était créé ses véritables interprètes et porte-parole dans la personne des Say, des Cousin, des Royer-Collard, des Benjamin Constant et des Guizot. Ses véritables capitaines siégeaient derrière les comptoirs, et la «tête de lard » de Louis XVIII était sa tête politique. Complètement absorbée par la production de la richesse et par la lutte pacifique de la concurrence, elle avait oublié que les spectres de l'époque romaine avaient veillé sur son berceau. Mais si peu héroïque que soit la société bourgeoise, l'héroïsme, l'abnégation, la terreur, la guerre civile et les guerres extérieures n'en avaient pas moins été nécessaires pour la mettre au monde. Et ses gladiateurs trouvèrent dans les traditions strictement classiques de la République romaine les idéaux et les formes d'art, les illusions dont ils avaient besoin pour se dissimuler à eux-mêmes le contenu étroitement bourgeois de leurs luttes et pour maintenir leur enthousiasme au niveau de la grande tragédie historique. C'est ainsi qu'à une autre étape de développement, un siècle plus tôt, Cromwell et le peuple anglais avaient emprunté à l'Ancien Testament le langage, les passions et les illusions nécessaires à leur révolution bourgeoise. Lorsque le véritable but fut atteint, c'est-àdire lorsque fut réalisée la transformation bourgeoise de la société anglaise, Lock évinça Habacuc $^{2}$.

La résurrection des morts, dans ces révolutions, servit par conséquent à magnifier les nouvelles luttes, non à parodier les anciennes, à exagérer dans l'imagination la tâche à accomplir, non à se soustraire à leur solution en se réfugiant dans la réalité, à retrouver l'esprit de la révolution et non à évoquer de nouveau son spectre.

La période de 1848 à 1851 ne fit qu'évoquer le spectre de la grande Révolution française, depuis Marrast, le républicain aux gants jaunes qui prit la défroque du vieux Bailly, jusqu'à l'aventurier qui dissimule ses traits d'une trivialité repoussante sous le masque mortuaire de fer de Napoléon. Tout un peuple qui croit s'être donné, au moyen d'une révolution, une force de mouvement accrue, se trouve brusquement transporté dans une époque abolie et pour qu'aucune illusion concernant cette rechute ne soit possible, réapparaissent les anciennes dates, l'ancien calendrier, les anciens noms, les anciens édits tombés depuis longtemps dans le domaine des érudits et des antiquaires, et tous les cieux sbires qui semblaient depuis longtemps tombés en décomposition. La nation entière se conduit comme cet Anglais toqué de Bedlam ${ }^{3}$, qui s'imaginait vivre à l'époque des anciens Pharaons et se plaignait tous les

2 L'un des douze petits prophètes hébreux. En dénonçant la tyrannie qui régnait à son époque, il prédit la soumission du peuple d'Israël aux Chaldéens et sa libération ultérieure, dans laquelle il voyait la victoire définitive du bien sur le mal. Il vécut probablement au $\mathrm{VII}^{\mathrm{e}}$ siècle avant l'ère chrétienne.

3 Maison d'aliénés à Londres. 
jours des pénibles travaux qu'il était obligé d'accomplir comme mineur dans les mines d'or d'Éthiopie, emmuré dans cette prison souterraine, avec, sur la tête, une lampe éclairant misérablement, derrière lui, le gardien d'esclaves armé d'un long fouet, et, aux issues, toute une foule de mercenaires barbares qui ne comprenaient ni les ouvriers astreints au travail des mines, ni ne se comprenaient entre eux, ne parlant pas la même langue. «Et tout cela, ainsi se lamentait-il, m'est imposé à moi, libre citoyen de la Grande-Bretagne, pour extraire de l'or au profit des anciens Pharaons ! » « Pour payer les dettes de la famille Bonaparte », se lamente la nation française. Tant qu'il avait sa raison, l'Anglais ne pouvait se débarrasser de l'idée fixe de faire de l'or, les Français, tant qu'ils firent leur révolution, ne purent se débarrasser des souvenirs napoléoniens, comme l'a prouvé l'élection du 10 décembre. Ils éprouvaient le désir d'échapper aux dangers de la révolution en retournant aux marmites de l'Égypte, et le 2 décembre 1851 fut la réponse. Ils n’ont pas seulement caricaturé le vieux Napoléon lui-même, tel qu'il lui faut se conduire au milieu du XIX ${ }^{\mathrm{e}}$ siècle.

La révolution sociale du $\mathrm{XIX}^{\mathrm{e}}$ siècle ne peut pas tirer sa poésie du passé, mais seulement de l'avenir. Elle ne peut pas commencer avec elle-même avant d'avoir liquidé complètement toute superstition à l'égard du passé. Les révolutions antérieures avaient besoin de réminiscences historiques pour se dissimuler à elles-mêmes leur propre contenu. La révolution du $\mathrm{XIX}^{\mathrm{e}}$ siècle doit laisser les morts enterrer leurs morts pour réaliser son propre objet. Autrefois, la phrase débordait le contenu, maintenant, c'est le contenu qui déborde la phrase.

La révolution de février fut un coup de main réussi par surprise contre l'ancienne société, et le peuple considéra ce coup de main heureux comme un événement historique ouvrant une nouvelle époque. Le 2 Décembre, la révolution de février est escamotée par le tour de passepasse d'un tricheur, et ce qui semble avoir été renversé, ce n'est plus la monarchie, ce sont les concessions libérales qui lui avaient été arrachées au prix de luttes séculaires. Au lieu que la société elle-même se soit donné un nouveau contenu, c'est l'État qui paraît seulement être revenu à sa forme primitive, à la simple domination insolente du sabre et du goupillon. C'est ainsi qu'au « coup de main » de février 1848 répond le «coup de tête » de décembre 1851 . Aussi vite perdu que gagné. Malgré tout, la période intermédiaire ne s'est pas écoulée en vain. Au cours des années 1848 à 1851, la société française, par une méthode plus rapide, parce que révolutionnaire, a rattrapé les études et les expériences qui, si les événements s'étaient développés de façon régulière, pour ainsi dire académique, eussent dû précéder la révolution de février au lieu de la suivre, pour quelle fût autre chose qu'un simple ébranlement superficiel. La société semble être actuellement revenue à son point de départ. En réalité, c'est maintenant seulement qu'elle doit se créer son point de départ révolutionnaire, c'est-à-dire la situation, les rapports, les conditions qui seuls, permettent une révolution sociale sérieuse. 
Les révolutions bourgeoises, comme celles du XVIII ${ }^{\mathrm{e}}$ siècle, se précipitent rapidement de succès en succès, leurs effets dramatiques se surpassent, les hommes et les choses semblent être pris dans des feux de diamants, l'enthousiasme extatique est l'état permanent de la société, mais elles sont de courte durée. Rapidement, elles atteignent leur point culminant, et un long malaise s'empare de la société avant qu'elle ait appris à s'approprier d'une façon calme et posée les résultats de sa période orageuse. Les révolutions prolétariennes, par contre, comme celles du XIX ${ }^{\mathrm{e}}$ siècle, se critiquent elles-mêmes constamment, interrompent à chaque instant leur propre cours, reviennent sur ce qui semble déjà être accompli pour le recommencer à nouveau, raillent impitoyablement les hésitations, les faiblesses et les misères de leurs premières tentatives, paraissent n'abattre leur adversaire que pour lui permettre de puiser de nouvelles forces de la terre et se redresser à nouveau en formidable en face d'elles, reculent constamment à nouveau devant l'immensité infinie de leurs propres buts, jusqu'à ce que soit créée enfin la situation qui rende impossible tout retour en arrière, et que les circonstances elles-mêmes crient :

Hic Rhodus, hic, salta ${ }^{4}$ !

C'est ici qu'est la rose, c'est ici qu'il faut danser !

D'ailleurs, tout observateur moyen, même sans avoir suivi pas à pas la marche du développement de la Révolution française, devait se douter que la révolution allait à une déconfiture inouïe. Il suffisait d'entendre les jappements de triomphe, dénués de toute modestie, avec lesquels ces messieurs les démocrates se félicitaient réciproquement des effets miraculeux du mai $1852^{5}$. Le 2 mai 1852 était devenu chez eux une idée fixe, un dogme, comme pour les chiliastes le jour où le Christ devait ressusciter et instaurer sur la terre le royaume millénaire. La faiblesse avait trouvé, comme toujours, son salut dans la croyance aux miracles, elle s'imagina avoir triomphé de l'ennemi, parce qu'elle l'avait exorcisé en imagination, et elle perdit toute compréhension du présent, se contentant de magnifier l'avenir qui l'attendait et les actes qu'elle se proposait d'accomplir un jour, mais qu'elle ne croyait pas encore le moment venu d'accomplir. Ces héros, qui s'efforcent de démentir leur incapacité notoire en s'apitoyant réciproquement les uns les autres et en se groupant étroitement les uns les autres, avaient fait leurs paquets, empoché en acompte leurs couronnes de laurier et étaient précisément occupés à faire escompter à la Bourse des valeurs des républiques in partibus ${ }^{6}$ pour lesquelles, dans le silence de leur âme modeste, ils avaient déjà eu la prévoyance de préparer le personnel gouvernemental. Le 2 Décembre les surprit comme un coup de tonnerre dans un ciel serein, et les peuples qui, aux époques de dépression, laissent volontiers assourdir

4 «Voici Rhodes, c'est ici qu'il faut sauter. » Proverbe latin inspiré d'une fable d'Ésope qui signifie : c'est le moment de montrer ce dont tu es capable.

5 Date à laquelle devait avoir lieu l'élection du président de la République.

6 Sur des territoires étrangers. Se dit de l'évêque dont le titre est purement honorifique et ne donne droit à aucune juridiction. On dit, par ironie, gouvernement, ministre, ambassadeur, etc., in partibus. 
leur crainte secrète par les braillards les plus bruyants, se seront peut-être convaincus que les temps sont passés où le caquetage d'un troupeau d'oies pouvait sauver le Capitole.

La Constitution, l'assemblée nationale, les partis dynastiques, les républicains bleus et rouges, les héros d'Afrique, le tonnerre de la tribune, les éclairs de la presse quotidienne, toute la littérature, les célébrités politiques et les renommées intellectuelles, le Code civil et le Code pénal, la «Liberté, Égalité, Fraternité » et le 2 mai 1852, tout cela disparut comme par enchantement devant l'incantation d'un homme que ses ennemis eux-mêmes ne considèrent pas comme un sorcier. Le suffrage universel semble n'avoir survécu un moment que pour écrire de sa propre main son testament à la face du monde et proclamer au nom du peuple luimême : Tout ce qui existe mérite de périr.

Il ne suffit pas de dire, comme le font les Français, que leur nation a été surprise. On ne pardonne pas à une nation, pas plus qu'à une femme, le moment de faiblesse où le premier aventurier venu a pu leur faire violence. Le problème n'est pas résolu par une telle façon de présenter les choses, mais seulement autrefois formulé. Il reste à expliquer comment une nation de 36 millions d'hommes a pu être surprise par trois chevaliers d'industrie et menée sans résistance en captivité.

Récapitulons, dans leurs grandes lignes, les phases parcourues par la révolution française du 24 février 1848 au mois de décembre 1851.

On doit distinguer trois périodes principales :

1. la période de février ;

2. Du 4 mai 1848 au 29 mai 1849, la période de la constitution de la République ou de l'Assemblée nationale constituante;

3. Du 29 mai 1849 au 2 décembre 1851, la période de la république constitutionnelle ou de l'Assemblée nationale législative.

La première période, qui s'étend du 24 février, date de la chute de Louis-Philippe, jusqu'au 4 mai 1848, date de la réunion de l'Assemblée constituante, et qui constitue la période de février proprement dite, peut être considérée comme le prologue de la révolution. Ce qui la caractérise officiellement, c'est le fait que le gouvernement improvisé par elle se déclara lui-même provisoire et que, de même, tout ce qui fut proposé, tenté, exprimé au cours de cette période ne le fut que provisoirement. Rien ni personne n'osa réclamer pour soi le droit à l'existence et à l'action véritable. Tous les éléments qui avaient préparé ou fait la révolution, l'opposition dynastique, la bourgeoisie républicaine, la petite bourgeoisie républicaine-démocrate, la classe ouvrière social-démocrate, trouvèrent provisoirement leur place dans le gouvernement de février. 
Il ne pouvait d'ailleurs en être autrement. Les Journées de février ne visaient qu'une réforme électorale pour élargir le cercle des privilégiés politiques parmi la classe possédante elle-même et renverser la domination exclusive de l'aristocratie financière. Mais lorsqu'on en vint au véritable conflit, que le peuple monta sur les barricades, que la garde nationale observa une attitude passive, que l'armée n'opposé aucune résistance sérieuse et que la royauté prit la fuite, la république parut s'imposer d'elle-même. Chaque parti l'interpréta à sa façon. Comme elle avait été conquise par le prolétariat les armes à la main, ce dernier lui imprima son sceau et la proclama république sociale. Ainsi fut déterminé le contenu général de la révolution moderne, contenu en contradiction tout à fait singulière avec tout ce qui pouvait être mis immédiatement en œuvre, dans la situation et les conditions données, avec les matériaux existants, et avec le degré de développement atteint par la masse. D'autre part, les prétentions de tous les autres éléments qui avaient participé à la révolution de février furent reconnues dans la part du lion qu'ils reçurent dans le gouvernement. C'est pourquoi nous ne trouvons dans aucune autre période un mélange plus varié de phrases élevés et d'insécurité et de maladresses réelles, d'aspiration plus enthousiasmes vers le progrès et de domination plus absolue de la vieille routine, d'harmonie plus apparente de toute la société et d'opposition plus profonde entre ses différents éléments. Tandis que le prolétariat parisien s'enivrait devant lui, et prenait plaisir à de graves discussion sur les problèmes sociaux, les anciennes puissances sociales s'étaient groupées, rassemblées, concertées, et trouvaient un appui inattendu dans la grande masse de la nation : les paysans et les petits bourgeois, qui s'étaient tombées les barrières de la monarchie de Juillet.

La deuxième période, qui va du 4 mai 1848 à la fin de mai 1849, est la période de la constitution, de la fondation de la république bourgeoise. Immédiatement après les Journées de février, non seulement l'opposition dynastique avait été surprise par les républicains et ceux-ci par les socialistes, mais toute la France l'avait été par Paris. L'Assemblée nationale, qui se réunit le 4 mai, issue des suffrages de la nation, représentait la nation. Elle était une protestation vivante contre les prétentions des Journées de février et avait pour mission de ramener à la mesure bourgeoise les résultats de la révolution. Vainement, le prolétariat parisien, qui se rendit immédiatement compte du caractère de cette Assemblée nationale, tenta, quelques jours après sa réunion, de lui dénier par la violence son droit à l'existence, de la dissoudre, de disperser à nouveau en ses différents éléments constitutifs l'organisme au moyen duquel le menaçait l'esprit de réaction de la nation. Comme l'on sait, le 15 mai n'eut d'autre résultat que d'éloigner de la scène publique, pour toute la durée de la période que nous considérons, Blanqui et ses partisans, les communistes révolutionnaires, c'est-à-dire les véritables chefs du parti prolétarien.

À la monarchie bourgeoise de Louis-Philippe ne peut succéder que la république bourgeoise. Cela veut dire que, tandis que, sous la monarchie, c'était une partie restreinte de la bourgeoisie qui avait régné au nom du roi, c'est, désormais, l'ensemble de la bourgeoisie 
qui doit régner au nom du peuple. Les revendications du prolétariat parisien sont des bourdes utopiques avec lesquelles il faut en finir une fois pour toutes. A cette déclaration de l'Assemblée nationale constituante, le prolétariat parisien répondit par l'insurrection de juin, l'événement le plus formidable dans l'histoire des guerres civiles européennes. La république bourgeoise l'emporta. Elle avait pour elle l'aristocratie financière, la bourgeoisie, l'armée, le sous-prolétariat organisé en garde mobile, les intellectuels, les prêtres et toute la population rurale. Au côtés du prolétariat, il n'y avait personne d'autre que lui-même. Plus de 3000 insurgés furent massacrés après la victoire, et 15000 déportés sans jugement. Cette défaite rejeta le prolétariat à l'arrière-plan de la scène révolutionnaire. Il s'efforça de reprendre sa place en avant chaque fois que le mouvement sembla prendre un nouvel élan, mais chaque fois avec une énergie diminuée et un résultat plus faible. Dès que l'une des couches sociales placées au-dessus de lui entre en fermentation révolutionnaire, le prolétariat conclut une alliance avec elle et partage ainsi toutes les défaites que subissent les uns après les autres les différents partis. Mais ces coups successifs s'affaiblissent de plus en plus à mesure qu'ils se répartissent davantage sur toutes les couches de la société. Ses principaux chefs à l'Assemblée nationale et dans la presse sont, les uns après les autres, livrées aux tribunaux et remplacés par des figures de plus en plus équivoques. Pour une part, il se jette dans des expériences doctrinaires, banques d'échange et associations ouvrières, c'est-à-dire dans un mouvement où il renonce à transformer le vieux monde à l'aide des grands moyens qui lui sont propres, mais cherche, tout au contraire, à réaliser son affranchissement, pour ainsi dire, derrière le dos de la société, de façon privée, dans les limites restreintes de ses conditions d'existence, et, par conséquent, échoue nécessairement. Il semble ne pouvoir ni retrouver en lui-même la grandeur révolutionnaire, ni puiser, dans les alliances nouvelles conclues par lui, une énergie nouvelle jusqu'à ce que toutes les classes, contre lesquelles il a combattu en juin, gisent sur le sol à ses côtés. Mais, du moins, il succombe ave les honneurs de la grande lutte historique. Non seulement la France, mais l'Europe tout entière est secouée d'épouvante par le tremblement de terre de juin, tandis que les victoires remportées sur les classes supérieures l'ont été si facilement qu'il faut toute l'exagération éhontée du parti victorieux pour les faire passer pour des événements d'importance, et elles sont d'autant plus honteuses que le parti vaincu est plus éloigné du prolétariat.

La défaite des insurgés de juin avait, à la vérité, préparé, aplani le terrain sur lequel pouvait se fonder, s'établir la république bourgeoise. Mais elle avait montré, en même temps, qu'en Europe se posaient d'autres problèmes que celui de la république ou de la monarchie. Elle avait montré que la république bourgeoise signifiait ici le despotisme absolu d'une classe sur les autres classes. Elle avait montré que, dans les pays de vieille civilisation, ayant une structure de classe très développée, des conditions modernes de production, pourvus d'une conscience morale dans laquelle toutes les idées traditionnelles ont été dissoutes au moyen d'un travail séculaire, la république n'est, d'une façon générale, que la forme de 
transformation politique de la société bourgeoise et non pas sa forme de conservation, comme c'est le cas, par exemple, aux Etats-Unis d'Amérique, où les classes déjà constituées, mais non encore fixées, modifient et remplacent constamment, au contraire, leurs éléments constitutifs, où les moyens de production modernes, au lieu de correspondre à une surpopulation stagnante, compensent plutôt le manque relatif de têtes et de bras, et où, enfin, le mouvement jeune et fiévreux de la production matérielle, qui a un nouveau monde à conquérir, n'a eu ni le temps ni l'occasion de détruire l'ancien monde spirituel.

Pendant les Journées de juin, toutes les classes et tous les partis s'étaient unis dans le «parti de l'ordre » en face de la classe prolétarienne, du «parti de l'anarchie», du socialisme, du communisme. Ils avaient «sauvé » la société des entreprises des «ennemis de la société ». Ils avaient repris et lancé parmi leurs troupes les vieux mots d'ordre de l'ancienne société : «propriété, famille, religion, ordre », et crié à la croisade contre-révolutionnaire : «Sous ce signe, tu vaincras ! A partir de ce moment, dès que l'un des nombreux partis qui s'étaient groupés sous ce signe contre les insurgés de juin, s'efforce de défendre le champ de bataille révolutionnaire dans ses propres intérêts de classe, il succombe sous le cri de «propriété, famille, religion, ordre ! » La société est sauvée aussi souvent que le cercle de ses maîtres se rétrécit et qu'un intérêt plus exclusif est défendu contre un intérêt plus large. Toute revendication de la plus simple réforme financière bourgeoise, du libéralisme le plus vulgaire, du républicanisme le plus formel, de la démocratie la plus plate, est à la fois punie comme « attentat contre la société » et flétrie comme « socialiste ». Et, finalement, les grands prêtres de « la religion et de l'ordre » sont eux-mêmes chassés à coups de pied de leurs trépieds pythiques, tirés de leur lit en pleine nuit, fourrés dans des voitures cellulaires, jetés au cachot ou envoyés en exil. Leur temple est rasé, leur bouche scellée, leur plume brisée, leur loi déchirée au nom de la religion, de la propriété, de la famille et de l'ordre. Des bourgeois fanatiques de l'ordre sont fusillés à leur balcon par une soldatesque ivre, la sainteté de leur foyer est profanée, leurs maisons sont bombardées en guise de passe-temps, tout cela au nom de la propriété, de la famille, de la religion et de l'ordre. La lie de la société bourgeoise constitue finalement la phalange sacrée de l'ordre et le héros Crapulinsky ${ }^{7}$ fait son entrée aux Tuileries comme «sauveur de la société ».

7 Nom d'un personnage d'un poème de Heine, intitulé « Deux Chevaliers » (Romanzero), dans la personne duquel le poète raille les Polonais appauvris par suite de leurs prodigalités. 


\section{II}

$\underline{\text { Retour à la table des matières }}$

Reprenons le fil des événements.

L'histoire de l'Assemblée nationale constituante, à partir des Journées de juin, est l'histoire de la domination et de la désagrégation de la fraction bourgeoise républicaine, cette fraction que l'on connaît sous le nom de républicains tricolores, de républicains purs, de républicains politiques, de républicains formalistes, etc.

Sous la monarchie bourgeoise de Louis-Philippe, cette fraction avait constitué l'opposition républicaine officielle, et avait été, par conséquent, une partie intégrante reconnue du monde politique de cette époque. Elle avait ses représentants dans les Chambres et possédait dans la presse une sphère d'action considérable. Son organe parisien, Le National, était considéré comme aussi respectable, à sa façon, que le Journal des débats. Cette position qu'elle occupait sous la monarchie constitutionnelle était tout à fait conforme à son caractère. Ce n'était pas une fraction de la bourgeoisie rassemblée par de grands intérêts communs, et séparée des autres par des conditions de production particulières. C'était simplement une coterie de bourgeois, d'écrivains, d'avocats, d'officiers et de fonctionnaires d'esprit républicain, et dont l'influence reposait sur l'antipathie personnelle que le pays ressentait à l'égard de Louis-Philippe sur les souvenirs de l'ancienne république, sur les convictions républicaines d'un certain nombre d'enthousiastes et surtout sur le nationalisme français, dont elle entretenait soigneusement la haine à l'égard des conventions de Vienne et de l'alliance avec l'Angleterre. Une grande partie de l'influence que Le National possédait sous Louis-Philippe était due précisément à cet impérialisme masqué ; mais il devait plus tard, sous la république, trouver sur ce terrain un concurrent redoutable en la personne de Louis Bonaparte. Il combattait l'aristocratie financière, comme le faisait alors tout le reste de l'opposition bourgeoise. Ses polémiques contre le budget, qui étaient liées en France à la lutte contre l'aristocratie financière, lui procuraient une popularité à trop bon marché et fournissaient une trop riche matière à des articles leaders puritains pour ne pas être exploités. La bourgeoisie industrielle lui était reconnaissante de sa défense servile du système protectionniste français, qu'il préconisait cependant pour des raisons plus nationales qu'économiques; l'ensemble de la bourgeoisie lui tenait compte de ses dénonciations haineuses du communisme et du socialisme. Au reste, le parti du National était républicain pur, c'est-à-dire qu'il voulait que la domination bourgeoise revêtît une forme républicaine au lieu d'une forme monarchique et demandait surtout la part du lion dans cette transformation, 
il n'en avait absolument aucune idée. Ce qui, par contre, lui était clair comme le jour, et ce qui fut déclaré publiquement dans les banquets de la Réforme, dans les derniers temps du règne de Louis-Philippe, c'était son impopularité parmi les petits bourgeois démocrates et surtout dans le prolétariat révolutionnaire. Ces républicains purs, comme c'est d'ailleurs naturel de la part de républicains purs, étaient déjà sur le point de se contenter tout d'abord d'une régence de la duchesse d'Orléans, lorsqu'éclata la révolution de février qui offrit à ses représentants les plus connus une place dans le Gouvernement provisoire. Ceux-ci possédaient naturellement d'avance la confiance de la bourgeoisie et la majorité à l'Assemblée nationale constituante. Les éléments socialistes du Gouvernement provisoire furent immédiatement exclus de la Commission exécutive nommée par l'Assemblée nationale dès sa première réunion, et le parti du National profita de l'Insurrection de juin pour dissoudre également la Commission exécutive et se débarrasser ainsi de ses rivaux les plus proches : les républicains petits-bourgeois ou démocrates (Ledru-Rollin, etc). Cavaignac, le général du parti républicain bourgeois, qui avait dirigé la bataille de juin, remplaça la Commission exécutive, investi d'une sorte de pouvoir dictatorial. Marrast, ancien rédacteur en chef du National, fut nommé président perpétuel de l'Assemblée nationale constituante, et les ministères, ainsi que tous les autres postes importants, échurent aux républicains purs.

La fraction des républicains bourgeois, qui se considérait depuis longtemps comme l'héritière légitime de la monarchie de Juillet, se trouvait ainsi avoir dépassé son idéal, mais elle arrivait au pouvoir, non pas, comme elle l'avait rêvé sous Louis-Philippe, à la suite d'une révolte libérale de la bourgeoisie contre le trône, mais à la suite d'un soulèvement, réprimé à coups de mitraille, du prolétariat contre le capital. Ce qu'elle s'était imaginé comme devant être l'événement le plus révolutionnaire se passa, en réalité, comme l'événement le plus contre-révolutionnaire. Le fruit tombait dans ses mains, mais il provenait de l'arbre de la science, et non de l'arbre de vie.

La domination exclusive des républicains bourgeois ne dura que du 24 juin au 10 décembre 1848. Son histoire se résume dans l'élaboration de la Constitution républicaine et dans la proclamation de l'état de siège à Paris.

La nouvelle Constitution n'était au fond que l'édition républicaine de la Charte constitutionnelle de 1830. Le système censitaire étroit de la monarchie de Juillet, qui excluait une grande partie de la bourgeoisie elle-même du pouvoir politique, était incompatible avec l'existence de la république bourgeoise. La révolution de février avait immédiatement proclamé à la place de ce cens le suffrage universel direct. Les républicains bourgeois ne pouvaient pas faire que cet événement n'eût eu lieu. Ils durent se contenter d'y adjoindre la clause restrictive de l'obligation d'une résidence de six moins dans la circonscription électorale. On conserva l'ancienne organisation administrative, municipale, judiciaire, 
militaire, etc., et là où la Constitution la modifia, cette modification porta uniquement sur la table des matières et non sur le contenu, sur le mot et non sur la chose.

L'inévitable état-major des libertés de 1848 : liberté personnelle, liberté de la presse, de la parole, d'association, de réunion, d'enseignement, des cultes, etc., reçut un uniforme constitutionnel qui le rendait invulnérable. Chacune de ces libertés fut proclamée comme un droit absolu du citoyen français, mais avec une réserve constante qu'elles étaient illimitées dans la mesure seulement où elles ne se heurtaient pas aux «droits égaux d'autrui et à la sûreté publique », ainsi qu'aux «lois » précisément chargées d'assurer cette harmonie. Par exemple : «Les citoyens ont le droit de s'associer, de s'assembler paisiblement et sans armes, de faire des pétitions et d'exprimer leurs opinions par la presse ou par tout autre moyen. $L a$ jouissance de ces droits n'a d'autres limites que les droits égaux d'autrui et la sûreté publique.» (Chap. II de la Constitution française, § 8.) — «L'enseignement est libre. La liberté de l'enseignement doit être exercée dans les conditions fixées par la loi et sous le contrôle suprême de l'État. » (L. c., § 9) — «Le domicile de tout citoyen est inviolable, sauf dans les conditions prévues par la loi. » (Chap. $\mathrm{I}^{\mathrm{er}}, \S 3$ ) etc., etc. - La Constitution renvoie continuellement à de futures lois organiques destinées à préciser ces réserves et à réglementer la jouissance de ces libertés absolues de telle façon qu'elles ne se heurtent pas entre elles, ni ne mettent en danger la sûreté publique. Et, dans la suite, les lois organiques ont été conçues par les amis de l'ordre, et toutes ces libertés réglementées de telle façon que la bourgeoisie pût en jouir sans se heurter aux droits égaux des autres classes de la société. Dans tous les cas où ces lois organiques interdirent complètement ces libertés «aux autres classes » ou n'en permirent la jouissance que dans des conditions qui sont autant de pièges policiers, ce fut chaque fois uniquement dans l'intérêt de la «sûreté publique », autrement dit de la sûreté de la bourgeoisie, conformément aux prescriptions de la Constitution. C'est pourquoi, dans la suite on put, de deux côtés, se prévaloir à bon droit de la Constitution, aussi bien les amis de l'ordre, qui supprimaient toutes ces libertés, que les démocrates, qui les réclamaient intégralement. Chaque paragraphe de la Constitution contient, en effet, sa propre antithèse, sa Chambre haute et sa Chambre basse : dans le texte la liberté, dans la marge la suppression de cette liberté. Par suite, tant que le mot de liberté fut respecté et que, seule, sa réalisation véritable fut interdite, par les voies légales s'entend, l'existence constitutionnelle de la liberté resta entière, intacte, bien que son existence réelle fût totalement anéantie.

Cette Constitution, si subtilement rendue inviolable, était cependant, comme Achille, vulnérable en un point, non pas au talon, mais à la tête, ou plutôt aux deux têtes dans lesquelles elle se perdait : l'Assemblée législative, d'un côté, le président, de l'autre. Que l'on feuillette la Constitution, et l'on se rendra compte que, seuls, les paragraphes où sont fixés les rapports du président avec l'Assemblée législative sont absolus, positifs, sans contradiction possible, impossible à tourner. Il s'agissait en effet, ici, pour les républicains bourgeois, de leur propre sûreté. Les paragraphes 45 à 70 de la Constitution sont rédigés de telle façon que, 
si l'Assemblée nationale peut écarter le président constitutionnellement, ce dernier ne peut se débarrasser de l'Assemblée nationale que par voie inconstitutionnelle, en supprimant la Constitution elle-même. Elle provoque ainsi, par conséquent, sa propre suppression violente. Elle ne sanctifie pas seulement, comme la Charte de 1830, la séparation des pouvoirs, elle l'élargit jusqu'à la contradiction la plus intolérable. Le jeu des pouvoirs constitutionnels c'est ainsi que Guizot appelait les querelles parlementaires entre pouvoir législatif et pouvoir exécutif - joue constamment «va banque * d dans la Constitution de 1848. D’un autre côté, 750 représentants du peuple, élus au suffrage universel et rééligibles, constituant une Assemblée nationale irresponsable, indissoluble, indivisible, une Assemblée nationale jouissant d'une toute-puissance législative, décidant en dernière instance en matière de guerre, de paix et de traités de commerce, possédant seule le droit d'amnistie et, par son caractère permanent, occupant constamment le devant de la scène. De l'autre côté, le président, avec tous les attributs de la puissance royale, le droit de nommer et de révoquer ses ministres indépendamment de l'Assemblée nationale, ayant en main tous les moyens d'action du pouvoir exécutif, disposant de tous les emplois et disposant ainsi en France de l'existence de plus d'un million et demi d'hommes, car tel est le nombre de tous ceux qui dépendent des 50000 fonctionnaires et des officiers de tous grades. Il a le commandement de toutes les forces armées du pays. Il jouit du privilège de gracier quelques criminels, de suspendre les gardes nationaux, de révoquer, d'accord avec le Conseil d'État, les conseiller généraux, cantonaux, municipaux, élus par les citoyens eux-mêmes. Il a l'initiative et la direction de toutes les négociations avec l'étranger. Tandis que l'Assemblée reste constamment sur la scène, exposée à la critique de l'opinion publique, il mène une vie cachée, aux Champs Élysées, ayant sous les yeux et dans son cœur l'article 45 de la Constitution, qui lui crie tous les jours : «Frère, il faut mourir ${ }^{* *}$ ! Ton pouvoir cesse le second dimanche du joli mois de mai, dans la quatrième année de ton élection! Alors, c'en sera fini de la splendeur ! Il n'y aura pas de seconde représentation, et si tu as des dettes, réfléchis à temps aux moyens de les payer sur les 600000 francs que t'alloue la Constitution, à moins que tu ne préfères partir pour Clichy ${ }^{8}$, le deuxième lundi du joli moi de mai ! ». Si la Constitution donne au président le pouvoir effectif, elle s'efforce du moins d'assurer à l'Assemblée nationale le pouvoir moral. Mais, outre qu'il est impossible de créer un pouvoir moral à l'aide d'articles de loi, la Constitution se détruit encore une fois elle-même en faisant élire le président au suffrage direct par tous les Français. Tandis que les suffrages de la France se dispersent sur les 750 membres de l'Assemblée nationale, ils se concentrent ici, par contre, sur un seul individu. Alors que chaque député ne représente que tel ou tel parti, telle ou telle ville, telle ou telle tête

\footnotetext{
En français dans le texte. Nous utiliserons régulièrement ce signe ${ }^{(*)}$ dans la suite du volume pour signaler les passages en français.

** En français dans le texte. Nous utiliserons régulièrement ce signe ${ }^{(*)}$ dans la suite du volume pour signaler les passages en français.

8 L'ancienne prison pour dettes de Paris.
} 
de pont, ou même la simple nécessité d'élire un sept-cent-cinquantième individu quelconque, opération dans laquelle on ne se montre pas plus difficile pour l'homme que pour la chose, il est, lui, l'élu de la nation, et son élection est l'atout que le peuple souverain joue une fois tous les quatre ans. L'Assemblée nationale élue est unie à la nation par un rapport métaphysique, mais le président élu à elle par un rapport personnel. L'Assemblée nationale représente bien dans ses différents membres les aspects multiples de l'esprit national, mais c'est dans le président que ce dernier s'incarne. Il a en face d'elle une sorte de droit divin. Il est, par la grâce du peuple.

Thésis, la déesse de la mer, avait prédit à Achille qu'il périrait dans la fleur de la jeunesse. La Constitution, qui avait son point vulnérable comme Achille, pressentait comme lui qu'elle mourrait d'une mort prématurée. Il suffisait aux républicains purs de la Constituante de jeter du ciel nébuleux de leur république idéale un regard sur le monde profane pour se rendre compte de l'arrogance des royalistes, des bonapartistes, des démocrates, des communistes, et de leur propre discrédit croissait de jour en jour, à mesure qu'ils se rapprochaient davantage du couronnement de leur grand chef-d'œuvre législatif, sans que Thétis eût besoin pour cela de quitter la mer et de leur confier son secret. Ils essayèrent de tromper le destin au moyen d'une ruse constitutionnelle, à l'aide du paragraphe 111 de la Constitution, aux termes duquel toute proposition de révision de la Constitution ne peut être votée, après trois débats successifs, séparés par un intervalle d'un mois, que par une majorité d'au moins trois quarts des voix, à condition encore que 500 membres au moins de l'Assemblée nationale participent au vote. Ce n'était là de leur part qu'une tentative désespérée d'exercer encore, en tant que minorité parlementaire, à laquelle ils se voyaient prophétiquement déjà réduits, un pouvoir qu'ils voyaient s'échapper tous les jours davantage de leurs mains débiles, au moment même où ils disposaient de la majorité parlementaire et de tous les moyens d'action du pouvoir gouvernemental.

Enfin, dans un paragraphe mélodramatique, la Constitution se confiait elle-même «à la vigilance et au patriotisme du peuple français tout entier, comme de chaque Français en particulier », après avoir, dans un autre paragraphe, signalé les «vigilants » et les «patriotes » à l'attention délicate et criminelle du tribunal suprême qu'elle avait inventé elle-même, à savoir la Haute Cour.

Telle était la Constitution de 1848, qui fut renversée le 2 décembre 1851, non par une tête, mais par le simple contact d'un chapeau. Il est vrai que ce chapeau était le tricorne de Napoléon.

Tandis que les bourgeois républicains étaient occupés à l'Assemblée à fignoler, à discuter et à voter cette Constitution, Cavaignac maintenait, en dehors de l'Assemblée, l'état de siège à Paris. La proclamation de l'état de siège à Paris avait servi à la Constituante d'accoucheuse dans les douleurs de son enfantement républicain. Si la Constitution fut plus tard assassinée à 
coups de baïonnettes, il ne faut pas oublier que c'est également par des baïonnettes, et encore dirigées contre le peuple, qu'il avait fallu la protéger déjà dans le sein de sa mère et que c'est également à l'aide de baïonnettes qu'elle avait dû être mise au monde. Les aïeux des «républicains honnêtes » avaient fait faire à leur symbole, le drapeau tricolore, le tour de l'Europe. Eux aussi, ils firent une intervention qui trouva d'elle-même son chemin dans tout le continent, mais qui revint avec une prédilection marquée en France, jusqu'à ce qu'elle eût acquis droit de cité dans la moitié des départements. Cette invention, c'était l'état de siège. Invention remarquable, régulièrement appliquée dans chaque crise qui éclata, dans la suite, au cours de la Révolution française. Mais la caserne et le bivouac, que l'on imposait ainsi périodiquement à la société française pour la faire tenir tranquille ; le sabre et le mousqueton, à qui l'on faisait périodiquement rendre la justice et diriger l'administration, exercer le rôle de tuteur et de censeur, de policier et de veilleur de nuit ; la moustache et l'uniforme, que l'on célébrait périodiquement comme la sagesse suprême de la société et comme recteurs de la société, ne devaient-ils pas finir par croire qu'il valait mieux sauver la société une fois pour toutes, en proclamant leur propre régime comme le régime suprême, et libérer complètement la société bourgeoise du souci de se gouverner elle-même ? La caserne et le bivouac, le sabre et le mousqueton, la moustache et l'uniforme devaient d'autant plus facilement en venir à cette idée qu'ils pouvaient s'attendre alors à être mieux payés pour ce service plus signalé, tandis que dans les proclamations simplement périodiques de l'état de siège, et dans les sauvetages momentanés de la société, à l'appel de telle ou telle fraction de la bourgeoisie, le résultat pour eux était maigre, en dehors de quelques morts et blessés et de quelques grimaces amicales de la bourgeoisie. L'armée ne devait-elle pas finalement vouloir jouer dans son propre intérêt de l'état de siège et assiéger en même temps les coffres-forts des bourgeois ? Il ne faut pas oublier, d'ailleurs, soit dit en passant, que le colonel Bernard, ce président de la commission militaire qui, sous les ordres de Cavaignac, avait déporté sans jugement 15000 insurgés, se trouvait à ce moment de nouveau à la tête de la commission militaire fonctionnant à Paris.

Dans le paragraphe 44 de la Constitution, il est dit: «Le président de la République française ne doit jamais avoir perdu la qualité de citoyen français. » Or, non seulement le premier président de la République française, Louis-Napoléon Bonaparte, avait perdu sa qualité de citoyen français, non seulement il avait été «spécial constable » en Angleterre, mais il s'était même fait naturaliser Suisse.

J'ai montré ailleurs quelle était l'importance de l'élection du 10 décembre. Je n'y reviendrai donc pas. Il suffit de remarquer ici qu'elle était une réaction des paysans, qui avait dû payer les frais de la révolution de février, contre les autres classes de la nation, une réaction de la campagne contre la ville. Elle fut très bien accueillie par l'armée, à qui les républicains du National n'avaient procuré ni gloire, ni profit, sous la grande bourgeoise, laquelle saluait Bonaparte comme le pont qui la conduisait à la monarchie, et par les 
prolétaires et les petits bourgeois, qui voyaient en lui l'homme qui châtierait Cavaignac. J'aurai plus tard l'occasion d'étudier de plus près l'attitude des paysans à l'égard de la Révolution française.

La période qui s'étend du 20 décembre 1848 à la dissolution de la Constituante, en mai 1849, comprend l'histoire de la chute des républicains bourgeois. Après avoir fondé une république pour la bourgeoisie, abattu le prolétariat révolutionnaire et réduit momentanément au silence la petite bourgeoisie démocratique, ils furent eux-mêmes mis à l'écart par la masse de la bourgeoisie qui, à juste raison mit l'embargo sur cette république comme étant sa propriété à elle. Mais cette masse bourgeoise était royaliste. Une partie d'entre elle, les grands propriétaires fonciers, avait régné sous la Restauration et était par conséquent légitimiste. L'autre partie, l'aristocratie financière et les grands industriels, avait régné sous la monarchie de Juillet et était par conséquent orléaniste. Les grands dignitaires de l'armée, de l'Université, de l'Église, du barreau, de l'Académie et de la presse étaient partagés, bien qu'en proportion inégale, entre les deux courants. Ils avaient trouvé dans la République bourgeoise, qui ne portait ni le nom de Bourbon, ni celui d'Orléans, mais celui de capital, la forme d'État dans laquelle ils pouvaient régner en commun. L'Insurrection de juin, déjà, les avait réunis en «parti de l'ordre ». Il s'agissait maintenant d'écarter la coterie des républicains bourgeois qui occupaient encore les sièges de l'Assemblée nationale. Autant ces purs républicains avaient fait preuve de brutalité en employant la violence contre le prolétariat autant ils furent lâches, pusillanimes, timides, humbles, sans défense, en reculant, maintenant qu'il s'agissait précisément de défendre leur républicanisme et leur pouvoir législatif contre le pouvoir exécutif et les royalistes. Je n'ai pas à relater ici la lamentable histoire de leur dissolution. Ils ne disparurent pas, ils se volatilisèrent. Leur histoire est à jamais terminée, et, dans la période suivante, ils ne figurent plus, tant à l'intérieur qu'à l'extérieur de l'Assemblée, que comme des souvenirs ne paraissant reprendre un peu de vie que dès qu'il s'agit à nouveau du simple mot de République et chaque fois que le conflit révolutionnaire menace de s'abaisser au niveau le plus bas. Je marque en passant que le journal qui donna son nom à ce parti, Le National, se convertit dans la période suivante au socialisme.

Avant d'en finir avec cette période, il nous faut encore reporter nos regards sur les deux puissances dont l'une anéantit l'autre le 2 décembre 1851, alors que, dans la période allant du 20 décembre 1848 jusqu'au départ de la Constituante, elles entretinrent de bons rapports conjugaux. Nous voulons parler de Louis Bonaparte, d'une part, et du parti des royalistes coalisés, parti de l'ordre, de la grande bourgeoisie, d'autre part. Dès le début de sa présidence, Bonaparte, constitua immédiatement un ministère du parti de l'ordre, à la tête duquel il plaça Odilon Barrot nota bene, l'ancien chef de la fraction la plus libérale de la bourgeoisie parlementaire. M. Barrot avait enfin réussi à obtenir le ministère dont la poursuite le hantait depuis 1830 , et, plus encore, la présidence de ce ministère, mais non pas, comme il se l'était imaginé sous Louis-Philippe, en qualité de leader le plus avancé de l'opposition 
parlementaire, mais avec la mission d'assassiner un Parlement, et comme allié de ses ennemis jurés, les jésuites et les légitimistes. Il ramenait enfin la fiancée à la maison, mais seulement après qu'elle se fut prostituée. Quant à Bonaparte lui-même, il s'éclipsa totalement en apparence. Le parti de l'ordre agissait pour lui.

Dès la première réunion du Conseil des ministres, on décida l'expédition de Rome, et l'on se mit d'accord pour l'entreprendre à l'insu de l'Assemblée nationale, et à lui arracher, sous un faux prétexte, les crédits nécessaires. On commença ainsi par une escroquerie à l'égard de l'Assemblée nationale et par une conspiration secrète avec les puissances absolues de l'étranger contre la République romaine révolutionnaire. C'est de la même façon et au moyen des mêmes manœuvres que Bonaparte prépara son coup du 2 décembre contre la Législative royaliste et sa République constitutionnelle. N'oublions pas que le même parti qui, le 20 décembre 1848, fournit à Bonaparte son ministère, constitua, le 2 décembre 1851, la majorité de l'Assemblée législative.

La Constituante avait décidé, au mois d'août, de ne se dissoudre qu'après avoir élaboré et promulgué toute une série de lois organiques destinées à compléter la Constitution. Le parti de l'ordre lui proposa, le 6 janvier 1849, par l'intermédiaire de son représentant Rateau, d'abandonner les lois organiques et de décider sa propre dissolution. Non seulement le ministère, M. Odilon Barrot en tête, mais tous les membres royalistes de l'Assemblée nationale lui déclarèrent sur un ton de maître que sa dissolution était nécessaire au rétablissement du crédit, à la consolidation de l'ordre, pour mettre fin au provisoire actuel et créer un état de choses définitif, que l'Assemblée gênait le travail du nouveau gouvernement, qu'elle cherchait à prolonger son existence par simple esprit de rancune et que le pays était fatigué d'elle. Bonaparte nota soigneusement toutes ces investives contre le pouvoir législatif, els apprit par cœur et prouva, le 2 décembre 1851, aux royalistes du Parlement, qu'il avait appris à leur école. Il retourna contre eux leurs propres arguments.

Le ministère Barrot et le parti de l'ordre allèrent plus loin. Ils suscitèrent par toute la France des pétitions à l'adresse de l'Assemblée nationale, dans laquelle celle-ci était priée très amicalement de disparaître. C'est ainsi qu'ils dressèrent contre l'Assemblée nationale, expression constitutionnelle organique du peuple, ses masses inorganisées. Ils apprirent à Bonaparte à en appeler des assemblées parlementaires au peuple. Enfin, le 29 janvier 1849, vint le jour où la Constituante devait décider de sa propre dissolution. L'Assemblée trouva le lieu de ses séances occupé militairement. Changarnier le général du parti de l'ordre, entre les mains duquel était réuni le commandement suprême de la garde nationale et des troupes de ligne, passa en revue de nombreuses troupes à Paris, comme si l'on était à la veille d'une bataille, et les royalistes coalisés déclarèrent d'un ton menaçant à la Constituante qu'on emploierait la violence si elle ne se montrait pas docile. Elle fut docile et ne marchanda qu'une très brève prolongation d'existence. Que fut le 29 janvier, sinon le coup d'État du 2 
décembre 1851, réalisé cette fois-ci contre l'Assemblée nationale républicaine par les royalistes, avec la collaboration de Bonaparte ? Ces messieurs ne remarquèrent pas ou ne voulurent pas remarquer que Bonaparte profita du 29 janvier 1849 pour faire défiler devant lui, aux Tuileries, une partie des troupes et saisit avidement l'occasion de cette première levée de troupes dirigée contre le pouvoir parlementaire pour faire présager Caligula ${ }^{9}$. Mais ils ne voyaient que leur Changarnier.

Les lois organiques destinées à compléter la Constitution, telles que les lois sur l'enseignement, sur les cultes, etc., étaient l'une des raisons qui poussaient tout particulièrement le parti de l'ordre à abréger de façon violente l'existence de la Constituante. Il était de toute première importance pour les royalistes coalisés de faire eux-mêmes es lois et de ne pas les laisser faire par les républicains devenus méfiants. Parmi ces lois organiques, d'ailleurs, il y en avait une relative à la responsabilité du président de la république. En 1851, l'Assemblée législative était précisément occupée à l'élaboration de cette loi, quand Bonaparte prévint ce coup par le coup du 2 décembre. Que n'auraient pas donné les royalistes coalisés, lors de leur campagne d'hiver parlementaire de 1851, pour trouver toute faite cette loi sur la responsabilité présidentielle et encore faite par une Assemblée républicaine défiante, hostile!

Après que la Constituante eût, le 29 janvier 1849, brisé elle-même sa dernière arme, le ministre Barrot et ses amis de l'ordre la poussèrent aux abois, n'épargnèrent rien de ce qui pouvait l'humilier, et arrachèrent à sa faiblesse désespérée des lois qui lui coûtèrent les derniers vestiges de considération dont elle jouissait encore dans le public. Bonaparte, occupé de son idée fixe napoléonienne, eut la hardiesse d'exploiter publiquement cette déchéance du pouvoir parlementaire. Lorsque, en effet, l'Assemblée nationale infligea, le 8 mai 1849, au ministère, un vote de blâme pour l'occupation de Civita-Vecchia par Oudinot, et ordonna de ramener l'expédition romaine à sa prétendue destination, Bonaparte publia, le soir même, dans Le Moniteur, une lettre à Oudinot, le félicitant de ses actions d'éclat et se posant déjà, en face des plumitifs parlementaires, en protecteur magnanime de l'armée. Cela fit sourire les royalistes, qui le tenaient simplement pour leur dupe. Enfin, lorsque Marrast, président de la Constituante, ayant cru un moment la sécurité de l'Assemblée nationale menacée, et, s'appuyant sur la Constitution, requit un colonel avec son régiment, le colonel refusa d'obéir, argua de la discipline et renvoya Marrast à Changarnier, qui l'éconduit ironiquement avec cette remarque qu'il n'aimait pas les « baïonnettes intelligentes ». En novembre 1851, lorsque les royalistes coalisés voulurent engager la bataille décisive contre Bonaparte, ils cherchèrent,

9 Empereur romain (37-41), parent de l'empereur Tibère. Il grandit en Allemagne parmi les soldats dans les camps. Son nom provient du mot caliga, qui désigne la chaussure des soldats romains. Célèbre par sa cruauté, ses débauches et son gaspillage effréné, il fut assassiné par des prétoriens lors d'une conspiration de palais. 
au moyen de leur célèbre «proposition des questeurs ${ }^{10}$ » à faire adopter le principe de la réquisition directe des troupes par le président de l'Assemblée nationale. L'un des généraux, Leflô, avait signé le projet de loi. En vain, Changarnier vota la proposition et Thiers rendit hommage à la sagesse prévoyante de l'ancienne Constituante. Le ministre de la Guerre SaintArnaud lui répondit comme Changarnier avait répond à Marrast et cela aux applaudissements de la Montagne!

C'est ainsi que le parti de l'ordre lui-même, lorsqu'il n'était pas encore Assemblée nationale et qu'il n'était encore que ministère, avait flétri le régime parlementaire. Et il jeta les hauts cris lorsque le 2 Décembre bannit de France ce régime !

Nous lui souhaitons bon voyage!

10 Cette proposition tendait à donner au président de l'Assemblée le droit de requérir les troupes. Elle fut repoussée par l'Assemblée. 


\section{III}

\section{$\underline{\text { Retour à la table des matières }}$}

L'Assemblée législative se réunit le 29 mai 1849. Elle fut dissoute le 2 décembre 1851. Cette période est la période de la République constitutionnelle ou parlementaire.

Elle se divise elle-même en trois périodes principales : du 29 mai au 13 juin 1849, lutte entre la démocratie et la bourgeoisie, défaite du partie petit-bourgeois ou démocrate; du 13 juin 1849 au 31 mai 1850, dictature parlementaire de la bourgeoisie, c'est-à-dire des orléanistes et des légitimistes coalisés, ou du parti de l'ordre, dictature couronnée par la suppression du suffrage universel; du 31 mai 1850 au 2 décembre 1851, lutte entre la bourgeoisie et Bonaparte, renversement de la domination bourgeoise, chute de la république constitutionnelle ou parlementaire.

Dans la première Révolution française, la domination des constitutionnels fait place à la domination des Girondins, et celle-ci à celle des Jacobins. Chacun de ces partis s'appuie sur le plus avancé. Dès que chacun d'eux a poussé la révolution suffisamment loin pour ne plus pouvoir la suivre et à plus forte raison la précéder, il est mis à l'écart par l'allié le plus hardi qui le suit, et envoyé à la guillotine. La révolution se développe ainsi sur une ligne ascendante.

C'est le contraire avec la révolution de 1848. Le parti prolétarien apparaît comme une simple annexe du parti petit-bourgeois démocrate. Il est trahi et abandonné par ce dernier le 16 avril, le 15 mai, et pendant les Journées de juin. Le parti démocrate, de son côté, s'appuie sur les épaules du parti républicain bourgeois. A peine ce dernier pense-t-il avoir une base solide qu'il se débarrasse de son compagnon inopportun et s'appuie lui-même sur le parti de l'ordre. Ce dernier se dérobe, fait faire la culbute aux républicains bourgeois et s'appuie à son tour sur les épaules de la force armée. Il croit y être encore lorsqu'il remarque un beau matin que ces épaules se sont transformées en baïonnettes. Chaque parti frappe par derrière celui qui veut le pousser en avant et s'appuie par-devant sur celui qui le pousse en arrière. Il n'y a rien d'étonnant que, placé dans cette position ridicule, il perde l'équilibre et, qu'après avoir fait les grimaces inévitables, il s'écroule avec d'étranges cabrioles. La révolution suit ainsi une ligne descendante. Elle se trouve engagée dans ce mouvement rétrograde avant même que la dernière barricade de février ait été enlevée et qu'ait été constituée la première autorité révolutionnaire. 
La période que nous avons devant nous est le mélange le plus varié de contradictions criantes : des constitutionnels ; une Assemblée nationale qui veut être toute-puissante et reste constamment parlementaire; une Montagne qui fait de la patience une profession et se console de ses défaites présentes en prophétisant sa victoire future, des royalistes qui sont patres conscripti ${ }^{11}$ de la république et sont contraints par les circonstances de maintenir à l'étranger les maisons royales ennemies dont ils sont les partisans et de conserver en France la république qu'ils haïssent ; un pouvoir exécutif qui puise sa force dans sa faiblesse même et sa respectabilité dabs le mépris qu'il inspire ; une réplique qui n'est autre chose que l'infamie combinée de deux monarchies : la Restauration et la monarchie de Juillet, avec une étiquette impérialiste; des alliances dont la première loi est l'indécision. Au nom de l'ordre, une agitation sauvage et sans objet; au nom de la révolution, le prêche le plus solennel en faveur de l'ordre. Passions sans vérité, vérités sans passions; héros sans héroïsme, histoire sans événements ; développement dont la seule force motrice semble être le calendrier, fatigant par la répétition constante des mêmes tensions et des mêmes détentes; antagonismes qui ne semblent s'aiguiser périodiquement d'eux-mêmes que pour pouvoir s'émousser et s'écrouler sans se résoudre; efforts prétentieusement étalés et craintes bourgeoises devant le danger de la fin du monde ; et, en même temps, de la part des sauveurs du monde, les intrigues et les comédies de cours les plus mesquines, dont le «laisser-aller " " rappelle moins l'époque actuelle que les temps de la Fronde ${ }^{12}$; tout le génie officiel de la France condamné au néant par l'imbécillité astucieuse qu'elle se manifeste dans le suffrage universel, cherchant son expression adéquate chez les ennemis invétérés des intérêts des masses, jusqu'à ce qu'elle la trouve enfin dans la volonté obstinée d'un flibustier. Si jamais période historique fut peinte en grisaille, c'est bien celle-ci. Hommes et événements paraissent comme des Schlemihl ${ }^{13}$ à rebours, comme des ombres qui ont perdu leur corps. La révolution elle-même paralyse ses propres défenseurs et ne pourvoit que ses adversaires de véhémence et de passion. Lorsque le « spectre rouge », continuellement évoqué et conjuré par les contre-révolutionnaires, apparaît enfin, il n'apparaît pas coiffé du bonnet phrygien anarchiste, mais dans l'uniforme de l'ordre, en pantalon rouge.

Nous l'avons vu : le ministère que Bonaparte installa le 20 décembre 1848, jour de son élévation, était un ministère du parti de l'ordre, un ministère de coalition légitimiste et

11 «ères conscrits » : nom des sénateurs romains.

En français dans le texte.

12 Mouvement d'opposition à l'époque de la minorité de Louis XIV et de la domination du cardinal Mazarin, le favori de la reine-mère. La Fronde commença par l'opposition de la bourgeoisie parisienne et du Parlement aux projets financiers de la reine Anne d'Autriche et de Mazarin et fut accompagnée de combats de barricades. A cette Fronde parlementaire s'ajouta une Fronde des princes, qui fut un mouvement de la noblesse féodale contre l'absolutisme monarchiste. Mais les antagonistes d'intérêts qui se manifestèrent très rapidement dans la Fronde permirent à la puissance royale de diviser le mouvement et, finalement, de le réprimer complètement.

13 Héros d'une nouvelle de Chamisso, qui vend son ombre. 
orléaniste. Ce ministère Barrot-Falloux avait survécu à la Constituante républicaine, dont il avait abrégé plus ou moins violemment l'existence, et se trouvait encore au pouvoir. Changarnier, le général des royalistes coalisés, continuait de réunir dans sa personne le commandement en chef de la première division militaire et de la garde nationale de Paris. Les élections générales, enfin, avaient assuré au parti de l'ordre une grande majorité à l'Assemblée nationale. Les députés et les pairs de Louis-Philippe y trouvèrent une phalange sacrée de légitimistes, pour lesquels de nombreux bulletins de vote de la nation s'étaient transformés en cartes d'entrée sur la scène politique. Les députés bonapartistes étaient trop clairsemés pour pouvoir former un parti parlementaire indépendant. Ils n'apparaissaient que comme une «mauvaise queue " " du parti de l'ordre. C'est ainsi que le parti de l'ordre était en possession du pouvoir gouvernemental, de l'armée et du corps législatif, bref de tout le pouvoir de l'État, renforcé moralement par les élections générales, qui faisaient apparaître sa domination comme étant l'expression de la volonté du peuple, ainsi que par la victoire simultanée de la contre-révolution sur l'ensemble du continent européen.

Jamais un parti n'entra en campagne avec des moyens plus puissants et sous des auspices plus favorables.

Les républicains purs naufragés se trouvèrent réduits dans l'Assemblée législative à une clique d'environ cinquante personnes, ayant à leur tête les généraux d'Afrique, Cavaignac, Lamoricière, Bedeau. Mais le grand parti d'opposition fut constitué par la Montagne. C'est le nom de baptême parlementaire que s'était donné le parti social-démocrate. Disposant de plus de 200 voix, sur les 750 de l'Assemblée nationale, il était au moins aussi fort que n'importe laquelle des trois fractions du parti de l'ordre, prise séparément. Sa minorité relative à l'égard de l'ensemble de la coalition royaliste paraissait contre-balancée par des circonstances spéciales. Non seulement les élections départementales avaient montré qu'il avait acquis une influence considérable dans la population des campagnes, mais il comptait presque tous les députés de Paris. L'armée avait, en élisant trois sous-officiers, manifesté ses convictions démocratiques, et le chef de la Montagne, Ledru-Rollin, contrairement à tous les représentants du parti de l'ordre, avait été élevé à la noblesse parlementaire par cinq départements qui avaient groupé leur voix sur son nom. Ainsi, la Montagne paraissait, le 29 mai 1849, étant donné les conflits inévitables entre les différentes fractions monarchistes et entre l'ensemble du parti de l'ordre et Bonaparte, avoir pour elle tous les éléments de succès. Quinze jours plus tard, elle avait tout perdu, y compris l'honneur.

Avant de poursuivre l'histoire parlementaire de cette époque, nous devons faire ici quelques remarques pour éviter les illusions ordinaires sur le caractère de la période que nous étudions. A voir les choses du point de vue des démocrates, ce dont il s'agit pendant la période de l'Assemblée constituante, c'est d'une simple lutte entre républicain et royalistes.

En français dans le texte. 
Mais le mouvement lui-même, ils le résument sous le mot de réaction, nuit où tous les chats sont gris et qui leur permet de psalmodier leurs lieux communs dignes de veilleurs de nuit. Et, à la vérité, le partie de l'ordre présente au premier abord l'aspect d'un enchevêtrement de différentes fractions royalistes qui, non seulement intriguent entre elles pour élever chacune leur propre prétendant au trône et pour exclure le prétendant de la fraction adverse, mais aussi se réunissent toutes dans une même haine et dans les mêmes attaques contre la « République ». La Montagne, de son côté, paraît, en opposition à cette conspiration royaliste, représenter la «République ». Le parti de l'ordre semble être constamment occupé à diriger, ni plus ni moins qu'en Prusse, une « réaction » contre la presse, les associations, etc., et qui se traduit, tout comme en Prusse, par une brutale ingérence policière de la bureaucratie, de la gendarmerie et des parquets. La Montagne, de son côté, est tout aussi constamment occupée à repousser ces attaques et à défendre ainsi les «droits éternels de l'homme », comme l'a fait plus ou moins depuis un siècle et demi tout parti soi-disant populaire. Mais si l'on examine de plus près la situation et les partis, cette apparence superficielle qui dissimule la lutte des classes et la physionomie particulière de cette période disparaît.

Légitimistes et orléanistes continuaient, comme nous l'avons dit, les deux grandes fractions du parti de l'ordre. Ce qui attachait ces fractions à leurs prétendants, et les opposait l'une à l'autre, n'était-ce pas autre chose que les fleurs de lis et le drapeau tricolore, la maison des Bourbon et la maison d'Orléans, nuances différentes du royalisme ? Sous les Bourbon, c'était la grande propriété foncière qui avait régné, avec ses prêtres et ses laquais. Sous les Orléans, c'étaient la haute finance, la grande industrie, le grand commerce, c'est-à-dire le capital, avec sa suite d'avocats, de professeurs et de beaux parleurs. La royauté légitime n'était que l'expression politique de la domination héréditaire des seigneurs terriens, de même que la monarchie de Juillet n'était que l'expression politique de la domination usurpée des parvenus bourgeois. Ce qui, par conséquent, divisait entre elles les fractions, ce n'étaient pas de prétendus principes, c'étaient leurs conditions matérielles d'existence, deux espèces différentes de propriété, le vieil antagonisme entre la ville et a campagne, la rivalité entre le capital et la propriété foncière. Qu'en même temps de vieux souvenirs, des inimitiés personnelles, des craintes et des espérances, des préjugés et des illusions, des sympathies et des antipathies, des convictions, des articles de foi et des principes les aient liées à l'une ou à l'autre maison royale, qui le nie ? Sur les différentes formes de propriété, sur les conditions d'existence sociale s'élève toute une superstructure d'impressions, d'illusions, de façons de penser et de conceptions philosophiques particulières. La classe tout entière les crée et les forme sur la base de ces conditions matérielles et des rapports sociaux correspondants. L'individu qui les reçoit par la tradition ou par l'éducation peut s'imaginer qu'elles constituent les véritables raisons déterminantes et le point de départ de son activité. Si les orléanistes, les légitimistes et des rapports sociaux correspondants. L'individu qui les reçoit par la tradition ou par l'éducation peut s'imaginer qu'elles constituent les véritables raisons 
déterminantes et le point de départ de son activité. Si les orléanistes, les légitimistes, si chaque fraction s'efforçait de se persuader elle-même et de persuader les autres qu'elles étaient séparées par leur attachement à leurs deux maisons royales, les faits montrèrent dans la suite que c'était bien plus la divergence de leurs intérêts qui interdisait l'union des deux dynasties. Et, de même que dans la vie privée, on distingue être ce qu'un homme dit ou pense de lui et ce qu'il est et fait réellement, il faut distinguer, encore davantage, dans les luttes historiques, entre la phraséologie et les prétentions des partis et s'imaginent être et ce qu'ils sont en réalité. Orléanistes et légitimistes se trouvaient dans la république les uns à côté des autres, avec des prétentions égales. Si chaque fraction se proposait contre l'autre la restauration de sa propre dynastie, cela signifiait uniquement que les deux grands intérêts divisant la bourgeoisie - propriété foncière et capital — s'efforçaient, chacun de son côté, de rétablir sa propre suprématie et la subordination de l'autre. Nous parlons de deux intérêts de la bourgeoisie, car la grande propriété foncière, malgré sa coquetterie féodale et son orgueil de race, s'était complètement embourgeoisée, par suite du développement de la société moderne. C'est ainsi qu'en Angleterre les tories se sont longtemps imaginé qu'ils étaient enthousiastes de la royauté, de l'Église et des beautés de la vieille Constitution anglaise jusqu'au jour où le danger leur arracha l'aveu qu'ils n'étaient enthousiastes que de la rente foncière.

Les royalistes coalisés intriguaient entre eux dans la presse, à Ems, à Claremont, en dehors du Parlement. Derrière les coulisses, ils revêtaient leurs anciennes livrées orléanistes et légitimistes et recommençaient leurs anciens tournois. Mais, sur la scène publique, dans leur activité publique, en tant que grand parti parlementaire, ils n'adressaient et ajournaient in infinitum ${ }^{14}$ la restauration de la monarchie. Ils menaient leur véritable affaire en tant que parti de l'ordre, c'est-à-dire sous une étiquette sociale et non pas sous une étiquette politique, comme représentants de l'ordre bourgeois et non comme chevaliers de princesses errantes, en tant que classe bourgeoise opposée à d'autres classes, et non pas en tant que royalistes opposés aux républicains. Leur domination, en tant que parti de l'ordre, sur les autres classes de la société, fut plus absolue et plus dure qu'elle ne l'avait été auparavant sous la Restauration ou sous la monarchie de Juillet, et elle n'était possible que sous la forme de la République parlementaire, car c'est seulement sous cette forme que les deux grandes fractions de la bourgeoisie française pouvaient d'unir et, par conséquent, substituer la domination de leur classe à celle d'une fraction privilégiée de cette classe. Et si, néanmoins, en tant que parti de l'ordre, ils insultaient la république et exprimaient leur aversion à son égard, ils ne le faisaient pas seulement par conviction royaliste. Leur instinct leur disait que si la république rend plus complète leur domination politique, elle en mine en même temps les bases sociales en les opposant aux classes opprimée de la société et en les obligeant à lutter contre elles sans intermédiaire, sans le couvert de la couronne, sans pouvoir détourner l'intérêt de la nation au

\footnotetext{
14 Jusqu'à une date indéterminée.
} 
moyen de leurs luttes subalternes entre eux et contre la royauté. C'était le sentiment de leur faiblesse qui les faisait trembler devant les conditions pures de leur propre domination de classe et regretter les formes moins achevées, moins développées et, par conséquent, moins dangereuses de leur domination. Par contra, chaque fois que les royalistes coalisés entrèrent en conflit avec le prétendant qui leur était opposé, avec Bonaparte, chaque fois qu'ils crurent leur toute-puissance parlementaire menacée par le pouvoir exécutif, chaque fois qu'ils furent, par conséquent, obligés d'exhiber le titre politique de leur domination, ils agirent en tant que républicains et non pas en tant que royalistes, depuis l'orléaniste Thiers, prévenant l'Assemblée nationale que c'est, en somme, la république qui la divise le moins, jusqu'au légitimiste Berryer qui, le 2 décembre 1851, ceint de son écharpe tricolore, harangua, nouveau tribun, au nom de la république, le peuple assemblé devant la mairie du $\mathrm{X}^{\mathrm{e}}$ arrondissement. Il est vrai que l'écho moqueur lui répondit : Henri V ! Henri V !

En face de la bourgeoisie coalisée, s'était constituée une coalition entre petits bourgeois et ouvriers, le prétendu parti social-démocrate. Les petits bourgeois s'étaient vus mal récompensés au lendemain des Journées de juin 1848. Ils voyaient leurs intérêts matériels menacés et les garanties démocratiques, qui devaient leur assurer la satisfaction de ces intérêts, mises en question par la contre-révolution. Aussi se rapprochèrent-ils des ouvriers. D'autre part, leur représentation parlementaire, la Montagne, tenue à l'écart pendant la dictature des républicains bourgeois, avait, pendant la seconde moitié de l'existence de la Constituante, grâce à sa lutte contre Bonaparte et les ministres royalistes, reconquis sa popularité perdue. Elle avait conclu une alliance avec les chefs socialistes. En février 1849, on organisa des banquets de réconciliation. On esquissa un programme commun, on créa des comités électoraux communs et l'on présenta des candidats communs. On enleva aux revendications sociales de la petite bourgeoisie. C'est ainsi que fut créée la social-démocratie. La nouvelle Montagne, qui fut le résultat de cette combinaison, comprenait, à part quelques figurants tirés de la classe ouvrière et quelques sectaires socialistes les mêmes éléments que l'ancienne Montagne, mais numériquement plus forts. A vrai dire, elle s'était modifiée, au cours du développement, de même que la classe qu'elle représentait. Le caractère propre de la social-démocratie se résumait en ce qu'elle réclamait des institutions républicaines démocratiques comme moyen, non pas de supprimer les deux extrêmes, le capital et le salariat, mais d'atténuer leur antagonisme et de le transformer en harmonie. Quelle que soit la diversité des mesures qu'on puisse proposer pour atteindre ce but, quel que soit le caractère plus ou moins révolutionnaire des conceptions dont il puisse être revêtu, le contenu reste le même. C'est la transformation de la société par voie démocratique, mais c'est une transformation dans le cadre petit-bourgeois. Il ne faudrait pas partager cette conception bornée que la petite bourgeoisie a pour principe de vouloir faire triompher un intérêt égoïste de classe. Elle croit au contraire que les conditions générales e dehors desquelles la société moderne ne peut être sauvée et la lutte des classes évitée. Il ne faut pas s'imaginer non plus 
que les représentants démocrates sont tous des shokeepers (boutiquiers) ou qu'ils s'enthousiasment pour ces derniers. Ils peuvent, par leur culture et leur situation personnelle, être séparés deux par un abîme. Ce qui en fait les représentants de la petite bourgeoisie, c'est que leur cerveau ne peut dépasser les limites que le petit bourgeois ne dépasse pas lui-même dans sa vie, et que, par conséquent, ils sont théoriquement poussés aux mêmes problèmes et aux mêmes solutions auxquelles leur intérêt matériel et leur situation sociale poussent pratiquement les petits bourgeois. Tel est, d'une façon générale, le rapport qui existe entre les représentants politiques et littéraires d'une classe et la classe qu'ils représentent.

Étant donné ce qui précède, il est tout naturel que si la Montagne luttait continuellement contre le parti de l'ordre pour la défense de la république et des prétendus droits de l'homme, ni la république, ni les droits de l'homme n'étaient ses buts suprêmes, pas plus qu'une armée qu'on veut dépouiller de ses armes et qui résiste, n'a engagé la bataille pour rester en possession de ses armes.

Le parti de l'ordre provoqua la Montagne dès l'ouverture de l'Assemblée nationale. La bourgeoisie sentait la nécessité d'en finir avec les petits bourgeois démocrates, de même qu'une année auparavant, elle avait compris la nécessité d'en finir avec le prolétariat révolutionnaire. Seulement, la situation de l'adversaire était différente. La force du parti prolétarien était dans la rue, celle de la petite bourgeoisie au sein de l'Assemblée nationale elle-même. Il s'agissait, par conséquent, de l'attirer hors de l'Assemblée nationale, dans la rue, et de lui faire ainsi briser elle-même sa puissance parlementaire, avant qu'elle eût le temps et l'occasion de la consolider. La Montagne donna tête baissée dans le panneau.

Le bombardement de Rome par les troupes françaises fut l'amorce qu'on lui jeta. Il constituait une violation de l'article $\mathrm{V}$ de la constitution, qui interdit à la République française d'employer ses forces militaires contre les libertés d'un autre peuple. En outre, l'article IV interdisait également toute déclaration de guerre de la part du pouvoir exécutif, sans l'assentiment de l'Assemblée nationale, et la Constituante avait, par sa décision du 8 mai, désapprouvé l'expédition romaine. C'est pour ces raisons que Ledru-Rollin déposa, le 11 juin 1849, une demande de mise en accusation de Bonaparte et de ses ministres. Irrité par les piqûres de Thiers, il alla jusqu'à menacer de vouloir défendre la Constitution par tous les moyens, y compris la force des armes. La Montagne se dressa comme un seul homme et répéta cet appel aux armes. Le 12 juin, l'Assemblée nationale repoussa la demande de mise en accusation et la Montagne quitta le Parlement. On connaît les événements du 13 juin : la proclamation d'une partie de la Montagne, déclarant Bonaparte et ses ministres « hors la Constitution », la procession dans les rues de gardes nationaux démocrates qui, sans armes comme ils l'étaient, se dispersèrent à leur première rencontre avec les troupes de Changarnier, etc., etc. Une partie de la Montagne se réfugia à l'étranger, une autre fut déférée à la Haute Cour à Bourges, et un règlement parlementaire soumit le reste à la surveillance magistrale du 
président de l'Assemblée nationale. Paris fut mis à nouveau en état de siège et la fraction démocrate de sa garde nationale dissoute. Ainsi furent brisées l'influence de la Montagne au Parlement et la force de la petite bourgeoisie à Paris.

Lyon, où le 13 juin avait donné le signal d'une sanglante insurrection ouvrière, fut, de même, avec les cinq départements environnant, déclaré en état de siège, situation qui se prolonge jusqu'à présent ${ }^{15}$.

Le gros de la Montagne avait abandonné son avant-garde en se refusant à signe sa proclamation. La presse avait déserté, en ce sens que deux journaux seulement avaient osé publier le pronunciamento. Les petits bourgeois trahirent leurs représentants, car les gardes nationaux furent absents, ou, là où ils se montrèrent, s'opposèrent à la construction de barricades. Les représentants avaient trompé les petits bourgeois, car il fut impossible de trouver nulle part les prétendus affiliés qu'on avait dans l'armée. Enfin, au lieu de tirer un supplément de force du prolétariat, le parti démocrate avait infecté ce dernier de sa propre faiblesse et, comme cela se produit d'ordinaire lors des prouesses démocratiques, les chefs eurent la satisfaction de pouvoir accuser leur «peuple» de désertion, et le peuple celle de pouvoir accuser ses chefs de duperie.

Rarement action fut annoncée avec plus de fracas que le fut l'entrée en campagne imminente de la Montagne, et rarement événement fut annoncé à son de trompe avec plus d'assurance et plus longtemps d'avance que le fut la victoire inévitable de la démocratie. Assurément, les démocrates croient aux trompettes dont les sonorités renversèrent les murailles de Jéricho. Chaque fois qu'ils rencontrent devant eux les remparts du despotisme, ils s'efforcent de refaire le miracle. Si la Montagne voulait vaincre au Parlement, elle ne devait pas appeler aux armes. Si elle appelait aux armes au Parlement, elle ne devait pas se conduire parlementairement dans la rue. Si l'on se proposait sérieusement une démonstration pacifique, il était stupide de ne pas prévoir qu'elle serait accueillie belliqueusement. S'il fallait s'attendre à une lutte véritable, il était vraiment original de déposer les armes avec lesquelles il fallait mener cette lutte. Mais les menaces révolutionnaires des petits bourgeois et de leurs représentants démocrates ne sont que de simples tentatives d'intimidation de l'adversaire. Et quand ils sont acculés, quand ils se sont suffisamment compromis pour se voir contraints de mettre leurs menaces à exécution, ils le font d'une manière équivoque qui n'évite rien tant que les moyens propres au but et cherche avidement des prétextes de défaite. L'ouverture éclatante annonçant le combat se perd en un faible murmure dès la que le combat doit commencer. Les acteurs cessent de se prendre au sérieux et l'action s'écroule lamentablement comme une baudruche que l'on perce avec une aiguille.

151852. 
Aucun parti ne s'exagère davantage les moyens dont il dispose que le parti démocrate. Aucun ne s'illusionne plus légèrement sur la situation. Parce qu'une partie de l'armée avait voté pour elle, la Montagne était persuadée que l'armée se soulèverait en sa faveur. Et à quelle occasion? A une occasion qui, du point de vue des troupes, ne signifiait autre chose que ceci : les révolutionnaires prenaient parti pour les soldats romains contre les soldats français. D'autre part, les souvenirs de juin 1848 étaient encore trop vivaces pour que le prolétariat ne ressentit pas une aversion profonde à l'égard de la garde nationale, et pour que les chefs des sociétés secrètes n'eussent pas une profonde méfiance à l'égard des chefs du parti démocrate. Pour aplanir ces différends, il fallait les grands intérêts communs qui étaient en jeu. La violation d'un paragraphe abstrait de la Constitution ne pouvait pas offrir cet intérêt. La Constitution n'avait-elle pas été déjà violée à différentes reprises, de l'aveu des démocrates eux-mêmes ? Les journaux les plus populaires ne l'avaient-ils pas stigmatisée comme une machination contre-révolutionnaire ? Mais le démocrate, parce qu'il représente la petite bourgeoisie, par conséquent une classe intermédiaire, au sein de laquelle s'émoussent les intérêts des deux classes opposées, s'imagine être au-dessus des antagonismes de classe. Les démocrates reconnaissent qu'ils ont devant eux une classe privilégiée, mais eux, avec tout le reste de la nation, ils constituent le peuple. Ce qu'ils représentent, c'est le droit du peuple; ce qui les intéresse, c'est l'intérêt du peuple. Ils n'ont donc pas besoin, avant d'engager une lutte, d'examiner les intérêts et les positions des différentes classes. Ils n'ont pas besoin de peser trop minutieusement leurs propres moyens. Ils n'ont qu'à donner le signal pour que le peuple fonce avec toutes ses ressources inépuisables sur ses oppresseurs. Mais si, dans la pratique, leurs intérêts apparaissent sans intérêt, et si leur puissance se révèle comme impuissance, la faute en est ou aux sophistes criminels qui divisent le peuple indivisible en plusieurs camps ennemis, ou à l'armée qui est trop abrutie ou trop aveuglée pour considérer les buts de la démocratie comme son propre bien, ou encore, c'est qu'un détail d'exécution a tout fait échouer, ou, enfin, c'est qu'un hasard imprévu a fait comprendre cette fois la partie. En tous cas, le démocrate sort de la défaite la plus honteuse tout aussi pur qu'il était innocent lorsqu'il est entré dans la lutte, avec la conviction nouvelle qu'il doit vaincre, non pas parce que lui et son parti devront abandonner leur ancien point de vue, mais parce que, au contraire, les conditions devront mûrir.

C'est pourquoi il ne faut pas se représenter la Montagne décimée, abattue et humiliée par le nouveau règlement parlementaire, comme trop malheureuse. Si le 13 juin avait éloigné ses chefs, il faisait place à des capacités inférieures flattées de cette nouvelle situation. Comme leur impuissance au parlement ne pouvait plus être mise en doute, ils étaient dès lors en droit de limiter leur activité à des accès d'indignation morale et à des déclamations ronflantes. Si le parti de l'ordre feignait de voir en eux les derniers représentants officiels de la révolution, l'incarnation de toutes les horreurs de l'anarchie, ils pouvaient, en réalité, être d'autant plus plats et plus modestes. Mais ils se consolèrent du 13 juin par ce profond détour : Qu'on ose 
seulement toucher au suffrage universel ! Nous montrerons alors ce que nous sommes ! Nous verrons $^{(*)}$.

En ce qui concerne les Montagnards réfugiés à l'étranger, il suffit de faire remarquer ici que Ledru-Rollin, parce qu'il avait réussi à ruiner en moins de quinze jours, sans espoir de retour, le puissant parti à la tête duquel il se trouvait, se crut désigné pour former un gouvernement français in partibus, que sa figure, dans le lointain, éloignée du terrain de l'action, paraissait grandir au fur et à mesure que baissait le niveau de la révolution et que les grandeurs officielles de la France officielle devenaient de plus en plus minuscules. Il put faire figure de prétendant républicain pour 1852, envoyant des circulaires périodiques aux Valaques et autres peuples, dans lesquelles il menaçait les despotes du continent de son intervention et de celle de ses alliés. Proudhon avait-il complètement tort quand il criait à ces messieurs : Vous n'êtes que des blagueurs ${ }^{(*)}$ ?

Le 13 juin, le parti de l'ordre n'avait pas seulement abattu la Montagne, il avait encore réussi à subordonner la Constitution aux décisions de la majorité de l'Assemblée nationale. Il concevait la république de la façon suivante : la bourgeoise dominait maintenant sous des formes parlementaires, sans que cette domination fût limitée, comme dans la monarchie, par le veto du pouvoir exécutif ou le droit de dissolution du Parlement. C'était la République parlementaire, comme l'appelait Thiers. Mais si la bourgeoisie assura, le 13 juin, sa toutepuissance à l'intérieur du Parlement, ne frappait-elle pas ce Parlement lui-même, à l'égard du pouvoir exécutif et du peuple, d'une faiblesse irrémédiable, en expulsant sa fraction la plus populaire? En livrant, sans autres formes de cérémonie, de nombreux députés aux réquisitions des parquets, elle supprimait sa propre immunité parlementaire. Le règlement humiliant auquel elle soumettait la Montagne élevait le président de la République dans la mesure où il abaissait chaque représentant du peuple. En flétrissant comme anarchiste, comme un acte visant au renversement de la société, l'insurrection entreprise pour la défense de la Constitution, elle s'interdisait à elle-même l'appel à l'insurrection, dès que le pouvoir exécutif violerait à ses dépens la Constitution. L'ironie de l'histoire a voulu que le général qui, sur l'ordre de Bonaparte, bombarda Rome, et fut ainsi la cause directe de l'émeute constitutionnelle du 13 juin, Oudinot, fut, le 2 décembre 1851, présenté instamment et vainement au peuple par le parti de l'ordre comme général de la Constitution contre Bonaparte. Un autre héros du 13 juin, Vieyra, qu'on félicita, du haut de la tribune de l'Assemblée nationale, pour les brutalités qu'il avait exercées dans les locaux des journaux démocratiques, à la tête d'une bande de gardes nationaux appartenant à la haute finance, ce même Vieyra fut initié à la conspiration de Bonaparte, et contribua considérablement à priver l'Assemblée nationale, quand sa dernière heure fut arrivée, de toute protection de la part de la garde nationale. 
Le 13 juin eut encore une autre signification. La Montagne avait voulu arracher la mise en accusation de Bonaparte. Sa défaite fut, par conséquent, une victoire directe de Bonaparte, son triomphe personnel sur ses adversaires démocrates. Le parti de l'ordre combattit pour obtenir la victoire. Bonaparte n'eut qu'à l'encaisser. C'est ce qu'il fit. Le 14 juin, on put lire sur les murs de Paris une proclamation dans laquelle le président, pour ainsi dire, à son insu, malgré lui, contraint par la seule force des événements, sortait de son isolement monacal, se plaignait, vertu méconnue, des calomnies de ses adversaires, et, tout en paraissant identifier sa personne avec la cause de l'ordre, identifiait plutôt la cause de l'ordre avec sa propre personne. De plus, si l'Assemblée nationale avait approuvé, quoique après coup, l'expédition contre Rome ${ }^{16}$, c'était lui, Bonaparte, qui en avait pris l'initiative. Après avoir ramené au Vatican le grandprêtre Samuel ${ }^{17}$, il pouvait espérer, nouveau roi David ${ }^{(3)}$, s'installer aux Tuileries. Il avait gagné les curés.

L'émeute du 13 juin se borna, comme nous l'avons vu, à une procession pacifique dans les rues. Il n'y eut donc pas de lauriers militaires à conquérir contre elle. Il n'en est pas moins vrai que, dans cette époque aussi pauvre en héros qu'en événements, le parti de l'ordre transforma cette bataille sans effusion de sang en un second Austerlitz ${ }^{18}$. La tribune et la presse célébrèrent dans l'armée la puissance de l'ordre opposée aux masses populaires, représentant l'impuissance de l'anarchie, et glorifièrent Changarnier, le « rempart de la société ». Mystification à laquelle celui-ci finit par croire lui-même. Mais, en sous-main, les corps qui paraissaient douteux durent éloignés de Paris, les régiments qui avaient voté en faveur des démocrates furent exilés de France en Algérie, les têtes chaudes des troupes envoyées aux compagnies de discipline. Enfin, on coupa systématiquement la presse de la caserne, et la caserne de la société bourgeoise.

Nous voici au tournant décisif de l'histoire de la garde nationale française. En 1830, c'est elle qui avait décidé du renversement de la Restauration. Sous Louis-Philippe, chaque émeute dans laquelle la garde nationale se plaça du côté des troupes échoua. Quand, lors des Journées de février 1848, elle observa une attitude passive à l'égard de l'insurrection, et douteuse à l'égard de Louis-Philippe, ce dernier se considéra comme perdu. C'est ainsi que s'enracina la conviction que la révolution ne pouvait pas vaincre sans la garde nationale et que l'armée ne pouvait pas vaincre contre elle. C'était là une croyance superstitieuse de l'armée dans la toute-puissance bourgeoise. Les Journées de juin 1848, au cours desquelles toute la garde nationale écrasa l'insurrection à l'aide des troupes de ligne, n'avaient fait que renforcer cette croyance superstitieuse. Après l'arrivée au pouvoir de Bonaparte, l'influence de la garde nationale diminua, en quelque sorte, par suite de la réunion inconstitutionnelle de son

16 Pie IX, débordé par le mouvement populaire de 1848, s'enfuit. Une armée française le ramène, après avoir pris Rome par la force le 2 juin 1849.

17 Prophète et dernier juge des hébreux, Samuel sacra roi Saül, puis David.

18 Grande victoire remportée par Napoléon sur les Austro-Russes, le 2 décembre 1805. 
commandement avec le commandement de la première division militaire dans la personne de Changarnier.

Le commandement de la garde nationale paraissait maintenant comme un simple attribut du commandement militaire suprême, la garde nationale ne fut plus semble-t-il, qu'une dépendance des troupes de ligne. Le 13 juin, elle fut enfin brisée et pas seulement par suite de sa dissolution partielle, qui, depuis cette époque, se répéta périodiquement dans toutes les parties de la France et n'en laissa subsister que des débris. La démonstration du 13 juin avait été avant tout une démonstration des gardes nationaux démocrates. Ils n'avaient pas opposé à l'armée leurs armes, mais leur uniforme. Or c'est précisément dans cet uniforme que résidait le talisman. L'armée put se convaincre que cet uniforme était un chiffon de laine tout comme un autre. Le charme était rompu. Lors des Journées de juin 1848, la bourgeoisie et la petite bourgeoisie, en tant que garde nationale, s'étaient unies avec l'armée contre le prolétariat. Le 13 juin 1849, la bourgeoisie fit disperser la garde nationale petite bourgeoise par l'armée. Le 2 décembre 1851, la garde nationale bourgeoise disparaissait d'elle-même, et Bonaparte ne fit que constater un fait accompli, lorsqu'il signa après coup son décret de dissolution. C'est ainsi que la bourgeoisie avait brisé elle-même sa dernière arme contre l'armée, à partir du moment où la petite bourgeoisie ne fut plus pour elle une vassale, mais une rebelle, de même qu'elle devait, d'une façon générale, détruire de sa propre main tous ses moyens de défense contre l'absolutisme, dès qu'elle fut devenue elle-même absolue.

Cependant, le parti de l'ordre célébra la reprise d'un pouvoir qu'il ne semblait avoir perdu en 1848 que pour le retrouver en 1849 sans aucune limite, par des invectives contre la république et la Constitution, par des anathèmes contre toutes les révolutions passées, présentes et futures, y compris celle qu'aveint faites ses propres chefs, et par des lois muselant la presse, supprimant le droit d'association et faisant de l'état de siège une institution régulière, organique. Puis, l'Assemblée nationale s'ajourna de ma mi-août à la mi-octobre, après avoir nommé une commission permanente pour toute la durée de son absence. Pendant ces vacances, les légitimistes intriguèrent Ems ${ }^{19}$, les orléanistes avec Claremont ${ }^{20}$, Bonaparte le fit par des tournées princières, et les conseils départementaux en discutant la révision de la Constitution. Incidents qui se reproduisirent régulièrement lors des vacances périodiques de l'Assemblée nationale et dont je ne parlerai qu'une fois devenus des événements. Remarquons simplement ici que l'Assemblée nationale agissait d'une façon non politique, en disparaissant de la scène pour un long intervalle de temps et en ne laissant apercevoir à la tête de la république qu'une seule silhouette, même aussi lamentable que celle de Louis

19 Lieu de séjour du prétendant au trône de France de la dynastie des Bourbon, le comte de Chambord (que ses partisans appelèrent Henri V). Son rival de la dynastie d'Orléans (Louis-Philippe), qui s'enfuit après la révolution de Février en Angleterre, vivait à Claremont, dans le voisinage de Londres. Ems et Claremont étaient donc les centres d'intrigues monarchistes.

20 Idem. 
Bonaparte, tandis que le parti de l'ordre, au grand scandale du public, se divisait en ses différents éléments royalistes, et s'abandonnait à ses divergences intérieures concernant la restauration monarchiste. Chaque fois que, pendant ces vacances, s'éteignit le bruit confus du Parlement, et que ce dernier se sépara pour se répandre dans la nation, il apparut d'une façon indiscutable qu'il ne manquait d'une façon indiscutable qu'il ne manquait plus qu'une seule chose pour compléter la véritable figure de cette république : rendre ses vacances permanentes et remplacer sa devise : «Liberté, Égalité, Fraternité !» par les termes non équivoques de : «Infanterie, Cavalerie, Artillerie !» 


\section{IV}

\section{$\underline{\text { Retour à la table des matières }}$}

L'Assemblée nationale se réunit de nouveau à la mi-octobre 1849 . Le $1^{\mathrm{er}}$ novembre, Bonaparte la surprit par un message dans lequel il annonçait le renvoi du ministère BarrotFalloux et la formation d'un nouveau cabinet. Jamais on ne renvoya des laquais avec aussi peu de cérémonie que Bonaparte ses ministres. Les coups de pied, destinés à l'Assemblée nationale, ce furent Barrot et $\mathrm{C}^{\mathrm{ie}}$ qui les reçurent en attendant.

Le ministère Barrot était, comme nous l'avons vu, composé de légitimes et d'orléanistes, un ministère du parti de l'ordre. Bonaparte en avait besoin pour dissoudre la Constitution républicaine, entreprendre l'expédition contre Rome et briser le parti démocrate. Il s'était, en apparence, éclipsé derrière ce ministère, avait abandonné le pouvoir gouvernemental entre les mains du parti de l'ordre, et arboré le masque modeste, que portait sous Louis-Philippe le gérant responsable des journaux, le masque de $l^{\prime}$ « homme de paille ${ }^{(*)} »$. Maintenant, il se débarrassait de ce déguisement qui n'était plus le voile léger sous lequel il pouvait dissimuler sa physionomie, mais le masque de fer qui l'empêchait de montrer sa physionomie propre. Il avait installé au gouvernement le ministère Barrot pour briser, au nom du parti de l'ordre, l'Assemblée nationale républicaine, et il le renvoyait pour bien montrer qu'il ne dépendait pas de l'Assemblée, du parti de l'ordre.

Il ne manquait d'ailleurs pas de raisons plausibles pour ce renvoi. Le ministère Barrot négligeait même les formes de bienséance qui auraient pu faire paraître le président de la République comme une puissance à côté de l'Assemblée nationale. Pendant les vacances de l'Assemblée nationale, Bonaparte publia une lettre adressée à Edgar Ney, dans laquelle il semblait désapprouver la conduite libérale du pape, de même que, en opposition avec la Constituante, il avait publié une lettre dans laquelle il félicitait Oudinot de son attaque contre la République romaine. Lorsque l'Assemblée nationale vota les crédits pour l'expédition romaine, Victor Hugo, par un prétendu libéralisme, mit la lettre en discussion. Le parti de l'ordre étouffa l'incident sous des interruptions méprisantes, comme si les lubies de Bonaparte pouvaient avoir la moindre importance politique. Aucun des ministres ne releva le gant. A une autre occasion, Barrot, avec son pathos grandiloquent, fit entendre, du haut de la tribune, des paroles d'indignation au sujet des «intrigues abominables » qui, d'après lui, se tramaient dans l'entourage immédiat du président. Enfin, alors qu'il obtenait de l'Assemblée nationale un douaire pour la duchesse d'Orléans, le ministère repoussa toute proposition 
d'augmentation de la liste civile présidentielle. Or, chez Bonaparte, le prétendant impérial se confondait si étroitement avec le chevalier de fortune déchu qu'à sa grande idée de se croire prédestiné à restaurer l'Empire, s'ajoutait toujours, pour la compléter, celle que le peuple français était prédestiné à payer ses dettes.

Le ministère Barrot-Falloux fut le premier et le dernier ministère parlementaire de Bonaparte. Son renvoi constitue, par conséquent, un tournant décisif. Avec lui, le parti de l'ordre perdit, sans pouvoir la reconquérir une position indispensable pour la défense du régime parlementaire de la possession du pouvoir exécutif. On se rend compte immédiatement que, dans un pays comme la France, où le pouvoir exécutif dispose d'une armée de fonctionnaires de plus d'un demi-million de personnes et tient, par conséquent, constamment sous sa dépendance la plus absolue une quantité énorme d'intérêts et d'existences, où l'État enserre contrôle, réglemente, surveille et tient en tutelle la société civile, depuis ses manifestations d'existence les plus vastes jusqu'à ses mouvements les plus infimes, de ses modes d'existence les plus généraux jusqu'à la vie privée des individus, où ce corps parasite, grâce à la centralisation la plus extraordinaire, acquiert une omniprésence, une omniscience une plus rapide capacité de mouvement et un ressort, qui n'ont d'analogues que l'état de dépendance absolue, la difformité incohérente du corps social, on comprend donc que, dans un tel pays, l'Assemblée nationale, en perdant le droit de disposer des postes ministériels, perdait également toute influence réelle, si elle ne simplifiait pas en même temps l'administration de l'État, ne réduisait pas le plus possible l'armée des fonctionnaires et ne permettait pas, enfin, à la société civile et à l'opinion publique, de créer leurs propres organes, indépendants du pouvoir gouvernemental. Mais l'intérêt matériel de la bourgeoisie française est précisément lié de façon très intime au maintien de cette machine gouvernementale vaste et compliquée. C'est là qu'elle case sa population superflue et complète sous forme d'appointements ce qu'elle ne peut encaisser sous forme de profits, d'intérêts, de rentes et d'honoraires. D'autre part, son intérêt politique l'obligeait à aggraver de jour en jour la répression, et, par conséquent, à augmenter les moyens et le personnel du pouvoir gouvernemental, tandis qu'en même temps il lui fallait mener une guerre ininterrompue contre l'opinion publique, mutiler et paralyser jalousement les organes moteurs indépendants de la société, là où elle ne réussissait pas à les amputer complètement. C'est ainsi que la bourgeoisie française était obligée, par sa situation de classe, d'une part, d'anéantir les conditions d'existence de tout pouvoir parlementaire et, par conséquent aussi, du sien même, et, d'autre part, de donner une force irrésistible au pouvoir exécutif qui lui était hostile.

Le nouveau ministère s'appelait d'Hautpoul. Non pas que le général d'Hautpoul eût obtenu le rang de président du Conseil. En renvoyant Barrot, Bonaparte supprima au contraire cette dignité, qui condamnait, il est vrai, le président de la République au néant d'un roi constitutionnel, mais d'un roi constitutionnel sans trône ni couronne, sans sceptre ni glaive, sans irresponsabilité, sans la possession imprescriptible de la plus haute dignité de l'État et, ce 
qui était le plus fatal, sans liste civile. Le ministère d'Hautpoul ne comptait qu'un seul homme jouissant d'un certain renom parlementaire, le Juif Fould, l'un des membres les plus tristement fameux de la haute finance. On lui donna le ministère des Finances. Il suffit de feuilleter les cotes de la Bourse de Paris pour se rendre compte qu'à partir du $1^{\text {er }}$ novembre 1849 les valeurs françaises montent et descendent selon la hausse et la baisse des actions bonapartistes. Pendant que Bonaparte trouvait ainsi des affiliés à la Bourse, il s'emparait en même temps de la police, en nommant Carlier préfet de police de Paris.

Cependant, les conséquences du changement de ministère ne pouvaient se manifester qu'à la longue. Tout d'abord, Bonaparte n'avait fait un pas en avant que pour pouvoir d'une façon plus évidente être repoussé en arrière. Son message brutal fut suivi de la déclaration de soumission la plus servile à l'Assemblée nationale. Chaque fois que les ministres faisaient une tentative timide de présenter ses marottes personnelles à l'Assemblée sous forme de projets de loi, ils ne semblaient eux-mêmes que remplir à contre-cœur, contraints par leur situation, des ordres comiques, de l'insuccès desquels ils étaient persuadés d'avance. Chaque fois que Bonaparte divulguait ses intentions derrière le dos des ministres et jouait de ses idées napoléoniennes $^{(*)}$, ses propres ministres le désavouaient du haut de la tribune de l'Assemblée nationale. Ses désirs d'usurpation ne semblaient se faire entendre que pour entretenir les rires malicieux de ses adversaires. Il se comportait comme génie méconnu que le monde entier considère comme un simple d'esprit. Jamais, il ne fut complètement l'objet du mépris de toutes les classes qu'au cours de cette période. Jamais, la bourgeoisie ne domina de façon plus absolue, jamais, elle ne fit plus ostensiblement étalage des insignes du pouvoir.

Je n'ai pas à faire ici l'histoire de son activité législative qui se résume, au cours de cette période, en deux lois principales : la première, qui rétablit l'impôt sur les boissons, et la seconde, la loi sur l'enseignement, qui abolit l'incrédulité. Si l'on rendait ainsi plus difficile aux Français la jouissance du vin, on leur versait avec d'autant plus abondance l'eau de la vraie vie. Si la bourgeoisie, en rétablissant les impôts sur les boissons, proclamait l'intangibilité du vieux système fiscal détesté, elle s'efforçait, au moyen de la loi sur l'enseignement, de maintenir l'ancien état d'esprit des masses, qui le leur faisait supporter. On est surpris de voir les orléanistes, les bourgeois libéraux, ces anciens apôtres du voltairisme et de la philosophie éclectique, confier à leurs ennemis héréditaires, les jésuites, la direction de l'esprit français. Mais orléanistes et légitimistes pouvaient diverger en ce qui concerne le prétendant à la couronne, ils comprenaient que leur domination commune imposait l'unification des moyens d'oppression de deux époques, et qu'il fallait compléter et renforcer les moyens d'asservissement de la monarchie de Juillet par ceux de la Restauration.

Les paysans, déçus dans tous leurs espoirs, plus que jamais écrasés, d'une part, par le cours bas des céréales, d'autre part, par l'accroissement des charges fiscales et de la dette hypothécaire, commencèrent à s'agiter dans les départements. On leur répondit en traquant les 
instituteurs, qui furent soumis aux ecclésiastiques, les maires, qui furent soumis aux préfets, et en organisant tout un système d'espionnage, auquel tout le monde fut soumis. A Paris et dans les grandes villes, la réaction elle-même revêt la physionomie de son époque et provoque plus qu'elle n'abat. A la campagne, elle est plate, grossière, mesquine, fatigante, tracassière, en un mot, elle est gendarmée. On se rend compte comment trois années d'un pareil régime de gendarme, consacré par le régime des curés, devaient démoraliser des masses inéduquées.

Quelle que fût la somme de passion et de déclamation que le parti de l'ordre pût dépenser, du haut de la tribune de l'Assemblée nationale, contre la minorité, ses discours restaient monosyllabiques comme celui du chrétien dont les paroles doivent se borner à : «Oui, oui, non, non! » Monosyllabiques du haut de la tribune comme dans la presse, fades comme une énigme dont on connaît d'avance la solution. Qu'il s'agisse du droit de pétition ou de l'impôt sur les boissons, de la liberté de la presse ou du libre-échange, des clubs ou de l'organisation municipale, de la protection de la liberté personnelle ou de la réglementation du budget, le mot d'ordre revenait toujours à nouveau, le thème restait toujours le même, la sentence était toujours prête et invariablement la même: Socialisme! On déclara socialiste même le libéralisme bourgeois, la culture bourgeoise, la réforme financière bourgeoise. C'était du socialisme que de construire un chemin de fer là où il y avait déjà un canal, et c'était du socialisme que de se défendre avec un bâton quand on vous attaquait avec une épée.

Ce n'était pas là une simple façon de parler, une mode, une tactique de parti. La bourgeoisie se rendait très bien compte que toutes les armes qu'elle avait forgées contre le compte que toutes les armes qu'elle avait forgées contre le féodalisme se retournaient maintenant contre elle-même, que tous les moyens d'instruction qu'elle avait institués se retournaient contre sa propre culture, que tous les dieux qu'elle avait créés l'abandonnaient. Elle se rendait compte que toutes les prétendues libertés bourgeoises et institutions de progrès attaquaient et menaçaient sa domination de classe, à la fois dans sa base sociale et à son sommet politique, et étaient, par conséquent, devenues « socialistes ». Elle voyait avec raison dans cette menace et dans cette attaque le secret du socialisme, dont elle comprend mieux le sens et la tendance que le prétendu socialisme lui-même, ce socialisme qui ne peut pas arriver à comprendre pourquoi la bourgeoisie se ferme obstinément à lui, qu'il gémisse sentimentalement sur les souffrances de l'humanité ou qu'il annonce chrétiennement la venue du royaume millénaire et l'ère de la fraternité universelle, qu'il radote à la manière des humanistes sur l'esprit, la culture, la liberté ou invente un système de réconciliation et de prospérité de toutes les classes de la société. Mais ce que la bourgeoisie ne comprenait pas, c'était que son propre régime parlementaire, sa domination politique, en général, devaient fatalement à leur tour être condamnés comme socialistes. Tant que la domination de la classe bourgeoise ne s'était pas complètement organisée, n'avait pas trouvé son expression politique pure, l'antagonisme des autres classes ne pouvait pas, non plus, se manifester nettement, et là où il se manifestait, prendre cette tournure dangereuse qui transforme tout lutte contre le 
pouvoir d'État en une lutte contre le capital. Si, dans tout mouvement de la société, la bourgeoisie voyait l'« ordre » en danger, comment pouvait-elle vouloir défendre, à la tête de la société, le régime du désordre, son propre régime, le régime parlementaire, ce régime qui, suivant l'expression d'un de ses orateurs, ne vit que dans la lutte et par la lutte ? Le régime parlementaire vit de la discussion, comment l'interdirait-il ? Chaque intérêt, chaque institution sociale, y sont transformés en idées générales, discutés en tant qu'idées. Comment un intérêt, une institution quelconque pourraient-ils s'élever au-dessus de la pensée et s'imposer comme articles de foi ? La lutte oratoire à la tribune provoque les polémiques de presse. Le club de discussion au Parlement trouve son complément nécessaire dans les clubs de discussion des salons et des cabarets. Les représentants, donnent le droit de s'exprimer au moyen de pétitions. Le régime parlementaire remet tout à la décision des majorités, comment les grandes majorités en dehors du Parlement ne voudraient-elles pas décider, elles aussi ? Quand, au sommet de l'État, on -joue du violon, comment ne pas s'attendre que ceux qui sont en bas se mettent à danser?

Ainsi donc, en taxant d'hérésie «socialiste » ce qu'elle avait célébré autrefois comme «libéral », la bourgeoisie reconnaît que son propre intérêt lui commande de se soustraire aux dangers du self-government; que, pour établir le calme dans le pays, il faut avant tout ramener au calme son Parlement bourgeois ; que, pour conserver intacte sa puissance sociale, il lui faut briser sa puissance politique; que les bourgeois ne peuvent continuer à exploiter les autres classes et à jouir tranquillement de la propriété, de la famille, de la religion et de l'ordre qu'à la condition que leur classe soit condamnée au même néant politique que les autres classes ; que, pour sauver sa bourse, la bourgeoisie doit nécessairement perdre sa couronne et que le glaive qui doit la protéger est fatalement aussi une épée de Damoclès suspendue au-dessus de sa tête.

Dans le domaine des intérêts généraux de la bourgeoisie, l'Assemblée nationale se montra si improductive que, par exemple, les débats sur la construction du chemin de fer de Paris à Avignon, commencés pendant l'hiver 1850, n'étaient pas encore assez avancés pour être terminés le 2 décembre 1851. Quand elle ne faisait pas œuvre d'oppression ou de réaction, elle était frappée d'une incurable stérilité.

Tandis que le ministère de Bonaparte prenait l'initiative de lois conçues dans l'esprit du parti de l'ordre, ou exagérait encore leur sévérité dans leur application et leur exécution, le président s'efforçait, de son côté, par des propositions d'une bêtise puérile, de conquérir de la popularité, de montrer son opposition à l'égard de l'Assemblée nationale et de laisser entendre par une secrète arrière-pensée que, seules, les circonstances l'empêchaient momentanément d'ouvrir au peuple français ses trésors cachés. C'est ainsi qu'il proposait d'accorder aux sous-officiers un relèvement de solde de quatre sous par jour et de créer une banque de prêts d'honneur pour les ouvriers. Recevoir de l'argent sous forme de cadeaux ou 
de prêts, c'était là la perspective au moyen de laquelle il espérait séduire les masses. Offrir et emprunter de l'argent, c'est à cela que se réduit toute la science financière su sous-prolétariat, qu'il soit de condition distinguée ou de condition commune. C'est à cela que se réduisaient les ressorts que Bonaparte savait mettre en mouvement. Jamais prétendant ne spécula plus platement sur la platitude des masses.

L'Assemblée nationale s'indigna à différentes reprises de ces tentatives manifestes de se tailler une popularité à ses dépens, en présence du danger croissant d'un coup désespéré tenté par cet aventurier, aiguillonné par ses dettes, et que ne retenait aucune réputation acquise. Le désaccord entre le parti de l'ordre et le président avait pris un caractère menaçant repentant dans les bras de ce parti. Nous voulons parler des élections complémentaires du 10 mars 1850. Ces élections avaient pour but de pourvoir aux sièges que la prison ou l'exil avaient rendus vacants au lendemain du 13 juin. Paris n'élut que des candidats social-démocrates. Il groupa même la plupart des voix sur le nom d'un insurgé de juin 1848, Deflotte. La petite bourgeoisie parisienne, alliée au prolétariat, se vengeait ainsi de sa défaite du 13 juin1849. Le prolétariat semblait n'avoir disparu du théâtre de la lutte au moment du danger que pour y réapparaître à la première occasion favorable, avec des forces plus considérables, et avec un mot d'ordre plus audacieux. Une autre circonstance parut encore accroître le danger de cette victoire électorale. L'armée vota à Paris pour l'insurgé de juin contre Lahitte, l'un des ministres de Bonaparte, et, dans les départements, elle vota en majorité pour les Montagnards, qui, là, également, l'emportèrent sur leurs adversaires, quoique d'une façon moins nette qu'à Paris.

Bonaparte vit subitement la révolution se dresser contre lui. Comme au 29 janvier 1848, comme au 13 juin 1849, il se cacha, le 10 mars 1850, derrière le parti de l'ordre. Il s'inclina, fit humblement des excuses, s'offrit à nommer, sur l'ordre de la majorité parlementaire, n'importe quel ministère. Il supplia même les chefs des partis orléaniste et légitimiste, les Tiers, les Berryer, les Broglie, les Molé, bref ceux que l'on appelait les «burgraves », de prendre en main les rênes de l'État. Le parti de l'ordre ne sut pas profiter de l'occasion. Au lieu de s'emparer hardiment du pouvoir qu'on lui offrait, il ne sut même pas obliger Bonaparte à reprendre le ministère qu'il avait renvoyé le $1^{\mathrm{er}}$ novembre. Il se contenta de l'humilier en lui pardonnant et d'adjoindre M. Baroche au ministère d'Hautpoul. Ce Baroche avait, en qualité d'accusateur public, sévi contre les révolutionnaires du 15 mai, une seconde fois contre les démocrates du 13 juin, dans les deux cas pour attentats contre l'Assemblée nationale. Aucun des ministres de Bonaparte ne contribua dans la suite davantage à rabaisser l'Assemblée nationale, et, après le 2 décembre 1851, nous le retrouvons, dûment installé et grassement payé, à la vice-présidence du Sénat. Il avait craché dans la soupe des révolutionnaires pour que Bonaparte pût l'avaler. 
Le Parti social-démocrate, de son côté, ne semblait pressé que de trouver des prétextes pour remettre en question sa propre victoire et la diminuer. Vidal, l'un des députés de Paris nouvellement élus, avait été, en même temps, élu à Strasbourg. On le détermina à renoncer à son élection à Paris et à opter pour Strasbourg. Par conséquent, au lieu de donner à sa victoire électorale un caractère définitif et d'obliger ainsi le parti de l'ordre à la lui disputer immédiatement au Parlement, au lieu de forcer ainsi l'adversaire à la lutte au moment où le peuple était plein d'enthousiasme et où l'état d'esprit dans l'armée était favorable, le parti démocrate fatigua Paris pendant les mois de mars et d'avril par une nouvelle agitation électorale. Il laissa les passions populaires surexcitées se consumer ainsi dans ce nouvel intermède, l'énergie révolutionnaire se rassasier de succès constitutionnels et se dépenser en petites intrigues, en creuses déclamations et en une agitation illusoire. Il permit ainsi à la bourgeoisie de se regrouper et de prendre ses mesures. Enfin, il laissa fournir aux élections de mars un commentaire sentimental qui l'affaiblissait par l'élection complémentaire d'avril, celle d'Eugène Sue ! En un mot, il fi du 10 mars un poisson d'avril.

La majorité parlementaire se rendit compte de la faiblesse de son adversaire. Ss 17 burgraves, à qui Bonaparte avait abandonné la direction et la responsabilité de l'attaque élaborèrent une nouvelle loi électorale, dont le dépôt fut confié à M. Faucher, qui en avait réclamé pour lui l'honneur. Le 8 mai, il déposa la loi abolissant le suffrage universel, imposant aux électeurs l'obligation de résidence de trois ans au lieu du vote et faisant ainsi dépendre, pour les ouvriers, la preuve de cette résidence, de l'attestation de leur employeur.

Autant les démocrates avaient, pendant la lutte électorale constitutionnelle, mené une agitation révolutionnaire, autant leurs discours devenaient constitutionnels, maintenant qu'il s'agissait de montrer les armes à la main tout le sérieux de leur victoire électorale, prêchant l'ordre, le «calme majestueux », l'action légale, autrement dit la soumission aveugle à la volonté de la contre-révolution, qui s’imposait comme loi. Au cours des débats, la Montagne confondit le parti de l'ordre en opposant à la passion révolutionnaire de ce dernier l'attitude calme du brave homme qui reste sur le terrain du droit et en l'accablant sous l'effroyable reproche de se conduire révolutionnairement. Même les députés nouvellement élus s'efforcèrent de prouver par leur attitude décente et posée quelle erreur c'était de les accuser d'être des anarchistes et de considérer leur réélection comme une victoire de la révolution. Le 31 mai, la nouvelle loi électorale fut adoptée. La Montagne se contenta de glisser une protestation dans la poche du président de l'Assemblée. La loi électorale fut suivie d'une nouvelle loi sur la presse, au moyen de laquelle toute la presse révolutionnaire fut complètement supprimée. Elle avait mérité son sort. Après ce déluge, Le National et La Presse, deux organes bourgeois, restèrent mes postes avancés de la révolution.

Nous avons vu comment, en mars et en avril, les chefs démocrates avaient tout fait pour embarquer le peuple de Paris dans une lutte illusoire, et comment, après le 8 mai, ils firent 
tout leur possible pour le détourner de la lutte véritable. Il ne faut pas oublier, en outre, que l'année 1850 fut l'une des plus brillantes au point de vue de la prospérité industrielle et commerciale, et que, par conséquent, le prolétariat parisien était complètement occupé. Mais la loi électorale du 31 mai 1850 l'excluait de toute participation au pouvoir politique. Elle le coupait du champ de bataille même. Elle rejetait les ouvriers dans la situation de parias qu'ils occupaient avant la révolution de février. En se laissant diriger, devant un tel événement, par des démocrates, et en allant jusqu'à oublier l'intérêt révolutionnaire de leur classe pour un bien-être passager, les ouvriers renonçaient à l'honneur d'être une classe conquérante, ils s'abandonnaient à leur sort, prouvant que la défaite de juin 1848 les avait rendus, pour des années, impropres à la lutte, et que le processus historique devait de nouveau se poursuivre par-dessus leurs têtes. Quant aux démocrates petits-bourgeois qui s'écriaient le 13 juin: «Mais qu'on essaye de toucher au suffrage universel, et nous verrons ! », ils se consolaient en pensant que le coup contre-révolutionnaire qui les avait frappés n'était pas un coup, et que la loi du 31 mai n'était pas une loi. Le 2 mai 1852, chaque Français ira aux urnes, tenant d'une main, le bulletin de vote et, de l'autre, le glaive. Cette prophétie suffit pour les contenter. L'armée, enfin, fut punie par ses supérieurs pour les élections de mars et d'avril 1850, comme elle l'avait été pour celles du 29 mars 1849. Mais, cette fois, elle pensa décidément : «La révolution ne nous dupera pas une troisième fois ! »

La loi du 31 mai 1850 fut le «coup d'état " » de la bourgeoisie. Toutes ses conquêtes antérieures sur la révolution n'avaient qu'un caractère provisoire. Le départ de chaque Assemblée nationale les remettait en question. Elles dépendaient du hasard de nouvelles élections générales, et l'histoire des élections, depuis 1848, prouvait irréfutablement qu'à mesure que se développait la domination de fait de la bourgeoisie, celle-ci perdait son influence morale sur les masses populaires. Le suffrage universel s'était, le 10 mars, prononcé nettement contre la domination de la bourgeoisie. Celle-ci répondit en proscrivant le suffrage électoral universel. La loi du 31 mai était, par conséquent, l'une des nécessités de la lutte des classes. D'autre part, la Constitution exigeait, pour que l'élection du président de la république fût valable, un minimum de 2 millions de voix. Si aucun des candidats à la présidence n'obtenait ce minimum, l'Assemblée nationale devait choisir le président parmi les trois candidats ayant obtenu le plus de voix. A l'époque où la Constituante avait fait cette loi, 10 millions d'électeurs étaient inscrits sur les listes électorales. Par conséquent, aux termes de la Constitution, il suffisait d'un cinquième des électeurs pour rendre valable l'élection à la présidence. La loi du 31 mai raya au moins 3 millions d'électeurs des listes électorales, réduisant le nombre d'électeurs à 7 millions et maintint, néanmoins, le minimum légal à 2 millions de voix pour l'élection à la présidence. Elle élevait par conséquent le minimum légal d'un cinquième à presque un tiers des voix, c'est-à-dire qu'elle fit tout pour enlever l'élection

En français dans le texte. 
présidentielle des mains du peuple et la remettre entre les mains de l'Assemblée nationale. Ainsi, le parti de l'ordre sembla, par la loi électorale du 31 mai, avoir doublement raffermi sa domination en confiant l'élection de l'Assemblée nationale et celle du président de la République à la partie stationnaire de la société. 


\section{V}

$\underline{\text { Retour à la table des matières }}$

La lutte reprit aussitôt entre l'Assemblée nationale et Bonaparte, dès que la crise révolutionnaire eut été surmontée et le suffrage universel aboli.

La Constitution avait fixé à 600000 francs le traitement de Bonaparte. Six mois à peine après son installation, il réussit à faire doubler cette somme. Odilon Barrot arracha, en effet, à l'Assemblée constituante un supplément annuel de 600000 francs pour de prétendus frais de représentation. Après le 13 juin, Bonaparte avait fait entendre des sollicitations du même genre, mais sans trouver cette fois de succès auprès de Barrot. Après le 31 mai, il utilisa immédiatement le moment favorable et fit proposer par ses ministres à l'Assemblée nationale une liste civile de 3 millions. Une longue vie aventureuse de vagabond l'avait doté d'antennes extrêmement fines qui lui permettaient de saisir les moments propices où il pouvait soutirer de l'argent à ses bourgeois. C'était là un chantage en règle * formel. L'Assemblée nationale avait profané la souveraineté du peuple avec son concours et sa complicité. Il menaçait de dénoncer son crime au tribunal du peuple, au cas où elle se refuserait à ouvrir sa bourse et à acheter son silence au prix de 3 millions par an. Elle avait enlevé à 3 millions de Français leur droit de vote. Pour chaque Français mis de cours, il réclamait un franc ayant cours, soit exactement 3 millions de francs. Lui, l'élu de 6 millions d'hommes, il exigeait des dommages-intérêts pour les voix dont on l'avait filouté après coup. La commission de l'Assemblée nationale éconduisit l'importun. La presse bonapartiste menaça. L'Assemblée nationale pouvait-elle rompre avec le président de la République, au moment où elle-même avait rompu sur le principe même et définitivement avec la masse de la nation ? Elle repoussa bien la liste civile annuelle, mais accorda un supplément unique de 2168000 francs. Elle se rendit ainsi coupable d'une double faiblesse; d'une part, en accordant l'argent et, d'autre part, en montrant par sa mauvaise humeur qu'elle ne le faisait qu'à contrecœur. Nous verrons plus tard pour quelles fins Bonaparte avait besoin de cet argent. Après cet épilogue désagréable, qui suivit immédiatement l'abolition du suffrage universel, et où Bonaparte, laissant l'attitude humiliée qu'il avait eue pendant la crise de mars et d'avril, se montra d'un cynisme provocant à l'égard du Parlement usurpateur, l'Assemblée nationale s'ajourna pour trois mois, du 11 août au 11 novembre. Elle nomma pour la remplacer une Commission permanente de 18 membres, qui ne contenait aucun bonapartiste, mais un certain nombre de républicains

En français dans le texte. 
modérés. La Commission permanente de 1849 ne comprenait que des gens du parti e l'ordre et des bonapartistes. Mais, à cette époque, le parti de l'ordre se déclarait en permanence contre la révolution. Cette fois, c'était la république parlementaire qui se déclarait en permanence contre le président. Après la loi du 31 mai, le parti de l'ordre n'avait plus que ce seul rival en face de lui.

Lorsque l'Assemblée nationale se réunit de nouveau en novembre 1850, il sembla qu'à la place des escarmouches insignifiantes qu'elle avait livrées jusqu'alors au président une grande bataille impitoyable, une lutte à mort, fût devenue inévitable entre ces deux puissances.

Comme en 1849, le parti de l'ordre s'était, pendant les vacances parlementaires de cette année, devisé en ses différentes fractions, dont chacune était occupée de ses propres intrigues de restauration, qui avaient trouvé un nouvel aliment dans la mort de Louis-Philippe. Le roi des légitimistes, Henri $\mathrm{V}$, avait même nommé un véritable ministère qui résidait à Paris et dans lequel siégeaient des membres de la Commission permanente. Bonaparte était donc en droit de faire, de son côté, des tournées dans les départements français et, suivant l'état d'esprit de la population de la ville qu'il honorait de sa présence, de faire connaître, de façon plus ou moins dissimulée ou ouverte, ses propres projets de restauration, et de recruter des partisans. Dans ces voyages, que le grand Moniteur officiel et les petits Moniteurs privés de Bonaparte ne pouvaient moins faire que de célébrer comme des tournées triomphales, il était constamment accompagné d'affiliés de la société du 10 décembre. Cette société avait été fondée en 1849. Sous le prétexte de fonder une société de bienfaisance, on avait organisé le sous-prolétariat parisien en sections secrètes, mis à la tête de chacune d'elles des agents bonapartistes, la société elle-même étant dirigée par un général bonapartiste. A côté de «roués » ruinés, aux moyens d'existence douteux, et d'origine également douteuse, d'aventuriers et de déchets corrompus de la bourgeoisie, des forçats sortis du bagne, des galériens en rupture de ban, des filous, des charlatans, des lazzaroni, des pickpockets, des escamoteurs, des joueurs, des souteneurs, des tenanciers de maisons publiques, des porte-faix, des écrivassiers, des joueurs d'orgues, des chiffonniers, des rémouleurs, des rétameurs, des mendiants, bref, toute cette masse confuse, décomposée, flottante, que les Français appellent la «bohème ». C'est avec ces éléments qui lui étaient proches que Bonaparte constitua le corps de la société du 10 Décembre. «Société de bienfaisance », en ce sens que tous les membres, tout comme Bonaparte, sentaient le besoin de se venir en aide à eux-mêmes aux dépens de la nation laborieuse. Ce Bonaparte, qui s'institue le chef du sous-prolétariat, qui retrouve là seulement, sous une forme multipliée, les intérêts qu'il poursuit lui-même personnellement, qui, dans ce rebut, ce déchet, cette écume de toutes les classes de la société, reconnaît la seule classe sur laquelle il puisse s'appuyer sans réserve, c'est le vrai Bonaparte, le Bonaparte « sans phrase ${ }^{(*)}$ ». Vieux roué retors, il considère la vie des peuples, leur activité et celles de l'État, comme une comédie au sens le plus vulgaire du mot, comme une 
mascarade, où les grands costumes, les grands mots et les grandes poses ne servent qu'à masquer les canailles les plus mesquines. C'est ainsi que, lors de son voyage à Strasbourg, un vautour suisse apprivoisé représente l'aigle napoléonien. Pour son entrée à Boulogne, il affuble d'uniformes français quelques laquais de Londres, chargés de représenter l'armée. Dans sa société du 10 Décembre, il rassemble 10000 gueux, chargés de représenter le peuple, tout comme Klaus Zettel ${ }^{21}$ représente le lion. A un moment où la bourgeoisie elle-même jouait la comédie la plus achevée, mais le plus sérieusement du monde, sans enfreindre aucune des exigences les plus pédantesques de l'étiquette dramatique française, alors qu'elle était elle-même à demi roulée, à demi convaincue par la solennité de ses propres actions d'État, c'était l'aventurier qui devait l'emporter, lui qui prenait la comédie tout simplement pour une comédie. C'est seulement quand il s'est débarrassé de son solennel adversaire, quand il prend lui-même son rôle impérial au sérieux et s'imagine, parce qu'il arbore le masque napoléonien, représenter le véritable napoléon, qu'il devient lui-même la victime de sa propre conception du monde, le grave polichinelle qui ne prend plus l'histoire pour une comédie, mais sa propre comédie pour l'histoire. Ce que les ouvriers nationaux avaient été pour les ouvriers socialistes, ce que les gardes mobiles avaient été pour les républicains bourgeois, la société du 10 Décembre, qui constituait son parti spécial, le fut pour Bonaparte. Dans ses voyages, les sections de cette société, emballés dans les wagons de chemins de fer, avaient pour mission de lui improviser un public, de simuler l'enthousiasme populaire, de hurler «Vive l'empereur ! ${ }^{(*)} »$, d'insulter et de rosser les républicains, naturellement sous la protection de la police. Lors de ses retours à Paris, elles étaient chargées de former l'avantgarde, de prévenir ou de disperser les contre-manifestations. La société du 10 Décembre lui appartenait, elle était son œuvre, sa pensée la plus propre. Ce qu'il s'approprie, c'est la force des circonstances qui le lui donne, ce qu'il fait, ce sont les circonstances qui le font pour lui, ou bien il se contente simplement de copier les actions des autres. Mais lui, parlant publiquement devant les citoyens et dans le langage officiel de l'ordre, de la religion, de la famille, de la propriété, ayant derrière lui la société secrète des escrocs et des voleurs, la société du désordre, de la prostitution et du vol, c'est Bonaparte lui-même, il est bien là auteur original, et l'histoire de la société de la société du 10 Décembre est bien sa propre histoire. Il était arrivé exceptionnellement que des députés appartenant au parti de l'ordre eussent tâté des gourdins des décembriseurs. Plus encore, le commissaire de police Yon, attaché à l'Assemble nationale et chargé de veiller à sa sécurité, communiqua à la Commission permanente, sur la déposition d'un certain Alais, qu'une section des décembriseurs avait décidé l'assassinat du général Changarnier et de Dupin, le président de l'Assemblée, et déjà désigné les individus chargés de l'exécution. On comprend la terreur de M. Dupin. Une enquête parlementaire sur la société du 10 Décembre, ce qui eût été une profanation du monde secret bonapartiste, sembla inévitable. Immédiatement avant la réunion de l'Assemblée, Bonaparte fit dissoudre

21 Le tisserand de la pièce de Shakespeare : Le songe d'une nuit d'été. 
prudemment sa société, mais, bien entendu, seulement sur le papier, car, encore à la fin de 1851, le préfet de police Carlier, dans un mémoire détaillé, s'efforça en vain de l'amener à dissoudre réellement cette société.

La société du 10 Décembre devait rester l'armée particulière de Bonaparte jusqu'à ce qu'il eût réussi à transformer l'armée régulière en une vaste société du 10 Décembre. Bonaparte fit une première tentative en ce sens peu de temps après la prorogation de l'Assemblée nationale, en utilisant à cet effet l'argent qu'il venait précisément de lui arracher. En tant que fataliste, il était convaincu qu'il existe certaines puissances suprêmes auxquelles l'homme et surtout le soldat ne peuvent résister. Parmi ces puissances, il comptait en première ligne les cigares et le champagne, la volaille froide et le saucisson à l'ail. C'est pourquoi il commença par traiter les officiers et les sous-officiers, dans les salons de l'Élysée, en leur offrant de la volaille froide et du saucisson à l'ail. Le 3 octobre, il renouvela cette manœuvre avec les troupes à la revus de Saint-Maur et, le 10 octobre, il la répéta, sur une plus grande échelle encore, à la revue de Satory. L'oncle se rappelait les campagnes d'Alexandre le Grand ${ }^{22}$ en Asie, le neveu les expéditions de Bacchus dans le même pays. Alexandre le Grand, il est vrai, n'était qu'un demi-dieu, tandis que Bacchus ${ }^{23}$ était un dieu et, qui plus est, le dieu tutélaire de la société du 10 Décembre.

Après la revue du 3 octobre, la Commission permanente convoqua devant elle le ministre de la Guerre d'Hautpoul. Celui-ci promit que ces infractions à la discipline ne se reproduiraient plus. On sait comment Bonaparte tint, le 10 octobre, la promesse faite par d'Hautpoul. Le général Changarnier avait dirigé les deux revues en question en qualité de commandant en chef de l'armée de Paris. A la fois membre de la Commission permanente, chef de la garde nationale, «sauveur » du 29 janvier et du 13 juin, « rempart de la société », candidat du parti de l'ordre à la dignité présidentielle, Monk ${ }^{24}$ présumé de deux monarchies, il n'avait jusqu'alors jamais reconnu sa subordination envers le ministre de la Guerre. Il s'était toujours moqué ouvertement de la Constitution républicaine et avait poursuivi Bonaparte d'une protection distinguée et équivoque. Le voilà, qui devenait maintenant le défenseur de la discipline contre le ministre de la Guerre et de la Constitution contre Bonaparte. Tandis que le 10 octobre une partie de la cavalerie faisait entendre le cri de : «Vive Napoléon! Vivent les saucissons * !», Changarnier prit ses dispositions pour qu'au moins l'infanterie, défilant sous le commandement de son ami Neumeyer, observât un silence

22 AleXANDRE LE GRAND (356-323) : roi de Macédoine. Capitaine célèbre qui conquit presque tout le monde civilisé de son époque. Ses expéditions en Asie sont particulièrement célèbres

23 BACChus, ou DyONISOS : Dieu de la vieille mythologie grecque. Primitivement, le dieu éveillant les forces créatrices de l'homme et plus tard, dieu du vin. Après la campagne d'Asie d'Alexandre le Grand, apparut le mythe de l'expédition de Dyonisos dans l'Inde et autres pays d'Asie.

24 MonK (1608-1669) : général anglais à l'époque de la grande révolution anglaise, il restaura l'ancienne dynastie des Stuarts et étouffa la révolution.

* En français dans le texte. 
glacial. Pour le punir, le ministre de la Guerre, à l'instigation de Bonaparte, releva le général Neumeyer de son poste à Paris, sous prétexte de lui confier le commandement des $14^{\mathrm{e}}$ et $15^{\mathrm{e}}$ divisions. Neumeyer refusa ce déplacement et fut obligé, par suite de donner sa démission. Changarnier, de son côté, publia, le 2 novembre, un ordre du jour où il interdisait aux troupes sous les armes les cris et les manifestations politiques de toute nature. Les feuilles à la dévotion de l'Élysée attaquèrent Changarnier, celles du parti de l'ordre attaquèrent Bonaparte. La Commission permanente multiplia ses séances secrètes, où l'on proposa, à différentes reprises, de déclarer la patrie en danger. L'armée parut divisée en deux camps ennemis, ayant chacun son propre état-major, siégeant, l'un à l'Élysée, où habitait Bonaparte, l'autre aux Tuileries, où demeurait Changarnier. Il sembla un moment qu'on n'attendait que la réunion de l'Assemblée nationale pour donner le signal du combat. Le public français apprécia ces frottements entre Bonaparte et Changarnier comme ce journaliste anglais qui les caractérisait de la façon suivante: "Les servantes politiques de la France débarrassent avec de vieux balais la lave brûlante de la révolution et se chamaillent en accomplissant cette besogne. »

Entre temps, Bonaparte se hâta de relever de ses fonctions le ministre de la Guerre d'Hautpoul, de l'expédier précipitamment à Alger et de nommer à sa place comme ministre de la Guerre le général Schramm. Le 12 novembre, il adressa à l'Assemblée nationale un immense message surchargé de détails, embaumant l'ordre, respirant l'esprit de réconciliation, résigné à la Constitution, traitant de tout et de chacun, sauf des questions brûlantes du moment. Comme en passant, il y laissait échapper que, conformément aux dispositions expresses de la Constitution, le président, seul, dispose de l'armée. Le message se terminait par ces protestations solennelles :

La France demande avant toute chose de la tranquillité... Uniquement lié par mon serment, je me tiendrai dans les limites étroites qu'il m'a tracées... En ce qui me concerne, élu par le peuple, et devant à lui seul mon pouvoir, je me soumettrai toujours à sa volonté légalement exprimée. Si vous décidez, au cours de cette session, la révision de la Constitution, une Assemblée constituante réglera la situation du pouvoir exécutif. Sinon, le peuple proclamera solennellement en 1852 sa décision. Mais quelles que puissent être les solutions de l'avenir, mettons-nous d'accord pour ne jamais laisser la passion, la surprise ou la violence décider du sort d'une grande nation... Ce qui requiert avant tout mon attention, ce n'est pas la question de savoir qui gouvernera la France en 1852, mais c'est d'employer le temps dont je dispose pour que la période à courir se passe sans agitation ni trouble. Je vous ai ouvert mon cœur avec sincérité : vous répondrez à ma franchise par votre confiance, à ma bonne volonté par votre collaboration, et Dieu fera le reste.

Le langage honnête, hypocritement modéré, plein de lieux communs vertueux de la bourgeoisie, revêt ici sa signification la plus profonde dans la bouche du chef souverain de la société du 10 Décembre et du héros de pique-nique de Saint-Maur et de Satory. 
Les burgraves du parti de l'ordre ne se firent pas un seul instant illusion sur la confiance que méritait cette effusion de cœur. Depuis longtemps blasés sur la valeur des serments, ils comptaient dans leurs rangs des vétérans, des virtuoses du parjure. Le passage sur l'armée ne leur avait pas échappé. Ils constatèrent avec indignation que le message, dans l'énumération prolixe des lois récemment promulguées, avait, avec affectation, passé sous le silence la loi la plus importante, la loi électorale, et, tout au contraire, confié au peuple, en cas de non-révision de la Constitution, l'élection du président pour 1852. La loi électorale était le boulet aux pieds du parti de l'ordre, qui entravait sa marche, et, à plus forte raison, ses assauts. De plus, Bonaparte, en dissolvant officiellement la société du 10 Décembre et en relevant de ses fonctions le ministre de la Guerre d'Hautpoul, avait, de sa propre main, immolé les boucs émissaires sur l'autel de la patrie. Il avait atténué la gravité la gravité de la collision attendue. Enfin, le parti de l'ordre lui-même s'efforçait, avec angoisse, d'éviter, d'affaiblir, d'étouffer tout conflit décisif avec le pouvoir exécutif. De peur de perdre les conquêtes arrachées à la révolution, il en faisait cueillir les fruits à ses rivaux. «La France demande avant tout de la tranquillité. » C'était l'appel que le parti de l'ordre adressait à la révolution depuis février, c'était l'appel que Bonaparte, dans son message, adressait au parti de l'ordre. «La France demande avant tout de la tranquillité.» Bonaparte commettait des actes tendant à l'usurpation, mais le parti de l'ordre se rendait coupable de «désordre » lorsqu'il protestait bruyamment contre ces actes et qu'il les commentait avec hypocondrie. Les saucissons de Satory seraient restés muets si personne n’en avait parlé. « La France demande avant tout de la tranquillité. » Par conséquent, Bonaparte demandait qu'on le laissât tranquillement faire, et le parti parlementaire était paralysé pat une double crainte : celle de provoquer à nouveau les troubles révolutionnaires et celle d'apparaître lui-même comme fauteur de désordre aux yeux de sa propre classe, la bourgeoisie. Comme la France demandait avant tout de la tranquillité, le parti de l'ordre n'osa pas, après que Bonaparte, dans son message, eut employé le mot « paix », y répondre par le mot «guerre ». Le public, qui s'attendait à de grandes scènes de scandale à l'ouverture de l'Assemblée nationale, fut déçu dans son attente. Les députés de l'opposition, qui réclamaient le dépôt des procès-verbaux de la Commission permanente sur les événements d'octobre, furent battus par la majorité. On évita par principe tous les débats irritants. Les travaux de l'Assemblée nationale en novembre et en décembre 1850 furent sans intérêt.

Enfin, vers la fin de décembre, commença la guerre d'escarmouches autour de certaines prérogatives du Parlement. Le mouvement se rabaissait à des chicanes mesquines sur les prérogatives des deux pouvoirs, depuis que la bourgeoisie, en abolissant le suffrage universel, avait mis fin elle-même à la lutte des classes.

Une condamnation pour dettes avait été obtenue contre Mauguin, l'un des députés de l'Assemblée. A la demande du président du Tribunal, le ministre de la Justice, Rouher, déclara qu'il fallait, sans autres formalités, décerner un mandat d'arrêt contre le débiteur. 
Mauguin fut donc jeté dans la prison pour dettes. L'Assemblée nationale éclata de colère lorsqu'elle apprit l'attentat. Non seulement elle ordonna la mise en liberté immédiate de Mauguin, mais elle le fit, le soir même, tirer violemment de la prison de Clichy par son greffier. Cependant, pour affirmer sa foi en la sainteté de la propriété privée, et avec l'arrièrepensée d'ouvrir, en cas de besoin, un asile pour Montagnards devenus importants du peuple, à condition qu'elle en accordât préalablement l'autorisation. Elle oublia de décréter que le président pouvait être, lui aussi, incarcéré pour dettes. Elle anéantit ainsi la dernière apparence d'immunité qui protégeait encore ses propres membres.

On se souvient que le commissaire de police Yon avait, sur le témoignage d'un certain Alais, accusé une section des décembriseurs d'avoir prémédité le meurtre de Dupin et de Changarnier. Dès la première séance de l'Assemblée, les questeurs firent, à cette occasion, la proposition de constituer une police parlementaire spéciale, payée sur le budget particulier de l'Assemblée nationale et complètement indépendante du préfet de police. Le ministre de l'Intérieur, Baroche, avait protesté contre cette incursion dans son ressort. On conclut alors un misérable compromis, aux termes duquel le commissaire de police de l'Assemblée devait bien être appointé sur le budget particulier de cette dernière et être nommé et révoqué par ses questeurs, mais après entente préalable avec le ministre de l'Intérieur. Entre temps, Alais avait été traduit devant les tribunaux par le gouvernement et, là, il lui fut facile de présenter ses déclarations comme une mystification de sa part et de ridiculiser, par la bouche de l'accusateur public, Dupin, Changarnier, Yon et toute l'Assemblée nationale. A la date du 29 décembre, le ministre Baroche écrivit une lettre à Dupin, dans laquelle il exigeait le renvoi de Yon. Le Bureau de l'Assemblée nationale décida de maintenir Yon à son poste, mais l'Assemblée, effrayée de son acte de violence dans l'affaire Mauguin, et habituée, quand elle osait porter un coup au pouvoir exécutif, à en recevoir deux en échange, ne sanctionna point cette décision. Elle renvoya Yon pour le récompenser de son zèle et se priva d'une prérogative parlementaire indispensable contre un homme qui ne décide pas pendant la nuit pour exécuter pendant le jour, mais décide le jour et exécute la nuit.

Nous avons vu comment l'Assemblée nationale, au cours des mois de novembre et de décembre, évita, dans ces occasions décisives, d'engager la lutte avec le pouvoir exécutif. Nous la voyons maintenant obligée de l'engager sous les prétextes les plus mesquins. Dans l'affaire Mauguin, elle confirme le principe de l'incarcération pour dettes des représentants du peuple, mais se réserve de n'en permettre l'application qu'à des représentants qui lui déplaisent, et elle se querelle pour ce privilège infâme avec le ministre de la Justice. Au lieu de profiter du soi-disant projet d'assassinat contre Dupin pour ordonner une enquête sur la société du 10 Décembre et démasquer impitoyablement devant la France et devant l'Europe entière Bonaparte sous son véritable aspect de chef du sous-prolétariat parisien, elle ravale ce conflit à la seule question de savoir qui, d'elle ou du ministre de l'Intérieur, est compétent pour nommer et révoquer un commissaire de police. C'est ainsi que nous voyons le parti de 
l'ordre contraint, pendant toute cette période, par sa position équivoque, de consumer, d'émietter sa lutte contre le pouvoir exécutif en de mesquines querelles de compétence, en chicanes, en conflits de pouvoir et de faire des questions de forme les plus ineptes le principal de son activité. Il n'ose pas engager la lutte au moment où les principes sont en jeu, où le pouvoir exécutif a réellement levé le masque et où la cause de l'Assemblée serait celle de la nation. C'est qu'elle aurait donné par là à la nation un ordre de marche, et elle ne craint rien tant que de voir la nation se mettre en mouvement. C'est pourquoi, en de telles occasions, elle repousse la plupart du temps les propositions de la Montagne et passe à l'ordre du jour. La question litigieuse une fois abandonnée telle qu'elle se posait dans toute son ampleur, le pouvoir exécutif attend tranquillement le moment où il peut la reprendre sous les motifs les plus mesquins, les plus insignifiants, où, pour ainsi dire, elle n'offre plus qu'un intérêt étroitement parlementaire. Alors, éclate la fureur contenue du parti de l'ordre. Il déchire le rideau qui cache les coulisses, il dénonce le président, déclare la république en danger, mais sa grandiloquence apparaît insipide et le motif invoqué pour la lutte ne semble plus qu'un prétexte hypocrite ou sans aucune valeur. La tempête parlementaire devient une tempête dans un verre d'eau, la lutte une intrigue, l'affrontement un scandale. Tandis que la joie maligne des classes révolutionnaires se repait de l'humiliation de l'Assemblée nationale, car elles ont autant d'enthousiasme pour les libertés publiques, la bourgeoisie en dehors du Parlement ne comprend pas comment la bourgeoisie à l'intérieur du parlement puisse gaspiller son temps dans des querelles aussi mesquines et troubler sa tranquillité publique par d'aussi misérables rivalités avec le président. Elle est déconcertée par une stratégie qui consiste à conclure la paix au moment où tout le monde s'attend à la guerre et à engager la lutte au moment où tout le monde croit la paix conclue.

Le 20 décembre, Pascal Duprat interpella le ministre de l'Intérieur sur la loterie des lingots d'or. Cette loterie était une « fille de l'Élysée ». Elle devait le jour à Bonaparte et à ses fidèles, et le préfet de police. Carlier l'avait prise sous sa protection officielle, bien que la loi française interdise toutes les loteries, à l'exception de celles poursuivant des buts de bienfaisance. Sept millions de billets à un franc, dont le bénéfice était prétendument destiné à payer le transport en Californie des vagabonds de Paris. On voulait tout d'abord remplacer par des rêves dorés les songes socialistes du prolétariat parisien et par le mirage du gros lot le droit doctrinal au travail. Les ouvriers parisiens ne reconnurent naturellement pas, sous l'éclat des lingots d'or californiens, les francs ternis qu'on leur soutirait de la poche. Il s'agissait, en somme, d'une escroquerie pure et simple. Les vagabonds qui voulaient exploiter les mines d'or de Californie sans quitter Paris, c'étaient Bonaparte lui-même et ses chevaliers de la Table ronde criblés de dettes. Les trois millions accordés par l'Assemblée nationale avaient été joyeusement dépensés, et il fallait, par un moyen ou un autre, remplir à nouveau la caisse. En vain, Bonaparte avait-il ouvert une souscription nationale pour la construction de prétendues «cités ouvrières », en tête de laquelle il figurait pour une somme considérable. 
Les bourgeois au cœur dur attendirent avec méfiance le versement du montant de sa souscription, et comme celle-ci se faisait par trop attendre, la spéculation sur les châteaux en Espagne socialistes tomba à plat. Les lingots d'or eurent plus de succès. Bonaparte et consorts ne se contentèrent pas d'empocher une partie de la différence entre les sept millions et la valeur des lingots d'or mis en loterie, ils fabriquèrent de faux billets, ils émirent sous le même numéro dix, quinze à vingt billets, opération financière tout à fait dans l'esprit de la société du 10 Décembre ! Ici, l'Assemblée nationale n'avait plus en face d'elle le président fictif de la république, mais le vrai Bonaparte, en chair et en os. Ici, elle pouvait le prendre sur le fait en conflit non plus avec la Constitution, mais avec le code pénal. Si elle passa à l'ordre du jour sur l'interpellation de Girardin de se déclarer «satisfait» rappelait au parti de l'ordre sa propre corruption. Le bourgeois, et avant tout le bourgeois gonflé à la dignité d'home d'État, complète sa bassesse pratique d'une redondance théorique. En tant qu'homme d'État, il devient, comme l'État lui-même, un être supérieur, que l'on ne peut combattre que par des moyens supérieurs, consacrés.

Bonaparte qui, précisément, en tant que «Bohémien», que gueux princier, avait sur le bourgeois gredin l'avantage de pouvoir mener la lutte bassement, vit alors, après l'Assemblée nationale elle-même l'eût amené de sa propre initiative sur le terrain elle-même l'eût amené de sa propre initiative glissant des banquets militaires, des revues, de la société du 10 Décembre, et enfin du code pénal, que le moment était venu de passer de la défensive apparente à l'offensive. Il était un peu gêné par les petites défaites essuyées entre temps par les ministres de la Justice, de la Guerre, de la Marine, des Finances, défaites au moyen desquelles l'Assemblée nationale manifestait son mécontentement grognon. Non seulement il empêcha les ministres de se retirer et de reconnaître ainsi la subordination du pouvoir exécutif à l'égard du Parlement, mais il put dès lors achever ce qu'il avait commencé pendant les vacances de l'Assemblée nationale, c'est-à-dire arracher le pouvoir militaire au Parlement et révoquer Changarnier.

Une feuille à la dévotion de l'Élysée publia un ordre du jour prétendument adressé pendant le moi de mai à la première division militaire, par conséquent, émanant de Changarnier, et dans lequel on recommandait aux officiers, en cas d'émeute, de ne faire aucun quartier aux traîtres dans leurs propres rangs, de les fusiller sur-le-champ et, au cas où l'Assemblée nationale voudrait réquisitionner les troupes, de les lui refuser. Le 3 janvier 1851, le ministère fut interpellé sur cet ordre du jour. Il demanda, pour examiner l'affaire, d'abord trois mois, puis une semaine, enfin seulement vingt-quatre heures de réflexion. L'Assemblée insista pour obtenir une explication immédiate. Changarnier se leva et déclara que cet ordre du jour n'avait jamais existé. Il ajouta qu'il s'empresserait toujours d'obéir aux ordres de l'Assemblée et qu'en cas de conflit elle pouvait compter sur lui. Celle-ci accueillit ses explications par des applaudissements frénétiques et lui décerna un vote de confiance. Elle abdiqua, décréta sa propre impuissance et la toute-puissance de l'armée, en se plaçant sous la 
protection particulière d'un général. Or ce dernier se leurrait quand il mettait à la disposition de l'Assemblée, contre Bonaparte, alors qu'il comptait, de son côté, être protégé par son protégé, le Parlement, qui avait lui-même tant besoin de sa protection. Mais Changarnier avait foi dans la puissance mystérieuse dont la bourgeoisie l'avait investi depuis le 29 janvier 1849. Il se considérait comme un troisième pouvoir à côté des deux autres pouvoirs d'État. Il partageait le sort des autres héros ou plutôt des saints de cette époque, dont la grandeur consistait précisément dans l'auréole dont leur parti les avait entourés d'une façon intéressée et qui ne devenaient plus que des figures banales dès que les circonstances les invitaient à accomplir les miracles. L'incrédulité est, de façon générale, l'ennemie mortelle de ces prétendus héros et de ces saints véritables. D’où leur indignation vertueuse, pleine de dignité, envers les faiseurs de bons mots et les moqueurs dénués d'enthousiasme.

Le soir même, les ministres furent convoqués à l'Élysée. Bonaparte exigea la destitution de Changarnier. Cinq ministres se refusèrent à la signer. Le Moniteur annonça une crise ministérielle, et, dans la presse, le parti de l'ordre menaça de constituer une armée parlementaire sous le commandement de Changarnier. La constitution lui en donnait le droit. Il n'avait qu'à nommer Changarnier président de l'Assemblée nationale et requérir n'importe quelles plus sûrement que Changarnier se trouvait encore véritablement à la tête de l'armée et de la garde nationale de Paris et, impatient, n'attendait que l'heure d'être réquisitionné avec l'armée. La presse bonapartiste n'osa même pas contester le droit à l'Assemblée nationale de réquisitionner directement les troupes, scrupule juridique qui, dans la circonstance, ne présageait aucun succès. Il est probable que l'armée eût obéi aux ordres de l'Assemblée nationale, si l'on considère que Bonaparte dut chercher pendant huit jours dans tout Paris pour trouver enfin deux généraux — Baraguay d'Hilliers et Saint-Jean d'Angely — qui se déclarèrent prêts à contresigner la destitution de Changarnier ? Que, par contre, le parti de l'ordre eût pu trouver dans ses propres rangs et au Parlement le nombre de voix nécessaire pour prendre pareille décision, c'est plus que douteux, si l'on songe que, huit jours plus tard, 286 voix se séparèrent de lui, et que la Montagne repoussa une proposition semblable encore en décembre 1851, c'est-à-dire au moment de la décision suprême. Cependant, les «burgraves », auraient peut-être encore réussi alors à entrainer la masse de leur parti à l'héroïsme consistant à se sentir en sécurité derrière une forêt de baïonnettes et à accepter les services d'une armée passée dans leur propre camp. Au lieu de cela, MM. Les burgraves se rendirent, le soir du 6 janvier, à l'Élysée, pour dissuader Bonaparte, par des arguments diplomatiques, de destituer Changarnier. Quand on cherche à convaincre quelqu'un, c'est qu'on le reconnaît maître de la situation. Bonaparte, rassuré par cette démarche, nomma, le 12 janvier, un nouveau ministère dans lequel il laissa les chefs de l'ancien cabinet, Fould et Baroche. Saint-Jean d'Angély fut nommé ministre de la Guerre. Le moniteur publia le décret de destitution de Changarnier. Son commandement fut partagé entre Baraguay d'Hilliers, qui obtint la première division, et Perrot, qui reçut le commandement de la garde nationale. Le 
« rempart de la société » fut congédié, et si aucune pierre n'en tomba des toits, par contre, les cours de la Bourse montèrent.

En repoussant ainsi l'armée qui, dans la personne de Changarnier, se mettait à sa disposition, et en la livrant ainsi irrévocablement au président, le parti de l'ordre déclarait que la bourgeoisie avait désormais perdu toute qualité pour régner. Il n'y avait déjà plus de ministère parlementaire. En perdant encore toute autorité sur l'armée et sur la garde nationale, quel moyen d'action lui restait-il pour défendre à la fois le pouvoir usurpé du Parlement sur le peuple et son pouvoir constitutionnel contre le président? Aucun. Il ne lui restait plus qu'à faire appel à des principes impuissants, qu'il n'avait lui-même toujours jugés que comme les règles générales que l'on prescrit aux autres, pour pouvoir conserver soi-même plus de liberté d'action.

C'est par la destination de Changarnier et la prise de possession du pouvoir militaire par Bonaparte que se termine la première partie de la période que nous considérons, celle de la lutte entre le parti de l'ordre et le pouvoir exécutif. La guerre entre ces deux pouvoirs est maintenant déclarée ouvertement, menée ouvertement, mais seulement après que le parti de l'ordre eut perdu armes et soldats. Sans ministère, sans armée, sans peuple, sans opinion publique, n'étant plus, depuis sa loi électorale du 31 mai, le représentant du peuple souverain, sans yeux, sans oreilles, sans dents, sans rien, l'Assemblée nationale s'était transformée tout doucement en un Parlement d'ancien régime, obligé d'abandonner toute action gouvernementale et de se contenter lui-même de remontrances bougonnes post festum ${ }^{25}$.

Le parti de l'ordre accueillit le nouveau ministère par une tempête d'indignation. Le général Bedeau rappela la bienveillance dont avait fait preuve la Commission permanente pendant les vacances de l'Assemblée et les scrupules exagérés qui lui avaient fait renoncer à publier ses procès-verbaux. Le ministre de l'Intérieur insista alors lui-même en faveur de la publication des pièces qui étaient maintenant, de toute évidence, devenues aussi insipides que de l'eau stagnante, ne révélaient aucun fait nouveau, et tombèrent parmi le public blasé sans produire le moindre effet. Sur la proposition de Rémusat, l'Assemblée se retira dans ses bureaux et nomma un «Comité de mesures extraordinaires ». Paris se détourna d'autant moins de ses occupations quotidiennes que le commerce prospérait à ce moment-là, que les prix des céréales étaient bas, les vivres abondants et que les caisses d'épargne recevaient tous les jours de nouveaux dépôts. Les «mesures extraordinaires » annoncées si bruyamment par le Parlement se réduisirent, le 18 janvier à un vote méfiance contre les ministres, où l'on ne fit même pas mention du général Changarnier. Le parti de l'ordre fut obligé de rédiger ainsi sa motion pour s'assurer les voix des républicains, étant donné que ces derniers, de toutes les mesures du ministère, n'approuvaient précisément que la destitution de Changarnier, tandis

25 « Après la fête », c'est-à-dire après coup. 
que le parti de l'ordre, en effet, ne pouvait blâmer les autres actes du ministère qu'il avait dictés lui-même.

Le vote de méfiance du 18 janvier fut adopté par 415 voix contre 286 . Il ne fut donc obtenu qu'au moyen d'une coalition des légitimistes et des orléanistes avérés avec les républicains purs et la Montagne. Il prouva, par suite, que le parti de l'ordre avait perdu non seulement le ministère et l'armée, mais aussi, dans ses conflits avec Bonaparte, sa propre majorité parlementaire, qu'un groupe de représentants avait déserté son camp par un esprit de conciliation poussé jusqu'au fanatisme, par crainte de la lutte, par suite de dépression, par égard pour des proches émargeant au Budget d'État, par spéculation sur les postes ministériels devenus vacants (Odilon Barrot), poussés par ce plat égoïsme du bourgeois ordinaire toujours prêt à sacrifier l'intérêt général de sa classe à tel ou tel intérêt particulier. A priori, les représentants bonapartistes ne faisaient corps avec le parti de l'ordre que dans la lutte contre la révolution. Le chef du parti catholique, Montalembert, jetait, déjà à cette époque, son influence dans la balance de Bonaparte, car il doutait de la vitalité du parti parlementaire. Les chefs de partis, enfin, obligés de se proclamer ouvertement républicains, de confesser que, si leur cœur était royaliste, leur tête était républicaine, et que leur République parlementaire était la seule forme possible de domination de la bourgeoisie. Ils se voyaient aussi contraints de flétrir aux yeux de la classe bourgeoise elle-même, comme une intrigue aussi dangereuse que frivole, les projets de restauration qu'ils poursuivaient inlassablement derrière le dos du Parlement.

Le vote de méfiance du 18 janvier frappait les ministres, mais non le président. Or ce n'était pas le ministère, mais le président qui avait destitué Changarnier. Le parti de l'ordre devait-il mettre Bonaparte lui-même en accusation? Pour ses velléités de restauration ? Mais elles ne faisaient que compléter les siennes propres. Pour ses menées conspiratrices dans les revues militaires et dans la société du 10 Décembre ? Mais les gens de l'ordre avaient depuis longtemps enterré ces questions sous les ordres du jour purs et simples. Pour la destitution du héros du 29 janvier et di 13 juin, de l'homme qui, en mai 1850, menaçait, en cas d'émeute, de mettre le feu aux quatre couins de Paris ? Leurs alliés de la Montagne et Cavaignac ne leur permirent même pas de relever par une manifestation de sympathie officielle le « rempart de la société » tombé par terre. Ils ne pouvaient pas contester au président le droit constitutionnel de destituer un général. Ils tempêtaient uniquement parce qu'il faisait de ce droit constitutionnel un usage antiparlementaire. N'avaient-ils pas eux-mêmes fait constamment de leurs prérogatives parlementaires un usage anticonstitutionnel et, notamment, en aboutissant le suffrage universel ? Ils étaient, par conséquent, tenus de se mouvoir exactement à l'intérieur des limites parlementaires. Et il leur fallait être atteints de cette maladie toute spéciale qui, depuis 1848, a sévi sur l'ensemble du continent, à savoir le crétinisme parlementaire, qui relègue dans un monde imaginaire ceux qui en sont atteints et leur enlève toute intelligence, tout souvenir et toute compréhension pour le rude monde extérieur; il leur 
fallait être atteints de crétinisme parlementaire, alors qu'ils avaient détruit de leurs propres mains, comme ils étaient obligés de le faire dans leur lutte contre les autres classes, toutes les conditions du pouvoir parlementaire, pour pouvoir considérer encore leurs victoires parlementaires comme de véritables victoires et s'imaginer atteindre le président en frappant sur ses ministres. Ils ne faisaient que lui donner par là l'occasion d'humilier à nouveau l'Assemblée nationale aux yeux de la nation. Le 20 janvier, Le Moniteur annonça que la démission du ministère tout entier était acceptée. Sous prétexte qu'aucun parti parlementaire n'avait plus la majorité au Parlement, comme le prouvait le vote du 18 janvier, ce fruit de la coalition entre la Montagne et les royalistes, et pour attendre la constitution d'une nouvelle majorité, Bonaparte nomma un prétendu ministère de transition, auquel n'appartenait aucun membre du Parlement, composé uniquement d'individus complètement inconnus et insignifiants, un ministère de simples commis et de scribes. Le parti de l'ordre pouvait désormais s'escrimer avec ces marionnettes, le pouvoir exécutif ne se donnait même plus la peine de se faire représenter sérieusement à l'Assemblée nationale. Bonaparte concentrait ainsi de façon d'autant plus apparente tout le pouvoir exécutif en sa propre personne et avait d'autant plus de possibilités d'exploiter ce pouvoir dans ces propres buts que ses ministres n'étaient que de simples figurants.

Le parti de l'ordre, coalisé avec la Montagne, se vengea en repoussant la dotation présidentielle de 1800000 francs que le chef de la société du 10 Décembre avait obligé ses commis ministériels de proposer au Parlement. Cette fois, le vote de fut acquis qu'à une majorité de 102 voix, soit 27 voix de moins que le 18 janvier. La dissolution du parti de l'ordre faisait des progrès rapides. Pour qu'on ne se méprît pas un seul instant sur le sens de sa coalition avec la Montagne, il dédaigna de prendre même en considération une proposition signée de 189 membres de la Montagne en faveur d'une amnistie générale des condamnés politiques. Le ministre de l'Intérieur, un certain Vaissé, n'eut qu'à venir déclarer que le calme n'était qu'apparent, qu'il régnait une grande agitation clandestine, que des sociétés s'organisaient en secret partout à la fois, que des feuilles démocratiques prenaient leurs dispositions pour paraitre à nouveau, que les rapports provenant des départements étaient défavorables, que les réfugiés de Genève organisaient une conspiration qui s'étendait, en passant par Lyon, sur tout le midi de la France, que le pays était à la veille d'une crise commerciale et industrielle, que les fabricants de Roubaix avaient diminué la journée de travail, que les prisonniers de Belle-Isle s'étaient révoltés, etc., un simple Vaissé n'eut qu'à évoquer le spectre rouge pour que le parti de l'ordre rejetât sans discussion une proposition qui ne pouvait manquer de donner à l'Assemblée nationale une immense popularité et de rejeter à nouveau Bonaparte dans ses bras. Au lieu de se laisser intimider par le pouvoir exécutif par la perspective de nouveaux troubles, il lui aurait fallu, au contraire, donner un plus de champ à la lutte des classes, pour placer le pouvoir exécutif sous sa dépendance. Mais elle ne se sentait pas de taille à jouer avec le feu. 
Cependant, le prétendu ministère transitoire végéta jusqu'au milieu d'avril. Bonaparte fatigua, berna l'Assemblée par des combinaisons ministérielles constamment renouvelées. Tantôt, il semblait vouloir constituer un ministère républicain avec Lamartine et Billault, tantôt un ministère parlementaire avec l'inévitable Odilon Barrot, dont le nom revenait toujours dès que l'on avait besoin d'une dupe, tantôt un ministère légitimiste avec Vatimesnil et Benoît d'Azy, tantôt un ministère orléaniste avec Malleville. Pendant qu'il maintenait ainsi des relations tendues entre les différentes fractions du parti de l'ordre et qu'il les effrayait toutes par la perspective d'un ministère républicain et du rétablissement, devenu inévitable, du suffrage universel, il suscitait dans la bourgeoisie la conviction que ses efforts sincères en vue de constituer un ministère parlementaire se heurtaient à l'intransigeance des fractions royalistes. Or la bourgeoisie réclamait d'autant plus bruyamment un « gouvernement fort » et trouvait d'autant plus impardonnable de laisser la France « sans administration » qu'une crise commerciale générale paraissait alors imminente, fait qui facilitait le recrutement en faveur du socialisme dans les grandes villes, de même qu'il facilitait à la campagne le bas prix ruineux des céréales. Le commerce devenait de jour en jour plus languissant, le nombre des chômeurs augmentait à vue d'œil. A Paris, 10000 ouvriers au moins étaient sans pain. A Rouen, A Mulhouse, à Lyon ; à Roubaix, à Tourcoing, à Saint-Étienne, à Elbeuf, etc., de nombreuses fabriques étaient arrêtées. Dans ces conditions, Bonaparte put oser réinstaller, le 11 avril, le ministère du 19 janvier, avec MM. Rouher, Fould, Baroche, et autres, renforcés de M. Léon Faucher, que l'Assemblée constituante, au cours des derniers jours, avait, à l'unanimité, à l'exception des vois de cinq ministres, flétri d'un vote de méfiance pour sa publication de fausses dépêches télégraphiques. Ainsi, l'Assemblée nationale avait remporté, le 18 janvier, une victoire sur le ministère, elle avait lutté pendant trois mois contre Bonaparte pour que, le 11 avril, MM. Fould et Baroche pussent admettre le puritain Faucher en tiers dans leur association ministérielle.

En novembre 1849, Bonaparte s'était contenté d'un ministère non parlementaire, en janvier 1851, d'un ministère extra-parlementaire. Le 11 avril, il se sentit assez fort pour constituer un ministère anti-parlementaire, qui groupait harmonieusement les votes de méfiance des deux Assemblées la Constituante et la Législative, la républicaine et la royaliste. Cette succession de ministères représentait le thermomètre auquel Bonaparte pouvait mesurer la diminution de sa propre chaleur vitale. Celle-ci était tombée si bas à la fin d'avril, que Persigny pouvait, dans une entrevue personnelle avec Changarnier, inviter ce dernier à passer dans le camp du président. Bonaparte, lui assura-t-il, considérait l'influence de l'Assemblée nationale comme complètement anéantie, et il tenait déjà prête la proclamation qui devait être publiée après le coup d'État, qu'on avait constamment en vue, mais qu'un simple hasard venait de faire remettre à plus tard. Changarnier communiqua aux chefs du parti de l'ordre cette déclaration de décès, mais qui peut croire que la morsure des punaises est mortelle ? Et le Parlement, si abattu, si décomposé, si corrompu qu'il fût, ne pouvait se résigner à voir dans 
son duel avec le chef grotesque de la société du 10 Décembre autre chose qu'un duel avec une punaise. Mais Bonaparte répondit au partie de l'ordre comme jadis Agésilas ${ }^{26}$ au roi Agis ${ }^{27}$ : «Je te parais une fourmi, mais un jour je serai lion.»

26 AgÉSILAS II (401-358) : roi de Sparte, frère cadet du roi Agis, capitaine célèbre. Les paroles d'Agélisas citées par Marx ne se rapportent pas à Agis, mais au roi égyptien Takhos.

27 AGIS II (427-401) : roi de Sparte, frère aîné d'Agélisas. 


\section{VI}

\section{$\underline{\text { Retour à la table des matières }}$}

La coalition avec la Montagne et les républicains purs, à laquelle le parti de l'ordre se vit condamné, dans ses vains efforts pour conserver la possession du pouvoir exécutifs, prouvait incontestablement qu'il avait perdu sa propre majorité parlementaire. La simple puissance du calendrier, l'aiguille des heures sonna, le 29 mai, le signal de sa décomposition complète. Avec le 29 mai, commença la dernière année de l'Assemblée nationale. Il lui fallait désormais se décider soit en faveur du maintien sans modification, soit en faveur de la révision de la Constitution. Mais révision de la Constitution, cela ne signifiait pas seulement domination de la bourgeoisie ou de la démocratie petite-bourgeoise, démocratie ou anarchie prolétarienne, République parlementaire ou Bonaparte, cela signifiait également Orléans ou Bourbon! C'est ainsi que tomba au milieu du Parlement la pomme de discorde autour de laquelle devait fatalement s'allumer le conflit des intérêts qui divisaient le parti de l'ordre en fractions opposées. Le parti de l'ordre était un mélange d'éléments sociaux hétérogènes ? La question de la révision de la Constitution créa une température politique qui décomposa le produit de ce mélange en ses éléments primitifs.

L'intérêt des bonapartistes à la révision était simple. Il s'agissait avant tout pour eux de supprimer l'article 45, qui interdisait la réélection de Bonaparte, et d'obtenir la prorogation de son pouvoir. L'attitude des républicains ne paraissait pas moins simple. Ils repoussaient absolument toute révision, n'y voyant qu'une conspiration générale contre la république. Comme ils disposaient de plus du quart des voix à l'Assemblée nationale et que, en vertu de la Constitution, il fallait les trois quarts des voix pour qu'on pût légalement décider la révision et convoquer une assemblée chargée de procéder à cette révision, ils n'avaient qu'à compter leurs voix pour être sûrs de la victoire ? Et ils la tenaient pour assurée.

En face de ces attitudes claires, le parti de l'ordre se trouvait en proie à des contradictions inextricables. S'il rejetait la révision, il mettait en péril le statu quo en laissant à Bonaparte une seule issue, l'emploi de la violence, en abandonnant la France, le 2 mai 1852, au moment de la décision, à l'anarchie révolutionnaire, avec un président qui perdait toute autorité, un Parlement qui n'en avait plus depuis longtemps et un peuple qui pensait à la reconquérir. S'il votait pour la révision constitutionnelle, il savait qu'il voterait pour rien et qu'il se heurterait fatalement, en vertu de la Constitution, au veto des républicains. S'il déclarait, contrairement à la Constitution, que la simple majorité des voix suffisait, il ne pouvait espérer empêcher la 
révolution qu'en se soumettant sans réserve à la discrétion du pouvoir exécutif, mais il faisait ainsi de Bonaparte le maître de la Constitution, de la révision et de lui-même. Une révision simplement partielle, prolongeant le pouvoir du président, préparait la voie à l'usurpation impériale. Une révision générale, abrégeant l'existence de la république, amenait nécessairement un conflit entre les prétentions dynastiques, car les conditions d'une restauration bourbonienne et celles d'une restauration orléaniste n'étaient pas seulement différentes, elles s'excluaient réciproquement.

La République parlementaire était plus que le terrain neutre où les deux fractions de la bourgeoisie française, légitimiste et orléaniste, grande propriété foncière et industrie, pouvaient coexister l'une à côté de l'autre, avec des droits égaux. Elle était la condition indispensable de leur domination commune, la seule forme d'État dans laquelle leur intérêt général de classe pouvait se subordonner à la fois les prétentions de ces différentes fractions et toutes les autres classes de la société. En tant que royalistes, ils retombaient dans leur antagonisme, dans la lutte pour la suprématie de la propriété foncière ou de l'argent, et l'expression suprême de cet antagonisme était personnifié dans les rois eux-mêmes, dans leurs dynasties. D'où la résistance du parti de l'ordre au rappel des Bourbon.

Le député orléaniste Ceton avait, à intervalles périodiques, en 1849, 1850 et 1851, déposé la proposition d'abroger le décret de bannissement dirigé contre les familles royales. Le Parlement offrait tout aussi périodiquement le spectacle d'une assemblée de royalistes fermant opiniâtrement à leurs rois bannis les portes par lesquelles ils pouvaient rentrer. Richard III avait assassiné Henri VI en déclarant qu'il était trop bon pour cette terre, et que sa place était au ciel. Ils déclaraient, eux, que la France était trop mauvaise pour posséder à nouveau ses rois. Contraints par la force des circonstances, ils étaient devenus républicains et sanctionnèrent à différentes reprises la décision du peuple qui avait chassé leurs rois de France.

La révision de la Constitution - et les circonstances forçaient à s'en préoccuper mettait en question, outre la république, la domination commune des deux fractions de la bourgeoisie et réveillait, avec la possibilité du rétablissement de la monarchie, la rivalité des intérêts qu'elle avait de préférence représentés à tour de rôle, la lutte par la suprématie d'une fraction sur l'autre. Les diplomates du parti de l'ordre croyaient pouvoir liquider la lutte par ce qu'ils appelaient une fusion des deux dynasties, des partis royalistes et de leurs maisons royales. La véritable fusion de la Restauration et de la monarchie de Juillet, c'était la République parlementaire, dans laquelle se fondaient les couleurs orléanistes et légitimistes et où les différentes sortes de bourgeois disparaissaient dans le bourgeois tout court, dans le genre bourgeois. Mais, maintenant, l’orléaniste devait devenir légitimiste, le légitimiste orléaniste. La royauté, qui personnifiait leur antagonisme, devait incarner leur unité et faire de l'expression de leurs intérêts exclusifs de fractions l'intérêt commun de leur classe. La 
monarchie devait réaliser ce que la négation des deux monarchies, à savoir, la république, pouvait réaliser et avait vraiment réalisé. C'était la pierre philosophale, à la fabrication de laquelle les docteurs du parti de l'ordre se cassaient la tête. Comme si la monarchie légitime pouvait jamais devenir la monarchie de la bourgeoisie industrielle, ou la royauté bourgeoise être jamais la royauté de l'aristocratie terrienne héréditaire ! Comme si la propriété foncière et l'industrie pouvaient fraterniser sous une même couronne, alors que la couronne ne pouvait coiffer qu'une seule et même tête, celle du frère aîné ou du cadet ! Comme si l'industrie pouvait, en général, se réconcilier avec la propriété foncière, tant que celle-ci ne se déciderait pas à devenir elle-même industrielle! Si Henri V mourait demain, le comte de Paris n'en deviendrait pas pour cela le roi des légitimistes, à moins qu'il ne cessât d'être le roi des orléanistes. Cependant, les philosophes de la fusion, qui se donnaient d'autant plus d'importance que la question de la révision passait de plus en plus au premier plan, qui s'étaient créés dans l'Assemblée nationale un organe quotidien officiel et qui, en ce moment même (février 1852), sont de nouveau à l'œuvre, s'expliquaient toute la difficulté de la question par la résistance et la rivalité des deux dynasties. Les tentatives de réconciliation de la famille d'Orléans avec Henri V, entreprises dès la mort de Louis-Philippe, mais, comme les intrigues dynastiques, en général, menées dans les coulisses et pendant les vacances de l'Assemblée, pendant les entr'actes, et plutôt en jouant de coquetterie sentimentale avec une vieille superstition qu'en prenant au sérieux la question, devinrent désormais une affaire d'État et furent apportées par le parti de l'ordre sur la scène publique, au lieu de l'être, comme jusqu'alors sur la scène publique, au lieu de l'être, comme jusqu'alors, sur le théâtre d'amateurs. Les courriers volèrent de Paris à Venise, de Venise à Claremont, de Claremont à Paris. Le comte de Chambord publia un manifeste dans lequel il annonça non pas sa restauration, mais la restauration «nationale», «avec l'aide de tous les membres de sa famille ». L'orléaniste Salvandy se jeta aux pieds d'Henri V. Les chefs légitimistes Berryer d'Azy, Saint-Priest se rendirent à Claremont pour convaincre les Orléans, mais en vain. Les fusionnistes s'aperçurent trop tard que les intérêts des deux fractions bourgeoises ne perdaient rien de leur exclusivisme et ne gagnaient rien en esprit de conciliation à s'aiguiser sous la forme d'intérêts de famille, d'intérêts de deux maisons royales. Si Henri V reconnaissait comme son successeur le comte de Paris - le seul succès que la fusion pût rempoter dans le meilleur des cas, - la maison d'Orléans ne recueillerait aucun avantage que la stérilité d'Henri V ne lui eût déjà assuré, mais elle renonçait à toutes les prétentions qu'elle avait acquises du fait de la révolution de juillet. Elle renonçait à ses prétentions primitives, à tous les titres qu'elle avait arrachés, au cours d'une lutte presque séculaire, à la branche aînée des Bourbon, elle troquait contre cet avantage douteux sa prérogative historique, la prérogative de son arbre généalogique. La fusion n'était, par conséquent, autre chose qu'une abdication volontaire de la maison d'Orléans, sa résignation légitimiste, son retour repentant de l'Église protestante à l'Église catholique. Retour qui ne la replacerait pas sur le trône qu'elle avait 
perdu, mais sur les marches du trône sur lesquelles elle était née. Les anciens ministres orléanistes Guizot, Duchâtel, et autres, qui se précipitèrent également à Claremont pour défendre la cause de la fusion, ne représentaient en fait que l'écœurement provenant de la révolution de juillet, le manque de confiance dans la royauté bourgeoise et dans la royauté des bourgeois, la foi superstitieuse en la légitimité, comme dernière amulette contre l'anarchie. Ils s'imaginaient être les médiateurs entre Orléans et les Bourbon, mais en réalité, ils n'étaient que des orléanistes renégats, et c'est comme tels que le prince de Joinville les reçut. Quant à la partie vivante, belliqueuse, des orléanistes, Thiers, Baze, et autres, ils persuadèrent très facilement la famille de Louis-Philippe que si toute restauration monarchique supposait la fusion des deux dynasties, toute fusion de cette nature supposait à son tour l'abdication de la maison d'Orléans, et que, par contre, il était tout à fait conforme à la tradition de ses ancêtres de reconnaître provisoirement la république et d'attendre que les événements permissent de transformer le fauteuil présidentiel en un trône. On répandit le bruit de la candidature du prince de Joinville, la curiosité publique fut tenue en haleine, et, quelques mois plus tard, après le rejet de la révision, en septembre, cette candidature fut officiellement posée.

Ainsi, la tentative de fusion royaliste entre orléanistes et légitimistes avait non seulement échoué, mais elle avait encore brisé leur fusion parlementaire, leur forme commune républicaine et décomposé à nouveau le parti de l'ordre en ses éléments primitifs. Mais à mesure que les relations devenaient plus tendus entre Claremont et Venise, que leur accord se brisait, que l'agitation autour de Joinville gagnait du terrain, les négociations engagées entre Faucher, le ministre de Bonaparte, et les légitimistes, devenaient plus ardentes, plus sérieuses.

La dissolution du parti de l'ordre ne s'arrêta pas à ses éléments primitifs. Chacune de deux grandes fractions se décomposa à son tour. Il sembla que toutes les anciennes nuances politiques, qui s'étaient autrefois heurtés et combattues à l'intérieur de chacun des clans, légitimistes ou orléaniste, réapparaissaient de nouveau, tels des infusoires desséchés reprenant vie au contact de l'eau, et qu'elles avaient acquis suffisamment de force vitale pour constituer à leur tour des groupes propres et des antagonismes indépendants. Les légitimistes se remémorèrent les conflits entre les Tuileries et le pavillon de Marsan ${ }^{28}$, entre Villèle et Polignac. Les orléanistes vécurent à nouveau l'âge d'or des tournois entre Guizot, Molé, Broglie, Thiers et Odilon Barrot.

La fraction du parti de l'ordre partisan de la révision, mais divisée en dehors de cette question, et composée des légitimistes, dirigés par Berryer et Falloux, d'une part, et La Rochejaquelein d'autre part, et des orléanistes fatigués de la lutte, sous la direction de Molé, de Broglie, de Montalembert et d'Odilon Barrot, s'unit aux représentants bonapartistes pour déposer la proposition vague et confuse suivante : «Les représentants soussignés, en vue de

28 Le pavillon de Marsan, au palais des Tuileries, fut sous Louis XVIII le lieu de séjour du futur Charles X, le comte d'Artois. Celui-ci, ultra-réactionnaire, était en opposition avec la politique modérée de Louis XVIII, ce qui fut la source de toutes sortes d'intrigues. 
rendre à la nation le plein exercice de sa souveraineté, proposent de réviser la Constitution. » Mais, en même temps, ils déclaraient unanimement, par la bouche de leur rapporteur Tocqueville, que l'Assemblée nationale n'avait pas le droit de proposer l'abolition de la république et que seule la Chambre de révision en avait le pouvoir. D'ailleurs, la Constitution ne pouvait être révisée que par la voie «légale », par conséquent, seulement si la majorité des trois quarts des voix prescrites par la Constitution décidait de cette révision. Après six jours de débats tumultueux, le 18 juillet, la révision, comme c'était à prévoir, fut repoussée. 446 vois se prononcèrent en sa faveur, mais 278 voix contre. Les orléanistes avérés, Thiers, Changarnier et autres, votèrent avec les républicains et la Montagne.

La majorité du Parlement se déclarait ainsi contre la Constitution, mais cette Constitution elle-même se déclarait pour la minorité et donnait à sa décision un caractère obligatoire. Or le parti de l'ordre n'avait-il pas, le 31 mai 1850, le 13 juin 1849, subordonné la Constitution à la majorité parlementaire? N'avait-il pas laissé aux démocrates la croyance biblique en la terre de la loi, et n'en avait-il pas puni les démocrates ? Mais, en ce moment, la révision de la Constitution ne signifiait pas autre chose que le maintien du pouvoir présidentiel, de même que le maintien de la Constitution ne signifiait pas autre chose que la destitution de Bonaparte. Il s'agissait, par conséquent, dans l'esprit du Parlement, en déchirant la Constitution, et dans le sens de la Constitution en chassant le Parlement.

Le Parlement avait déclaré «hors la majorité » la Constitution et, avec elle, sa propre domination. Il avait, par sa décision, supprimé la Constitution, prolongé le pouvoir présidentiel et déclaré en même temps que l'un ne pourrait mourir ni l'autre vivre tant qu'il subsisterait lui-même. Les fossoyeurs qui devaient l'enterrer étaient déjà à sa porte. Pendant qu'il discutait la révision, Bonaparte enlevait au commandement de la première division militaire, et nommait à sa place le général Magnan, le vainqueur de Lyon, le héros des journées de décembre, l'une de ses créatures, qui s'était déjà, sous Louis-Philippe, plus ou moins compromise pour lui à l'occasion de l'expédition de Boulogne.

Le parti de l'ordre montra, par sa décision concernant la révision, qu'il ne savait ni régler ni servir, ni vivre ni mourir, ni supporter la république, ni la renverser, ni maintenir la Constitution ni s'en débarrasser, ni collaborer avec le président, ni rompre avec lui. De qui attendait-il donc la solution de toutes ces contradictions? Du calendrier, de la marche des événements. Il cessait de s'attribuer un pouvoir sur les événements, les obligeant ainsi à faire violence et provoquait par là la puissance à laquelle il avait, dans sa lutte contre le peuple, abandonné les uns après les autres tous les attributs du pouvoir, jusqu'à ce qu'il apparut luimême complètement impuissant en face d'elle. Pour permettre au chef du pouvoir exécutif d'élaborer plus tranquillement son plan de campagne contre lui, de renforcer ses moyens d'attaques, de choisir ses armes, de fortifier ses positions, il décida, en plein moment critique, de quitter la scène et de s'ajourner à trois mois, du 10 août au 4 décembre. 
Le parti parlementaire s'était non seulement divisé en ses deux grandes fractions, non seulement chacune de ces fractions s'était divisée elle-même, mais le parti de l'ordre au Parlement était entré en conflit avec le parti de l'ordre en dehors du Parlement. Les orateurs et les écrivains de la bourgeoisie, sa tribune et sa presse, bref, les idéologues de la bourgeoisie et la bourgeoisie elle-même, les représentants et les représentés étaient devenus étrangers les uns aux autres et ne se comprenaient plus.

Les légitimistes dans les provinces, avec leur horizon borné et leur enthousiasme illimité, accusaient leurs chefs parlementaires, Berryer et Falloux, de désertion dans le camp bonapartiste et de défection à la cause de Henri V. Leur intelligence qui avait la pureté du lis croyait au péché, mais non à la diplomatie.

Incomparablement plus fatale et plus décisive fut la rupture de la bourgeoisie commerçant avec les politiciens qui la représentaient. Elle leur reprochait non pas comme les légitimistes à leurs représentants d'avoir abandonné les principes, mais au contraire de rester fidèles à des principes devenus inutiles.

J'ai déjà indiqué que, depuis l'entrée de Fould au ministère, la partie de la bourgeoisie commerçante qui avait possédé la plus grande partie du pouvoir sous Louis-Philippe, l'aristocratie financière était devenue bonapartiste. Fould ne représentait pas seulement les intérêts de Bonaparte à la Bourse, il représentait également les intérêts de la Bourse auprès de Bonaparte. L'attitude de l'aristocratie financière est décrite de la façon la plus frappante dans un passage de son organe européen, l'Economist, de Londres. Dans son numéro du $1^{\text {er }}$ février 1851, ce journal se fait écrire de Paris :

Nous avons pu maintenant constater de tous côtés que la France demande avant tout de la tranquillité. Le président le déclare dans son message à l'Assemblée législative, l'écho en retentit à la tribune de l'Assemblée, cela est affirmé par la presse, proclamé en chaire, c'est prouvé par la sensibilité des valeurs d'État à la plus légère perspective de troubles, par leur fermeté chaque fois que le pouvoir exécutif l'emporte.

Dans son numéro du 29 novembre 1851, l'Economist déclare en son propre nom :

Dans toutes les Bourses d'Europe, le président est actuellement reconnu comme la sentinelle de l'ordre.

L'aristocratie financière maudissait par conséquent la lutte parlementaire menée par le parti de l'ordre contre le pouvoir exécutif comme un trouble apporté à l'ordre, et célébrait chaque victoire du président sur les prétendus représentants comme une victoire de l'ordre. Il ne faut pas entendre ici par aristocratie financière uniquement les grands entrepreneurs d'emprunts et spéculateurs sur les valeurs d'État, dont on comprend immédiatement que leur intérêt coïncide avec les intérêts du pouvoir. Tout le monde financier moderne, tout le monde des banques est très étroitement intéressé au maintien du crédit public. Une partie de leur capital commercial est nécessairement placée dans les valeurs d'État rapidement convertibles. 
Les dépôts, le capital mis à leur disposition et qu'ils répartissent entre les commerçants et les industriels, provient en partie des intérêts perçus par les rentiers de l'État. Si, en tout temps, la stabilité du pouvoir a signifié Moïse et les prophètes, pour le marché de l'argent et les prêtres de ce marché, n'est-ce pas le cas surtout maintenant, où chaque déluge menace d'emporter, avec les vieux États, les vieilles dettes d'État?

Aussi, la bourgeoisie industrielle, dans son fanatisme de l'ordre, était-elle mécontente des querelles continuelles entre le parti de l'ordre parlementaire et le pouvoir exécutif. Thiers, Anglas, Sainte-Beuve, et autres, après leur vote du 18 janvier à l'occasion de la destination de Changarnier, reçurent de leurs mandants, appartenant précisément aux régions industrielles, des remontrances publiques dans lesquelles leur coalition avec la Montagne était flétrie comme un acte de haute trahison à l'égard de l'ordre. Si, comme nous l'avons vu, les provocations fanfaronnes, les intrigues mesquines au moyen desquelles se manifestait la lutte du parti de l'ordre contre le président ne méritaient pas un meilleur accueil, ce parti bourgeois, d'autre part, qui réclame de ses représentants de remettre sans résistance le pouvoir militaire, des mains de son propre Parlement, entre les mains d'un prétendant aventurier, ne méritait même pas les intrigues gaspillées dans son intérêt. Il prouvait que la lutte pour la défense des intérêts publics, ne faisait que l'indisposer et l'importuner comme gênant ses affaires privées.

Les notabilités bourgeoises des villes départementales, les autorités municipales, les juges aux tribunaux de commerce, etc., reçurent partout, presque sans exception, Bonaparte, au cours de ses tournées, de la façon la plus servile, même lorsque, comme à Dijon, il attaqua sans ménagement l'Assemblée nationale et, en particulier, le parti de l'ordre.

Quand les affaires allaient bien, comme c'était encore le cas au début de 1851, la bourgeoisie commerçante s'élevait contre toute la lutte parlementaire susceptible de nuire à son commerce. Quand les affaires allaient mal, come il en fut toujours ainsi à partir de la fin du mois de février 1851, elle se plaignait des luttes parlementaires, comme étant la cause de l'arrêt des affaires, et demandait à grands cris qu'on y mît fin pour que le commerce pût reprendre. Les débats sur la révision de la Constitution tombèrent précisément dans cette mauvaise période. Comme il s'agissait ici de l'existence de la forme même de l'État, la bourgeoisie se sentit d'autant plus en droit de demander à ses représentants de mettre fin à ce provisoire qui la torturait et, en même temps, de maintenir le statu quo. Il n'y avait là aucune contradiction. Mettre fin au provisoire, c'était pour elle précisément le continuer, reporter en un lointain nébuleux le moment où il lui faudrait prendre une décision. Le statu quo ne pouvait être maintenu que de deux façons : soit en prolongeant le pouvoir de Bonaparte, soit en lui retirant ses pouvoirs, conformément aux termes de la Constitution, et en élisant Cavaignac. Une partie de la bourgeoisie souhaitait cette dernière solution et ne savait donner à ses représentants de meilleurs conseils que de se taire et de ne pas toucher à cette question 
brûlante. Si les représentants ne parlaient pas, pensait-elle, Bonaparte n'agirait pas. Elle aurait désiré un Parlement-autruche qui se cachait la tête pour ne pas être vu. Une autre partie de la bourgeoisie désirait laisser Bonaparte au fauteuil présidentiel, du moment qu'il l'occupait déjà, afin que les choses restassent en l'état. Elle s'irritait parce que son Parlement ne violait pas ouvertement la Constitution et n'abdiquait pas sans autre forme de procès.

Les conseils généraux des départements, ces représentations provinciales de la grande bourgeoisie, qui siégèrent pendant les vacances de l'Assemblée nationale à partir du 25 août, se prononcèrent presque unanimement en faveur de lé révision, par conséquent contre le Parlement et pour Bonaparte.

Mais la bourgeoisie manifesta encore plus nettement sa fureur contre ses représentants littéraires, sa propre presse, que contre ses représentants parlementaires. Les condamnations à des amendes écrasantes et à des peines d'emprisonnement inouïes prononcées par les jurys bourgeois pour toute attaque des journalistes bourgeois dirigée contre les désirs d'usurpation de Bonaparte, pour toute tentative faite par la presse pour défendre les droits politiques de la bourgeoisie contre le pouvoir exécutif, provoquèrent l'étonnement général non seulement en France, mais dans l'Europe entière.

$\mathrm{Si}$, comme je l'ai mentionné plus haut, le parti parlementaire de l'ordre s'était condamné lui-même à l'inaction par ses criailleries en faveur de la tranquillité, s'il avait déclaré la domination politique de la bourgeoisie incompatible avec la sécurité et l'existence de la bourgeoisie, en détruisant de ses propres mains, dans sa lutte contre les autres classes de la société, toutes les conditions de son propre régime, du régime parlementaire, part contre, la masse extra-parlementaire de la bourgeoisie, par sa servilité envers le président, par ses injures contre le Parlement, par la brutalité avec laquelle elle traita sa propre presse, excita Bonaparte à réprimer, à exterminer ses orateurs et ses écrivains, ses politiciens et ses littérateurs, sa tribune et sa presse, afin de lui permettre de vaquer en confiance à ses affaires privées, sous la protection d'un gouvernement fort et absolu. Elle déclara nettement qu'elle brûlait du désir de se débarrasser en même temps des soucis et des dangers du pouvoir.

Et c'est cette bourgeoisie, qui s'était déjà indignée de la lutte purement parlementaire et littéraire menée en faveur de la domination de sa propre classe et qui avait trahi les chefs de cette lutte, qui ose maintenant reprocher après coup au prolétariat de ne pas s'être soulevé pour mener une lutte sanglante, une lutte à mort pour elle ! Cette bourgeoisie, qui, à chaque instant, sacrifiait son propre intérêt général de classe, son intérêt politique, à ses intérêts particuliers les plus bornés, les plus malpropres, et exigeait de ses représentants un sacrifice analogue, ose reprocher maintenant au prolétariat d'avoir sacrifié ses intérêts politiques généraux à ses intérêts matériels. Elle se conduit comme une belle âme méconnue et abandonnée au moment décisif par le prolétariat égaré par les socialistes. Elle trouve même un écho général dans le monde bourgeois. Je ne parle naturellement pas ici des politiciens de 
clocher et des maroufles intellectuels d'Allemagne. Je renvoie, par exemple, à ce même Economist qui, le 29 novembre 1851, c'est-à-dire quatre jours seulement avant le coup d'État, proclamait encore Bonaparte «sentinelle de l'ordre» et qualifiait Thiers et Berryer d'«anarchistes », et qui, le 27 décembre 1851 déjà, lorsque Bonaparte eut condamné ces anarchistes au repos, se lamentait sur la trahison que les

...masses prolétariennes ignorantes, grossières, stupides, ont perpétré contre l'habileté, la science, la discipline, les capacités intellectuelles et les qualités morales des couches moyennes et supérieures de la société.

Or cette masse stupide, ignorante et grossière, n'était autre que la masse bourgeoise ellemême.

La France avait, il est vrai, traversé en 1851 une sorte de crise commerciale. A la fin de février, on assista à une diminution des exportations par rapport à l'année précédente. En mars, le commerce diminua et les fabriques cessèrent le travail. En avril, la situation des départements industriels sembla aussi désespérée qu'au lendemain des Journées de février. En mai, les affaires n'avaient pas encore repris. Le 28 juin encore, le portefeuille de la Banque de France indiquait, par l'accroissement formidable des dépôts et une diminution aussi considérable des avances sur effets, l'arrêt de la production. Ce n'est qu'au milieu d'octobre qu'on assista à une amélioration progressive des affaires. La bourgeoisie française s'expliqua cette stagnation commerciale par des raisons d'ordre purement politique, par la lutte entre le Parlement et le pouvoir exécutif, par l'insécurité d'une forme de gouvernement simplement provisoire, par la perspective terrifiante du 2 mai 1852. Je ne veux pas nier que toutes ces circonstances aient amené une dépression dans certaines branches d'industrie à Paris et dans les départements. Mais, en tout cas, cette influence de la situation politique sur la marche des affaires n'était que locale et d'ordre insignifiant. En faut-il d'autres preuves que le fait l'amélioration du commerce se produisit précisément au moment où la situation politique s'aggravait, où l'horizon politique s'assombrissait et où l'on attendait à tout moment un éclair, venant de l'Élysée, c'est-à-dire à la mi-octobre ? Le bourgeois français, dont «l'habileté, la science, la clairvoyance et les capacités intellectuelles » ne dépassent pas le bout de son nez, put d'ailleurs, pendant toute la durée de l'Exposition industrielle de Londres, mettre le nez sur la cause véritable de sa misère commerciale. Tandis qu'en France, les fabriques étaient fermées, En Angleterre éclataient des banqueroutes commerciales. Tandis qu'en France la panique industrielle atteignait son apogée en avril et en mai, en Angleterre, la panique commerciale arrivait en avril et en mai à son point culminant. L'industrie de la laine anglaise souffrait de la crise tout comme l'industrie de la laine française, et l'industrie anglaise de la soie tout comme l'industrie française de la soie. Si les fabriques de cotonnades anglaises continuèrent à travailler, ce n'était plus avec les mêmes profits qu'en 1849 et 1850 . La seule différence entre les deux crises, c'est que la crise fut industrielle en France, et commerciale en Angleterre et que, tandis qu'en France, les fabriques cessaient le travail, elles 
se développaient en Angleterre, mais dans des condition plus défavorables qu'au cours des années précédentes, qu'en France, ce furent les exportations, et, en Angleterre, les importations qui furent le plus atteintes. La raison commune à ces deux crises qui dépassaient évidemment les limites de l'horizon politique français, sautait aux yeux. Les années 1849 et 1850 avaient été des années de très grande prospérité matérielle et de surproduction, qui ne se manifestèrent comme telle qu'en 1851. Cette surproduction fut encore tout particulièrement aggravée au début de l'année, par suite des perspectives de l'Exposition industrielle. A cela, il faut encore ajouter les circonstances particulières suivantes : tout d'abord la mauvaise récolte de coton des années 1850 et 1851 , puis la certitude d'une récolte de coton plus considérable qu'on ne s'y attendait ; d'abord la hausse, puis la baisse brusque, bref les oscillations des prix du coton. La récolte de soie brute était, du moins en France, tombée au-dessous de la moyenne. La fabrication des lainages, enfin, s'était tellement étendue depuis 1848 que la production de la laine ne pouvait y suffire et que le prix de la laine brute s'éleva d'une façon très disproportionnée avec celui des lainages. Nous avons, par conséquent, déjà ici, dans la production des matières premières de trois industries intéressant le marché mondial, une triple cause de stagnation commerciale. Abstraction faite de ces circonstances spéciales, la crise apparente de l'année 1851 n'était autre chose que l'arrêt que provoquent chaque fois dans le cycle industriel la surproduction et la sur-spéculation avant qu'elles aient rassemblé toutes leurs forces pour traverser fiévreusement la dernière partie du cycle et revenir à nouveau à leur point de départ, la crise commerciale générale. Dans de semblables intervalles de l'histoire du commerce, des banqueroutes commerciales éclatent en Angleterre, tandis qu'en France, l'industrie elle-même est arrêtée, en partie parce que contrainte à la retraite sur tous les marchés par la concurrence anglaise qu'elle ne peut alors supporter, soit parce que, en tant qu'industrie de luxe, c'est surtout elle qui est frappée par l'arrêt des affaires. C'est ainsi qu'en dehors des crises générales, la France traverse ses propres crises commerciales nationales, qui sont cependant déterminées et conditionnées beaucoup plus par l'état général du marché mondial que par des influences locales françaises.

Il ne sera pas sans intérêt d'opposer au préjugé du bourgeois français l'appréciation du bourgeois anglais. L'une des plus grandes firmes de Liverpool écrit dans son bilan annuel pour 1851:

Peu d'années ont plus trompé les prévisions faites à leur début que celle qui vient de s'écouler. Au lieu de la grande prospérité à laquelle tout le monde s'attendait, elle a été l'année la plus décourageante que l'on ait vue depuis un quart de siècle. Naturellement, cela n'est vrai que des classes commerçantes et non des classes industrielles. Et, cependant, on était certainement en droit, au début de l'année, de faire des déductions contraires. Les stocks de marchandises étaient réduits, le capital surabondant, les denrées alimentaires bon marché, une récolte abondante était assurée. Une paix ininterrompue sur le continent et pas de troubles politiques ou financiers à l'intérieur du pays. En fait, jamais les ailes du commerce n'avaient été plus libres de prendre leur essor... A quoi faut-il attribuer ce résultat défavorable ? Nous pensons 
qu'il faut l'attribuer aux excès du commerce, tant dans les importations que dans les exportations. Si nos négociants n'imposent pas eux-mêmes des limites à leur activité, rien ne pourra nous maintenir dans la voie normale, qu'une panique tous les trois ans.

Qu'on se représente maintenant le bourgeois français: au milieu de cette panique commerciale, combien sa cervelle, aussi malade que son commerce, ne devait-elle pas être torturée, abasourdie, ahurie, par les bruits de coup d'État et de rétablissement du suffrage universel, par la Fronde des orléanistes et des légitimistes, les conspirations communistes du midi de la France, les prétendues jacqueries dans les départements de la Nièvre et du Cher, les réclames faites par les différents candidats à la présidence, les mots d'ordre charlatanesques des journaux, les menaces des républicains de défendre la Constitution et le suffrage universel les armes à la main, les évangiles des héros in partibus émigrés à l'étranger, qui prophétisaient la fin du monde pour le 2 mai 1852, et l'on comprendra que, dans cette confusion incroyable, bruyante, de fusion, de révision, de propagation, de Constitution, de conspiration, de coalition, d'émigration, d'usurpation et de révolution, le bourgeois ait crié, dans un accès de fureur, à sa République parlementaire : «Plutôt une fin effroyable qu'un effroi sans fin! »

Bonaparte comprit cet appel. Ses facultés de compréhension étaient aiguisées par l'acharnement croissant de créanciers qui, à chaque coucher de soleil rapprochant le jour de l'échéance, le 2 mai 1852, voyaient dans le mouvement des étoiles une protestation contre leurs traits terrestres. Ils étaient devenus de véritables astrologues. L'Assemblée nationale avait enlevé à Bonaparte tout espoir d'une prorogation constitutionnelle de son mandat, et la candidature du prince de Joinville ne lui permettait pas d'hésiter plus longtemps.

Si jamais événement a projeté devant lui son ombre longtemps avant de se produire, ce fut bien le coup d'État de Bonaparte. Dès le 29 janvier, un mois à peine après son élection, il en avait fait la proposition à Changarnier. Son propre premier ministre, Odilon Barrot, avait, au cours de l'été 1849, dénoncé de façon voilée, Thiers, au cours de l'hiver 1850, de façon ouverte, la politique des coups d'État. En mai 1851, Persigny avait essayé à nouveau de gagner Changarnier au coup d'État. Le Messager de l'Assemblée avait publié cet entretien. A chaque tempête parlementaire, els journaux bonapartistes menaçaient d'un coup d'État, et plus la crise approchait, plus leur ton s'élevait. Dans les orgies que Bonaparte célébrait chaque nuit avec le sweell $m o b^{(1)}$ masculin et féminin, chaque fois que minuit approchait et que d'abondantes libations avaient délié les langues et échauffé l'imagination, on décidait le coup d'État pour le lendemain matin. On tirait les épées, on choquait les verres; les représentants s'enfuyaient par les fenêtres, le manteau impérial tombait sur les épaules de Bonaparte. L'aurore seule venait apaiser le vacarme, et Paris étonné apprenait de la bouche de vestales peu réservées et de paladins indiscrets le danger auquel il venait d'échapper une fois de plus. Au cours des mois de septembre et d'octobre, les bruits de coup d'État se multiplièrent. L'ombre prenait de la couleur, telle un daguerréotype multicolore. Que l'on

1. En anglais dans le texte : la haute pègre. 
feuillette les numéros de septembre et d'octobre des organes de presse quotidienne européenne, et l'on y trouvera textuellement des informations du genre de celle-ci :

Des bruits de coup d'État remplissent Paris. On dit que la capitale sera remplie de troupes dissolvant l'Assemblée nationale, proclamant l'état de siège dans le département de la Seine, rétablissant le suffrage universel et faisant appel au peuple. Bonaparte serait à la recherche de ministres pour exécuter ces décrets illégaux.

Les correspondances qui rapportent ces nouvelles se terminent toujours par le mot fatal : «Ajourné ». Le coup d'État fut toujours une idée fixe de Bonaparte. C'est avec cette idée qu'il était rentré en France. Elle le possédait à tel point qu'il la trahissait et la divulguait constamment. Il était si faible qu'il y renonçait tout aussi constamment. L'ombre du coup d'État était devenu un fantôme si familier aux Parisiens qu'ils ne voulaient plus y croire, lorsqu'il parut enfin en chair et en os. Ce ne fut, par conséquent, ni la discrétion du chef de la société du 10 Décembre, ni un coup de main imprévu contre l'Assemblée nationale, qui permit au coup d'État de réussir. S'il réussit, ce fut malgré l'indiscrétion du premier et malgré la connaissance qu'en avait la seconde, comme une conséquence nécessaire, inévitable, du développement antérieur.

Le 10 octobre, Bonaparte annonça à ses ministres sa volonté de rétablir le suffrage universel. Le 16, ils donnèrent leur démission. Le 26, Paris apprit la constitution du ministère Thorigny. En même temps, le préfet de police Carlier fut remplacé par Maupas, et le chef de la première division militaire, Magnan, rassembla dans la capitale les régiments les plus sûrs. Le 4 novembre, l'Assemblée nationale rouvrit ses séances. Il ne lui restait plus qu'à reprendre, comme en une courte et brève répétition, le cours qu'elle avait déjà suivi et à montrer qu'on ne l'enterrera qu'une fois morte.

La première position qu'elle avait perdue dans sa lutte contre le pouvoir exécutif était le ministère. Il lui fallut reconnaître solennellement cette perte en prenant au sérieux le ministère Thorigny, une simple apparente de ministère. La Commission permanente avait accueilli par des éclats de rire M. Giraud, quand il se présenta devant elle au nom du nouveau cabinet. Un si faible ministère pour des mesures aussi graves que le rétablissement du suffrage universel ! Mais il s'agissait précisément de ne rien faire dans le Parlement, mais de faire tout contre le Parlement.

Dès le premier jour de sa réouverture, l'Assemblée nationale reçut le message de Bonaparte où ce dernier demandait le rétablissement du suffrage universel et l'abrogation de la loi du 31 mai 1850. Ses ministres déposèrent le même jour un décret en ce sens. L'Assemblée repoussa immédiatement la motion d'urgence présentée par le cabinet et rejeta la loi elle-même, le 13 novembre, par 355 voix contre 348. Elle déchirait ainsi une fois de plus son mandat, elle confirmait une fois de plus que, de représentation du peuple librement élue, elle s'était transformée en Parlement usurpateur d'une classe, elle reconnaissait une fois 
de plus qu'elle avait elle-même tranché les muscles qui reliaient la tête parlementaire au cou de la nation.

Si le pouvoir exécutif, par sa proposition de rétablissement du suffrage universel, en appelait de l'Assemblée nationale au peuple, le pouvoir législatif, par sa «proposition des questeurs », en appelait du peuple à l'armée. Cette proposition des questeurs avait pour but d'établir son droit à la réquisition directe des troupes, à la constitution d'une armée parlementaire. Si le pouvoir législatif faisait ainsi de l'armée l'arbitre entre lui et le peuple, entre lui et Bonaparte, s'il reconnaissait l'armée comme un pouvoir politique décisif, il ne manquait pas, d'autre part, de confirmer qu'il avait depuis longtemps renoncé à la prétention de donner des ordres à l'armée. En discutant sur son droit de réquisition au lieu de requérir immédiatement les troupes, il trahissait son manque de confiance en sa propre force. En rejetant les propositions des questeurs, il avoua publiquement son impuissance. Cette proposition fut repoussée par une majorité de 108 voix, la Montagne ayant fait pencher la balance. Elle se trouvait ainsi dans la situation de l'âne de Buridan, non pas, certes, entre deux bottes de foin, et ayant à décider laquelle était la plus appétissante, mais bien entre deux volées de coups de bâtons, ayant à décider quelle était la plus rude. D'un côté, la peur de Changarnier, de l'autre la crainte de Bonaparte. Il faut avouer que la situation n'avait rien d'héroïque.

Le 18 novembre, on présenta à la loi déposée par le parti de l'ordre sur les élections municipales un amendement aux termes duquel une année de domicile devait suffire, au lieu de trois, pour les électeurs municipaux. L'amendement fut repoussé par une seule voix de majorité, et encore fut-il reconnu immédiatement que cette voix provenait d'un malentendu. En se scindant en ses fractions hostiles, le parti de l'ordre avait depuis longtemps perdu sa propre majorité parlementaire. Il montrait maintenant qu'il n'y avait plus de majorité du tout au Parlement. L'Assemblée nationale était devenue incapable de prendre une décision. Ses éléments atomiques n'étaient plus réunis par aucune force de cohésion. Elle avait consumé son dernier souffle de vis, elle était morte.

La masse extra-parlementaire bourgeoise, enfin, devait une fois encore, quelques jours avant la catastrophe, confirmer solennellement sa rupture avec les représentants de la bourgeoisie au Parlement. Thiers, en qualité de héros parlementaire, particulièrement atteint de la maladie incurable du crétinisme parlementaire avait, après la mort du Parlement, ourdi une nouvelle intrigue parlementaire avec le Conseil d'État, une loi sur la responsabilité qui devait enfermer le président dans les limites de la Constitution. De même que Bonaparte, le 15 septembre, à l'occasion de la fondation des nouvelles halles de Paris, avait, nouveau Masaniello ${ }^{29}$, séduit les «dames des halles *", les poissardes — et d'ailleurs, une puissance

29 Abréviation de Tomaso Aniello (1623-1647), pêcheur napolitain. C'est sur le marché où il vendait des fruits que commença l'insurrection dont il fut le dirigeant. Les masses populaires de Naples se soulevèrent contre les occupants espagnols qui les opprimaient et les écrasaient d'impôts. 
réelle, 17 burgraves - de même qu'après le dépôt de la proposition des questeurs, il avait enthousiasmé les lieutenants qu'il traitait à l'Élysée, de même, le 25 novembre, il gagna la bourgeoisie industrielle rassemblée au Cirque pour recevoir de sa main les médailles des prix de l'Exposition industrielle de Londres. Je repoduis ici la partie la plus caractéristique de son discours, d'après Le Journal des débats :

En présence de succès aussi inespérés, je suis en droit de déclarer encore une fois combien la République française serait grande s'il lui était permis de poursuivre ses intérêts réels et de réformer ses institutions, au lieu d'être constamment troublée, d'une part, par les démagogues, d'autre part, par les hallucinations monarchistes. (Applaudissements bruyants, enthousiastes et prolongés dans toutes les parties de l'amphithéâtre.) Les hallucinations monarchistes empêchent tout progrès et tout développement industriel sérieux. Au lieu du progrès, on n'a que la lutte. On voit des hommes, autrefois les soutiens les plus zélés de l'autorité et des prérogatives royales, devenir partisans d'une Convention, uniquement dans le dessein d'affaiblir l'autorité issue du suffrage universel. (Applaudissements enthousiastes et prolongés.) Nous voyons des hommes qui ont le plus souffert de la révolution et s'en sont plaints le plus, en provoquer une nouvelle, uniquement pour enchaîner la volonté de la nation... Je vous promets la tranquillité pour l'avenir, etc., etc. (Bravo! Bravo! Tonnerre d'applaudissements.)

C'est ainsi que la bourgeoisie industrielle applaudit servilement le coup d'État du 2 décembre, la suppression du Parlement, la ruine de sa propre domination, la dictature de Bonaparte. Au tonnerre de la canonnade du 10 décembre, et la maison de M. Salladrouze, l'un de ceux qui avaient applaudi le plus vigoureusement, fut également celle qui eut le plus à souffrir de la canonnade.

Cromwell, lorsqu'il procéda à la dissolution du Long Parlement, s'y rendit seul, tira sa montre, afin qu'il ne subsistât pas une minute de plus que le délai fixé par lui et chassa chacun de ses membres sous les brocards humoristiques. Napoléon, inférieur à son modèle, se rendit, du moins le 18 Brumaire, au Corps législatif, et lui donna lecture, quoique d'une voix oppressée, de son arrêt de mort. Le second Bonaparte, qui disposait d'ailleurs d'un tout autre pouvoir exécutif que Cromwell ou Napoléon, chercha son modèle, non pas dans les annales de l'histoire, mais dans celles de la société du 10 Décembre, dans les annales de la justice criminelle. Il vola à la Banque de France 25 millions de francs, acheta le général Magnan pour un million, les soldats 15 francs pièce, avec de l'eau-de-vie par-dessus le marché, se réunit secrètement dans la nuit, avec ses complices, comme un voleur, fit envahir les maisons des leaders parlementaires les plus dangereux et tirer de leur lit Cavaignac, Lamoricière, Leflô, Changarnier, Charras, Thiers, Baze, et autres, occuper militairement les principales places de Paris, ainsi que le Palais du Parlement, et le lendemain, dès l'aube, couvrir tous les murs d'affiches charlatanesques, où il annonçait la dissolution de l'Assemblée nationale et du Conseil d'État, le rétablissement du suffrage universel et la mise en état de siège du

En français dans le texte. 
département de la Seine. De même, peu de temps après, il fit passer dans Le Moniteur un faux document, selon lequel des parlementaires influents se seraient groupés autour de lui en un Conseil d'État.

Le Parlement-croupion rassemblé à la mairie du $\mathrm{X}^{\mathrm{e}}$ arrondissement, composé principalement de légitimistes et d'orléanistes, décida, aux cris répétés de : «Vive la république !» la destitution de Bonaparte, harangua vainement la foule des badauds assemblés devant l'édifice et fut finalement traîné, avec une escorte de chasseurs d'Afrique, à la caserne d'Orsay, puis entassé dans des voitures cellulaires et transporté dans les prisons de Mazas, de Ham et de Vincennes. Ainsi finirent le parti de l'ordre, l'Assemblée législative et la révolution de février.

Avant de passer rapidement à la conclusion, esquissons un schéma rapide de leur histoire :

I. Première période, du 24 février au 4 mai 1848. Période de février. Prologue. Comédie de la fraternisation générale.

II. Deuxième période. Période de la constitution de la république et de l'Assemblée nationale constituante.

1. Du 4 mai au 25 juin 1848. - Lutte de toutes les classes contre le prolétariat. Défaite du prolétariat au cours des Journées de juin ;

2. Du 25 juin au 10 décembre 1848. - Dictature des républicains bourgeois purs. Élaboration de la Constitution. Mise en état de siège de Paris. La dictature bourgeoise est écartée, le 10 décembre, par l'élection de Bonaparte à la présidence ;

3. Du 20 décembre 1848 au 29 mai 1849. - Lutte de la Constituante contre Bonaparte et le parti de l'ordre, allié à ce dernier. Fin de la Constituante. Chute de la bourgeoisie républicaine.

III. Troisième période. Période de la république constitutionnelle et de l'Assemblée nationale législative.

1. Du 29 mai 1849 au 13 juin 1849. - lutte de la petite bourgeoisie contre la grande bourgeoisie et contre Bonaparte. Défite de la démocratie petite-bourgeoise ;

2. Du 13 juin 1849 au 31 mai 1850. — Dictature parlementaire du parti de l'ordre. Le parti complète sa domination par l'abolition du suffrage universel, mais il perd le ministère parlementaire ;

3. Du 31 mai 1850 au 2 décembre 1851. - Lutte entre la bourgeoisie parlementaire et Bonaparte : 
a) Du 31 mai au 12 janvier 1851. - Le Parlement perd le commandement suprême de l'armée ;

b) Du 12 janvier au 11 avril 1851. - Le Parlement succombe dans ses tentatives de s'emparer à nouveau du pouvoir administratif. Le parti de l'ordre perd sa propre majorité parlementaire. Il s'allie aux républicains et à la Montagne ;

c) Du 11 avril 1851 au 9 octobre 1851. - Tentative de révision, de fusion et de propagation. Le parti de l'ordre se dissout en ses différents éléments. La rupture entre le Parlement bourgeois et la presse bourgeoise, d'une part, et la masse bourgeoise, d'autre part, se confirme ;

d) Du 9 octobre au 2 décembre 1851. - Rupture ouverte entre le Parlement et le pouvoir exécutif. Le Parlement exécute son acte de décès et succombe, abandonné par sa propre classe, par l'armée et par toutes les autres classes. Chute du régime parlementaire, et de la domination bourgeoise. Victoire complète de Bonaparte. Parodie de restauration impériale. 


\section{VII}

\section{$\underline{\text { Retour à la table des matières }}$}

La République sociale apparut, en tant que phrase, que prophétie, au seuil de la révolution de février. Au cours des Journées de juin 1848, elle fut étouffée dans le sang du prolétariat parisien, mais elle rôda comme un spectre, dans les actes suivants du drame. On proclama la République démocratique. Elle disparut le 13 juin 1849, emportée dans la fuite de ses petits bourgeois, mais dans sa fuite elle jeta derrière elle sa publicité doublement fanfaronne. La République parlementaire s'empara, avec la bourgeoisie, de toute la scène et s'étendit dans toute sa plénitude, mais le 2 décembre l'enterra, aux cris angoissés de: «Vive la république ! » poussés par les royalistes coalisés

La bourgeoisie française s'était cabrée contre la domination du prolétariat travailleur, et c'est elle qui mit au pouvoir le sous-prolétariat ayant à sa tête le chef de la société du 10 Décembre. La bourgeoisie avait tenu la France toute haletante dans la crainte des horreurs futures de l'anarchie rouge, et c'est Bonaparte qui lui escompta cet avenir en faisant, le 4 décembre, descendre de leurs fenêtres à coups de fusils, par les soldats de l'ordre saouls d'eau-de-vie, les bourgeois distingués du boulevard Montmartre et du boulevard des Italiens. La bourgeoisie avait fait l'apothéose du sabre, et c'est le sabre qui la domine. Elle avait supprimé la presse révolutionnaire, et c'est sa propre presse qui est supprimée. Elle avait placé les réunions populaires sous la surveillance de la police, et ce sont ses salons qui sont, à leur tour, placés sous la surveillance de la police. Elle avait dissous la garde nationale démocratique, et c'est sa propre garde nationale qui est dissoute. Elle avait proclamé l'état de siège, et c'est contre elle que l'état de siège est maintenant proclamé. Elle avait remplacé les jurys sont, à leur tour, remplacés par des commissions militaires.

Elle avait livré aux prêtres l'instruction publique, et maintenant, c'est sa propre instruction qui est livrée aux prêtres. Elle avait déporté sans jugement, et maintenant c'est elle que l'on déporte sans jugement. Elle avait réprimé à l'aide de la force publique tout mouvement de la société, et maintenant le pouvoir d'État réprime, à son tour, tout mouvement de sa propre société. Pour l'amour de son porte-monnaie, elle s'était révoltée contre ses propres politiciens et littérateurs. Maintenant, non seulement ses politiciens et littérateurs sont à l'écart, mais on pille son porte-monnaie, après l'avoir bâillonnée et après avoir brisé sa plume. La bourgeoisie avait crié infatigablement à la révolution, comme saint Arsène aux chrétiens : Fuge, tace 
quiesce! (fuis, tais-toi, reste tranquille!) et maintenant c'est Bonaparte qui crie à la bourgeoisie : Fuge, tace quiesce!

La bourgeoisie française avait résolu depuis longtemps le dilemme posé par Napoléon: «Dans cinquante ans, l'Europe sera républicaine ou cosaque *. " Elle l'avait résolu dans le sens de la «République cosaque * Aucune Circé $^{30}$ n'avait, en jetant un mauvais sort, transformé en monstre le chef-d'œuvre de la république bourgeoise. Cette république n'avait perdu que l'apparence de la respectabilité. La France actuelle était déjà tout entière dans la république parlementaire. Il avait suffi d'un coup de baïonnette pour crever l'enveloppe extérieure et faire apparaître le monstre à tous les yeux.

Le but immédiat de la révolution de février fut le renversement de la dynastie d'Orléans et de la fraction de la bourgeoisie qui dominait sous elle. C'est le 2 décembre 1851 seulement que ce but fut atteint. Alors, les immenses propriétés de la maison d'Orléans, bases réelles de son influence, furent confisquées, et ce qu'on avait attendu de la révolution de février ne se produisit qu'au lendemain du coup d'état du 2 décembre : la prison, la fuite, la destitution, le bannissement, le désarmement, le mépris à l'égard des hommes qui, depuis 1830, avaient fatigué la France de leur réputation. Mais, sous Louis-Philippe, dominait seulement une partie de la bourgeoisie commerçante. Les autres fractions de cette bourgeoisie constituaient une opposition dynastique et une opposition républicaine ou se trouvaient complètement en dehors de ce qu'on appelait la légalité. C'est la république parlementaire qui porta la première au pouvoir toutes les fractions de la bourgeoisie commerçante. Sous Louis-Philippe, la bourgeoisie commerçante exclut la bourgeoisie foncière. C'est la république parlementaire qui, la première, les mit sur un pied d'égalité, unit la monarchie de Juillet à la monarchie légitime et fondit en une seule deux périodes de domination de la propriété. Sous LouisPhilippe, la partie privilégiée de la bourgeoisie cachait sa domination sous le trône. Dans la république parlementaire, la domination de la bourgeoisie, après avoir uni tous ses éléments et fait de son domaine le domaine de sa classe, apparut dans toute sa nudité. Ainsi, il fallut que la révolution elle-même créât d'abord la forme dans laquelle la domination de la classe bourgeoise acquiert son expression la plus large, la plus générale et la plus complète, et pût, par conséquent, être renversée sans espoir de retour.

C'est alors seulement que fut exécutée la condamnation prononcée en février contre la bourgeoisie orléaniste, c'est-à-dire la fraction la plus vivante de la bourgeoisie française. C'est alors seulement qu'elle fut battue dans son Parlement, son barreau, ses tribunaux de commerce, ses représentations provinciales, son notariat, son université, sa tribune et sa justice, sa presse et sa littérature, ses revenus administratifs, son casuel judiciaire, ses

En français dans le texte.

En français dans le texte.

30 Enchanteresse de la mythologie grecque, qui transformait les hommes en bêtes. 
appointements d'officiers et ses rentes d'État, dans son esprit et dans sa chair. Blanqui avait posé comme première revendication à la révolution la dissolution des gardes bourgeoises, et les gardes bourgeoises, qui, en février, tendaient la main à la révolution pour l'entraver dans sa marche, disparurent en décembre de la scène. Le Panthéon lui-même redevint une église ordinaire. Avant la dernière forme du régime bourgeois fut également rompu le charme qui avait transformé en saints ses initiateurs du XVIII ${ }^{\mathrm{e}}$ siècle.

Pourquoi le prolétariat parisien ne s'est-il pas soulevé après le 2 décembre ?

Parce que la chute de la bourgeoisie n'avait été que décrétée et que le décret n'avait pas encore été exécuté. Toute révolte sérieuse du prolétariat l'aurait aussitôt rendue à la vie, réconciliée avec l'armée et aurait valu aux ouvriers une seconde défaite de juin.

Le 4 décembre, le prolétariat fut excité à la lutte par les bourgeois et les épiciers. Le soir de ce même jour, plusieurs légions de la garde nationale promirent d'apparaître en armes et en uniforme sur le champ de bataille. Bourgeois et épiciers s'étaient en effet aperçus que dans l'un de ses décrets du 2 décembre, Bonaparte abolissait le vote secret et ordonnait aux électeurs d'inscrire dans les registres officiels : oui ou non, en face de leurs noms. La résistance du 4 décembre intimida Bonaparte. Pendant la nuit, il fit placarder à tous les coins de rues des affiches annonçant le rétablissement du vote secret. Bourgeois et épiciers crurent dès lors avoir atteint leur but, et qui ne parut pas le lendemain, ce furent les épiciers et les bourgeois.

Par un coup de main de Bonaparte, pendant la nuit du $1^{\text {er }}$ au 2 décembre, le prolétariat parisien avait été privé de ses chefs de barricades. Devenu une armée sans officiers, à laquelle les souvenirs de juin 1848 et 1849 et de mai 1850 ôtaient toute envie de combattre sous la bannière des Montagnards, il laissa son avant-garde, les sociétés secrètes, le soin de sauver l'honneur insurrectionnel de Paris, et la bourgeoisie livra si facilement la capitale à la soldatesque que Bonaparte put, par la suite, désarmer la garde nationale sous le prétexte ironique qu'il craignait que les anarchistes n'utilisassent contre elle ses propres armes !

«C'est le triomphe complet et définitif du socialisme ${ }^{(*)} ! » C$ 'est ainsi que Guizot caractérisa le 2 Décembre. Mais si le renversement de la république parlementaire contient en germe le triomphe de la révolution prolétarienne, son premier résultat tangible n'en fut pas moins la victoire de Bonaparte sur le Parlement, du pouvoir exécutif sur le pouvoir législatif, de la violence sans phrase sur la violence de la phrase. Au Parlement, la nation élevait sa volonté générale à la hauteur d'une loi, c'est-à-dire qu'elle faisait de la loi de la classe dominante sa volonté générale. Devant le pouvoir exécutif, elle abdique toute volonté propre et se soumet aux ordres d'une volonté étrangère, l'autorité. Le pouvoir exécutif, contrairement au pouvoir législatif, exprime l'hétéronomie de la nation, en opposition à son autonomie. Ainsi, la France ne sembla avoir échappé au despotisme Ainsi, la France ne sembla avoir échappé au despotisme d'une classe que pour retomber sous le despotisme d'une classe que 
pour retomber sous le despotisme d'un individu, et encore sous l'autorité d'un individu sans autorité. La lutte parut apaisée en ce sens que toutes les classes s'agenouillèrent, également impuissantes et muettes, devant les crosses de fusils.

Mais la révolution va jusqu'au fond des choses. Elle ne traverse encore que le purgatoire. Elle mène son affaire avec méthode. Jusqu'au 2 décembre 1851, elle n'avait accompli que la moitié de ses préparatifs, et maintenant elle accomplit l'autre moitié. Elle perfectionne d'abord le pouvoir parlementaire, pour pouvoir le renverser ensuite. Ce but une fois atteint, elle perfectionne le pouvoir exécutif, le réduit à sa plus simple expression, l'isole, dirige contre lui tous les reproches pour pouvoir concentrer sur lui toutes ses forces de destruction, et, quand elle aura accompli la seconde moitié de son travail de préparation, l'Europe sautera de sa place et jubilera : «Bien creusé, vieille taupe ! »

Ce pouvoir exécutif, avec son immense organisation bureaucratique et militaire, avec son mécanisme étatique complexe et artificiel, son armée de fonctionnaires d'un demi-million d'hommes et son autre armée de cinq cent mille soldats, effroyable corps parasite, qui recouvre comme d'une membrane le corps de la société française et en bouche tous les pores, se constitua à l'époque de la monarchie absolue, au déclin de la féodalité, qu'il aida à renverser. Les privilèges seigneuriaux des grands propriétaires fonciers et des villes se transformèrent en autant d'attributs $d u$ pouvoir d'État, les dignitaires féodaux en fonctionnaires appointés, et la carte bigarrée des droits souverains médiévaux contradictoires devint le plan bien réglé d'un pouvoir d'État, dont le travail est divisé et centralisé comme dans une usine. La première Révolution française, qui se donna pour tâche de briser tous les pouvoirs indépendants, locaux, territoriaux, municipaux et provinciaux, pour créer l'unité bourgeoise absolue : la centralisation, mais, en même temps aussi, l'étendue, les attributs et l'appareil du pouvoir gouvernemental. Napoléon acheva de perfectionner ce mécanisme d'État. La monarchie légitime et la monarchie de Juillet ne firent qu'y ajouter une plus grande division du travail, croissant au fur et à mesure que la division du travail, à l'intérieur de la société bourgeoise, créait de nouveaux groupes d'intérêts, et, par conséquent, un nouveau matériel pour l'administration d'État. Chaque intérêt commun fut immédiatement détaché de la société, opposé à elle à titre d'intérêt supérieur, général, enlevé à l'initiative des membres de la société, transformé en objet de l'activité gouvernementale, depuis le pont, la maison d'école et la propriété communale du plus petit hameau jusqu'aux chemins de fer, aux biens nationaux et aux universités. La république parlementaire, enfin, se vit contrainte, dans sa lutte contre la révolution, de renforcer par ses mesures de répression les moyens d'action et la centralisation du pouvoir gouvernemental. Toutes les révolutions politiques n'ont fait que perfectionner cette machine, au lieu de la briser. Les partis qui luttèrent à tour de rôle pour le pouvoir considérèrent la conquête de cet immense édifice d'État comme la principale proie du vainqueur. 
Mais, sous la monarchie absolue, pendant la première Révolution et sous Napoléon, la Bureaucratie n'était que le moyen de préparer la domination de classe de la bourgeoisie. Sous la Restauration, sous Louis-Philippe, sous la République parlementaire, elle était l'instrument de la classe dominante, quels que fussent d'ailleurs ses efforts pour se constituer en puissance indépendante.

Ce n'est que sous le second Bonaparte que l'État semble être devenu complètement indépendant. La machine d'État s'est si bien renforcée en face de la société bourgeoise qu'il lui suffit d'avoir à sa tête le chef de la société du 10 Décembre, chevalier de fortune venu de l'étranger, élevé sur le pavois par une soldatesque ivre, achetée avec de l'eau-de-vie et du saucisson, et à laquelle il lui faut constamment en jeter à nouveau. C'est ce qui explique le morne désespoir, l'effroyable sentiment de découragement et d'humiliation qui oppresse la poitrine de la France et entrave sa respiration. Elle se sent comme déshonorée.

Cependant, le pouvoir d'État ne plane pas dans les airs. Bonaparte représente une classe bien déterminée, et même la classe la plus nombreuse de la société française, à savoir les paysans parcellaires.

De même que les Bourbon avaient été la dynastie de la grande propriété foncière et les Orléans la dynastie de l'argent, les Bonaparte sont la dynastie des paysans, c'est-à-dire de la masse du peuple français. L'élu des paysans, ce n'était pas le Bonaparte qui se soumettait au Parlement bourgeois, mais le Bonaparte qui dispersa ce Parlement. Pendant trois ans, les villes avaient réussi à fausser le sens de l'élection du 10 décembre et à voler aux paysans le rétablissement de l'Empire. C'est pourquoi le coup d'État du 2 décembre 1851 ne fit que compléter l'élection du 10 décembre 1848.

Les paysans parcellaires constituent une masse énorme dont mes membres vivent tous dans la même situation, mais sans être unis les uns aux autres par des rapports variés. Leur mode de production les isole les des autres, au lieu de les amener à des relations réciproque. Cet isolement est encore aggravé par le mauvais état des moyens de communication en France et par la pauvreté des paysans. L'exploitation de la parcelle ne permet aucune division du travail, aucune utilisation des méthodes scientifiques, par conséquent, aucune diversité de développement, aucune variété de talents, aucune richesse de rapports sociaux. Chacune des familles paysannes se suffit presque complètement à elle-même, produit directement ellemême la plus grande partie de ce qu'elle consomme et se procure ainsi ses moyens de subsistance bien plus par un échange avec la nature que par un échange avec la société. La parcelle, le paysan et sa famille ; à côté, une autre parcelle, un autre paysan et une autre famille. Un certain nombre de ces familles forment un village et un certain nombre de villages un département. Ainsi, la grande masse de la nation française est constituée par une simple addition de grandeurs de même nom, à peu près de la même façon qu'un sac rempli de pommes de terre forme un sac de pommes de terre. Dans la mesure où des millions de 
familles paysannes vivent dans des conditions économiques qui les séparent les unes des autres et opposent leur genre de vie, leurs intérêts et leur culture à ceux des autres classes de la société, elles constituent une classe. Mais elles ne constituent pas une classe dans la mesure où il n'existe entre les paysans parcellaires qu'un lien local et où la similitude de leurs intérêts ne crée entre eux aucune communauté, aucune liaison nationale ni aucune organisation politique. C'est pourquoi ils sont incapables de défendre leurs intérêts de classe en leur propre nom, soit par l'intermédiaire d'un Parlement, soir par l'intermédiaire d'une Assemblée. Ils ne peuvent se représenter eux-mêmes, ils doivent être représentés. Leurs représentants doivent en même temps leur paraître comme leurs maîtres, comme une autorité supérieure, comme une puissance gouvernementale absolue, qui les protège contre les autres classes et leur envoie d'en haut la pluie et le beau temps. L'influence politique des paysans parcellaires trouve, par conséquent, son ultime expression dans la subordination de la société au pouvoir exécutif.

La tradition historique a fait naître dans l'esprit des paysans français la croyance miraculeuse qu'un homme portant le nom de Napoléon leur rendrait toute leur splendeur. Et il se trouva un individu qui se donna pour cet homme, parce qu'il s'appelait Napoléon, conformément à l'article du code Napoléon qui proclame : «La recherche de la paternité est interdite $^{(*)}$. » Après vingt années de vagabondage et une série d'aventures grotesques, la légende se réalise, et l'homme devient empereur des Français. L'idée fixe du neveu se réalisa parce qu'elle correspondait à l'idée fixe de la classe la plus nombreuse de la population française.

Mais, objectera-t-on, et les insurrections paysannes dans la moitié de la France, et les expéditions militaires contre les paysans, l'incarcération et la déportation en masse des paysans?

Depuis Louis XIV, la France n'a pas connu de semblables persécutions des paysans «pour menées démagogiques ».

Mais entendons-nous. La dynastie des Bonaparte ne représente pas le paysan révolutionnaire, mais le paysan conservateur; non pas le paysan qui veut se libérer de ses conditions d'existence sociale représentées par la parcelle, mais le paysan qui veut, au contraire, les renforcer; non pas le peuple campagnard qui veut, par son énergie, renverser la vieille société, en collaboration étroite avec les villes, mais, au contraire, celui qui, étroitement confiné dans ce vieux régime, veut être sauvé et avantagé, lui et sa parcelle, par le fantôme de l'Empire. La dynastie des Bonaparte ne représente pas le progrès, mais la foi superstitieuse du paysan, non pas son jugement, mais son préjugé, non pas son avenir, mais son passé, non pas ses Cévennes, mais sa Vendée.

Les trois années de domination sévère de la République parlementaire avaient libéré une partie des paysans français de l'illusion napoléonienne, et les avaient révolutionnés, quoique de façon seulement superficielle, mais la bourgeoisie es repoussa violemment chaque fois 
qu'ils se mirent en mouvement. Sous la République parlementaire, la conscience moderne des paysans français entra en conflit avec leur conscience traditionnelle. Le processus se poursuivit sous la forme d'une lutte incessante entre les maîtres d'école et les prêtres. La bourgeoisie battit les maitres d'école. Pour la première fois, les paysans s'efforcèrent d'avoir une attitude indépendante à l'égard de l'action du gouvernement. Cette opposition s'exprima par des conflits continuels entre les maires et les préfets. La bourgeoisie révoqua les maires. Enfin, les paysans de différentes localités se soulevèrent, pendant la période de la République parlementaire, contre leur propre progéniture, l'armée. La bourgeoisie les en punit au moyen de l'état de siège et d'exécutions, et maintenant cette même bourgeoisie se lamente sur la stupidité des masses, de la «vile multitude ${ }^{(*)}$ » qui l'a trahie en faveur de Bonaparte. C'et elle-même qui a renforcé violemment l'impérialisme ${ }^{31}$ de la classe paysanne, c'est elle qui a maintenu les conditions qui ont donné naissance à cette religion paysanne. Assurément, la bourgeoisie ne peut que craindre la stupidité des masses, tant qu'elles restent conservatrices, et leur intelligence, dès qu'elles deviennent révolutionnaires.

Dans les soulèvements qui se produisirent au lendemain du coup d'État, une partie des paysans français protestèrent, les armes à la main, contre leur propre vote du 10 décembre 1848. L'expérience réalisée depuis 1848 les avait assagis. Mais ils s'étaient donnés aux enfers de l'histoire, et celle-ci les prit au mot. D'ailleurs, la majorité d'entre eux étaient encore à tel point prisonniers de leurs propres illusions que c'est précisément dans les départements les plus rouges que la population paysanne vota ouvertement pour Bonaparte. Pour eux, l'Assemblée nationale l'avait empêché d'agir et il avait simplement brisé les liens dans lesquels les villes avaient enfermé la volonté des campagnes. Ils nourrissaient même, par endroits, l'idée grotesque de placer à côté de Napoléon une Convention.

Après que la première révolution eut transformé les paysans demi-serfs en libres propriétaires fonciers, Napoléon consolida et réglementa les conditions leur permettant d'exploiter tranquillement les terres qui venaient de leur échoir et de satisfaire leur enthousiasme juvénile de propriétaires. Mais c'est précisément sa parcelle même, la division du sol, la forme de propriété que Napoléon consolida en France, qui ruine maintenant le paysan français. Ce sont précisément les conditions matérielles qui firent du paysan féodal français un paysan parcellaire et de Napoléon un empereur. Deux générations ont suffi pour produire ce résultat inévitable: aggravation progressive de la situation de l'agriculture, endettement progressif de l'agriculture. La forme de propriété «napoléonienne », qui, au début du XIX ${ }^{\mathrm{e}}$ siècle, était la condition nécessaire de la libération et de l'enrichissement de la population paysanne française, est devenue, au cours de ce siècle, la cause principale de son esclavage et de son appauvrissement? Et c'est précisément la première des «idées

31 Il s'agit ici du culte de l'empereur. 
napoléoniennes * " que doit défendre le second Bonaparte. S'il partage encore avec les paysans l'illusion que ce n'est pas dans la propriété parcellaire elle-même, mais en dehors d'elle, dans l'effet de circonstances d'ordre secondaire, qu'il faut chercher la cause de sa ruine, toutes les expériences qu'il tentera se briseront comme des bulles de savon au contact des rapports de production.

Le développement économique de la propriété parcellaire a renversé de fond en comble les rapports de la paysannerie avec les autres clases de la société. Sous Napoléon, le parcellement du sol ne fit que compléter à la campagne le régime de la libre concurrence et de la grande industrie à ses débuts dans les villes. Le traitement de faveur même dont bénéficia la classe paysanne était dans l'intérêt de la nouvelle société bourgeoise. Cette classe nouvellement créée était le prolongement universel du régime bourgeois au-delà des portes des villes, sa réalisation à l'échelle nationale. Elle constituait une protestation partout présente contre l'aristocratie foncière qu'on venait précisément de renverser. Si elle d'un traitement de faveur, c'est qu'elle fournissait, plus que toutes les autres classes, une base d'offensive contre la restauration des féodaux. Les racines que la propriété parcellaire jeta dans le sol français enlevèrent tout aliment au féodalisme. Ses barrières constituèrent le rempart naturel de la bourgeoisie contre tout retour offensif de ses anciens seigneurs. Mais, au cours du XIXe siècle, l'usurier des villes remplaça les féodaux, l'hypothèque, les servitudes féodales du sol, le capital bourgeois, la propriété foncière aristocratique. La parcelle du paysan n'est plus que le prétexte qui permet au capitalisme de tirer de la terre profit, intérêt et rente et de laisser au paysan lui-même le soin de voir comment il réussira à se procurer son salaire. La dette hypothécaire pesant sur le sol impose à la paysannerie française une redevance aussi considérable que l'intérêt annuel de toute la dette publique de l'Angleterre. La propriété parcellaire, à laquelle son développement impose inévitablement cet état d'esclavage à l'égard du capital, a transformé la masse de la nation française en troglodytes. Seize millions de paysans (femmes et enfants compris) habitent dans des cavernes, dont un grand nombre ne possède qu'une seule ouverture, une petite partie n'en a que deux, et la partie la plus favorisée en a seulement trois. Or les fenêtres sont à une maison ce que les cinq sens sont à la tête. L'ordre bourgeois qui, au début du siècle, fit de l'État une sentinelle chargée de veiller à la défense de la parcelle nouvellement constituée qu'il engraissait de lauriers, est actuellement devenu un vampire qui suce son sang et sa cervelle et les jette dans la marmite d'alchimiste du capital. Le code Napoléon n'est plus que le code des exécutions et de la vente forcée. Aux quatre millions (enfants, etc., compris) d'indigents officiels, de vagabonds, de criminels et de prostituées que compte la France, viennent s'ajouter cinq millions d'hommes suspendus au bord de l'abîme et qui, ou bien habitent eux-mêmes à la campagne, ou passent constamment avec leurs haillons et leurs enfants, de la campagne dans les villes, et inversement. L'intérêt

En français dans le texte. 
des paysans n'est plus, par conséquent, comme sous Napoléon, en accord, mais en contradiction avec les intérêts de la bourgeoisie, avec le capital. Ils trouvent, par conséquent, leur allié et leur guide naturel dans le prolétariat des villes, dont la tâche est le renversement de l'ordre bourgeois. Mais le gouvernement fort et absolu, et c'est là la deuxième «idée napoléonienne * » que le second Napoléon doit mettre à exécution, est précisément appelé à défendre par la force cet «ordre matériel ${ }^{*} »$. Aussi, cet «ordre matériel » fournit-il le mot d'ordre qui revient constamment dans toutes les proclamations de Bonaparte contre les paysans révoltés.

A côté l'hypothèque que lui impose le capital, l'impôt vient également peser sur la parcelle. L'impôt est la source de vie de la bureaucratie, de l'armée, de l'Église et de la cour, bref de tout l'appareil du pouvoir exécutif. Gouvernement fort et lourds impôts sont deux termes synonymes. La propriété parcellaire, par sa nature même, sert de base à une bureaucratie toute-puissante et innombrable. Elle sur toute la surface du pays l'égalité de niveau des rapports et des personnes et, par conséquent, la possibilité pour un pouvoir central d'exercer la même action sur tous les points de cette même masse. Elle anéantit les couches aristocratiques intermédiaires, placées entre la masse du peuple et ce pouvoir central. Elle provoque, par conséquent, de toutes parts, l'intervention directe de ce pouvoir, et l'ingérence de ses organes directs. Elle crée enfin une surpopulation sans travail qui, ne trouvant place ni à la campagne ni dans les villes, recherche, par conséquent, les postes de fonctionnaires comme une sorte d'aumône respectable, et en provoque la création. Sous Napoléon, de nombreuses personnes gouvernemental n'était pas seulement directement productif en ce sens qu'au moyen des impôts prélevés par l'État, il réalisait pour la paysannerie nouvellement constituée, sous forme de travaux publics, ce que la bourgeoisie ne pouvait encore réaliser à l'aide de son industrie privée. L'impôt d'État était, par conséquent, un moyen de contrainte nécessaire pour maintenir les échanges entre la ville et la campagne. Sinon, le paysan parcellaire, comme c'est le cas en Norvège et dans une partie de la Suisse, aurait rompu, en rustre satisfait de lui-même, tout rapport avec le citadin. En ouvrant de nouveaux marchés à l'aide de ses baïonnettes et en pillant le continent, Napoléon remboursa les impôts prélevés, capital et intérêts compris. Ces impôts constituaient alors un stimulant pour l'industrie du paysan, tandis qu'ils enlevèrent maintenant à cette industrie ses dernières ressources et finissent de la désarmer contre le paupérisme. Une énorme bureaucratie chamarrée de galons et bien nourrie, voilà l'«idée napoléonienne "» qui sourit le plus au second Bonaparte. Comment ne lui plairait-elle pas, à lui qui se voit contraint de créer, à côté des véritables classes de la société, une caste artificielle, pour laquelle le maintien de son régime devient une question de couteau et de fourchette ? Aussi, l'une de ses dernières opérations fut-elle le

En français dans le texte.

En français dans le texte.

En français dans le texte. 
relèvement des appointements des fonctionnaires à leur ancien taux et la création de nouvelles sinécures.

Un autre «idée napoléonienne ${ }^{*}$ » est la domination des prêtres, en tant que moyen de gouvernement. Mais si la parcelle nouvellement constituée, dans son accord avec la société, sa dépendance à l'égard des forces naturelles et sa soumission à l'autorité, qui la protège d'en haut, était naturellement religieuse, la parcelle accablée de dettes, brouillée avec la société et l'autorité, poussée au-delà de sa propre étroitesse, devient naturellement irréligieuse. Le ciel était un agréable supplément au mince lopin de terre que l'on venait d'acquérir, d'autant plus que c'est lui qui fait la pluie et le beau temps. Mais il devient une insulte dès qu'on veut l'imposer pour remplacer la parcelle. Le prêtre n'apparaît plus, dès lors, que comme le limier consacré de la police terrestre, autre «idée napoléonienne», destinée, sous le second Bonaparte, non pas comme Napoléon, à surveiller les ennemis du régime paysan dans les villes, mais les ennemis de Bonaparte à la campagne. L'expédition contre Rome aura lieu, la prochaine fois, en France même, mais dans un tout autre sens que le voudrait $M$. de Montalembert.

L' « idée napoléonienne » essentielle, c'est, enfin, la prépondérance de l'armée. L'armée était le "point d'honneur " " des paysans parcellaires, c'était eux-mêmes transformés en héros, défendant la nouvelle forme de propriété à l'extérieur, magnifiant leur nationalité nouvellement acquise, pillant et révolutionnant le monde. L'uniforme était leur propre costume d'État, la guerre leur poésie, la parcelle prolongée et arrondie en imagination la patrie et le patriotisme la forme idéale du sentiment de propriété. Mais les ennemis contre lesquels le paysan français doit maintenant défendre sa propriété, ce en sont plus les cosaques, ce sont les huissiers et les percepteurs. La parcelle ne se trouve plus dans la prétendue patrie, mais dans le registre des hypothèques. L'armée elle-même n'est plus la fleur de la jeunesse paysanne, c'est la fleur de marais du sous-prolétariat rural. Elle se compose en grande partie de remplaçants, de succédanés, de même que le second Bonaparte n'est que le remplaçant, le succédané de Napoléon. Ses exploits consistent maintenant en chasés à courre et en battues contre les paysans, en un service de gendarmerie, et lorsque les contradictions internes de son système pousseront le chef de la société du 10 Décembre hors des frontières françaises, elle récoltera, après quelques actes de banditisme, non des lauriers, mais des coups.

Comme on le voit, toutes les «idées napoléoniennes» sont des idées conformes aux intérêts de la parcelle non encore développée et ayant encore la fraîcheur de la jeunesse. Elles sont en contradiction avec les intérêts de la parcelle passée au stade de la vieillesse. Elles ne sont que les hallucinations de son agonie, des mots qui se transforment en phrases, des esprits qui se transforment en spectres. Mais la parodie de l'impérialisme était nécessaire

En français dans le texte.

En français dans le texte. 
pour libérer la masse de la nation française du poids de la tradition et dégager dans toute sa pureté l'antagonisme existant entre l'État et la société. Avec la décadence croissante de la propriété parcellaire, s'écroule tout l'édifice de l'État édifié sur elle. La centralisation politique dont la société moderne a besoin ne peut s'élever que sur les débris de l'appareil gouvernemental, militaire et bureaucratique, forgé autrefois pour lutter contre le féodalisme. La bureaucratie n'est que la forme inférieure et brutale d'une centralisation, qui est encore affectée de son contraire, le féodalisme. En désespérant de la restauration napoléonienne, le paysan français perd la foi en sa parcelle, renverse tout l'édifice d'État construit sur cette parcelle et la révolution prolétarienne réalise ainsi le chour sans lequel, dans toutes les nations paysannes, son solo devient un chant funèbre.

La situation des paysans français nous dévoile l'énigme des élections générales des 20 et 21 décembre, qui conduisirent le second Bonaparte sur le mont Sinaï, non pour recevoir les lois, mais pour en donner. A vrai dire, la nation française commit, au cours de ces journées fatales, un péché mortel à l'égard de la démocratie, qui est à genoux et prie quotidiennement : «Saint suffrage universel, priez pour nous !» Les adorateurs du suffrage universel ne veulent évidemment pas renoncer à une puissance merveilleuse qui a réalisé en leur faveur de si grandes choses, qui a transformé Bonaparte II en un Napoléon, un Saül ${ }^{32}$ en un saint Paul ou un $S_{i m o n}{ }^{33}$ en un saint Pierre. L'esprit du peuple leur parle par l'intermédiaire de l'urne électorale, comme le Dieu du prophète Ezéchiel ${ }^{34}$ parla aux ossements desséchés : Haec dicit dominus deux ossibus suis : Ecce, ego intromittan in vos spiritum et vivetis. (Ainsi parla le Seigneur à ses ossements : Voici, je ferai pénétrer en vous l'esprit et vous vivrez !)

La bourgeoisie n'avait alors manifestement d'autre choix que d'élire Bonaparte. Despotisme ou anarchie. Elle se prononça naturellement pour le despotisme. Lorsque au concile de Constance ${ }^{35}$, les puritains se plaignirent de la vie dissolue des papes et se lamentèrent sur la nécessité d'une réforme des mœurs, le cardinal Pierre d'Ailly leur cria d'une voix de tonnerre : «Seul, le diable en personne peut sauver l'Église catholique, et vous demandez des anges !» De même, la bourgeoisie française s'écria au lendemain du coup d'État : Seul, le chef de la société du 10 Décembre peur encore sauver la société bourgeoise ! Seul le vol peut encore sauver la société bourgeoise! Seul le vol bâtardise la famille, le désordre, l'ordre !

32 Saül fut le premier roi d'Israël, et David le second. Saül avait fait du berger David son favori et son gendre. Mais jaloux des succès de celui-ci, il le pourchassa dans les montagnes. Il fut finalement battu par David qui lui succéda.

33 Selon la théologie catholique, l'un des douze apôtres de Jésus-Christ.

34 Un des quatre grands prophètes hébreux.

35 Ce concile (15 novembre 1414-22 avril 1418) avait pour but de recréer l'unité de la chrétienté (il y avait alors trois papes) en luttant contre les hérésies et les mœurs dissolues du clergé. 
Bonaparte, en tant que pouvoir exécutif qui s'est rendu indépendant de la société, se sent appelé à assurer l'« ordre bourgeois ». Mais la force de cet ordre bourgeois, c'est la classe moyenne. C'est pourquoi il se pose en représentant de cette classe et publie des décrets dans cet esprit. Mais il n'est quelque chose que parce qu'il a brisé et brise encore quotidiennement l'influence politique de cette classe moyenne. C'est pourquoi il se pose en adversaire de la puissance politique et littéraire de la classe moyenne. Mais, en protégeant sa puissance matérielle, il crée à nouveau sa puissance politique. C'est pourquoi, il lui faut conserver la cause tout en supprimant l'effet, partout où il se manifeste. Mais tout cela ne peut se faire sans de petites confusions de cause et d'effet, étant donné que l'un et l'autre, dans leur action et réaction réciproques, perdent leur caractère distinctif. D'où de nouveaux décrets qui effacent la ligne de démarcation. En même temps, Bonaparte s'oppose à la bourgeoisie en tant que représentant des paysans et du peuple, en général, qui veut, dans les limites de la société bourgeoise, faire le bonheur des classes inférieures. D'où, de nouveaux décrets qui privent par avance les «vrais socialistes » de leur sagesse gouvernementale. Mais Bonaparte se pose en avant tout en chef de la société du 10 Décembre, en représentant du sous-prolétariat, auquel il appartient lui-même, ainsi que son entourage, son gouvernement et son armée, et pour lequel il s'agit, avant tout, de soigner ses intérêts et de tirer du Trésor public des billets de loteries californiennes. Et il s'affirme chef de la société du 10 Décembre par décrets, sans décrets et malgré les décrets.

Cette tâche contradictoire de l'homme explique les contradictions de son gouvernement, ses tâtonnements confus, s'efforçant tantôt de gagner, tantôt d'humilier telle ou telle classe, et finissant par les soulever toutes en même temps contre lui. Cette incertitude pratique forme un contraste hautement comique avec le style impérieux, catégorique, des actes gouvernementaux, style docilement copié sur celui de l'oncle.

L'industrie et le commerce, par conséquent, les affaires de la classe moyenne, doivent prospérer sous un gouvernement fort comme en serre chaude. Par conséquent, octroi d'une foule de concessions de lignes de chemins de fer. Mais il faut enrichir également le sousprolétariat bonapartiste. Par conséquent, tripotages à la Bourse par les initiés sur les concessions de chemins de fer. Mais aucun capital ne se présente pour financer la construction des chemins de fer. On oblige donc la banque à faire de $\mathrm{s}$ avances sur les actions des compagnies de chemins de fer. Mais on veut également exploiter personnellement la banque, et c'est pourquoi on la cajole. On la décharge de l'obligation de publier son bilan hebdomadaire. Contrat léonin de la banque avec le gouvernement. Mais il faut donner du travail au peuple. On ordonne donc des travaux publics. Mais les constructions publiques augmentent les charges fiscales du peuple. On diminue donc les impôts au détriment des rentiers, en convertissant les rentes $5 \%$ en rentes $4,5 \%$. Mais il faut également offrir quelque douceur aux clases moyennes. On double donc l'impôt sur le vin pour le peuple qui l'achète 
« au détail " » et on diminue de moitié pour les classes moyennes qui le boivent « en gros * ». On dissout les organisations ouvrières existantes, mais on célèbre les futures merveilles de l'association. Il faut venir en aide aux paysans. On crée donc des banques de crédit foncier, qui précipitent son endettement et la concentration de la propriété. Mais ces banques doivent servir à obtenir de l'argent sur les biens confisqués de la maison d'Orléans. Mais comme aucun capitaliste ne veut accepter cette condition qui n'est pas dans le décret, la banque foncière reste un simple décret, etc., etc.

Bonaparte voudrait apparaître comme le bienfaiteur patriarcal de toutes les classes de la société. Mais il ne peut rien donner à l'une qu'il ne prenne à l'autre. De même qu'à l'époque de la Fronde * on disait du duc de Guise qu'il était l'homme le plus obligeant de France, parce qu'il avait transformé tous ses biens en obligations de ses partisans envers lui, de même Bonaparte voudrait être l'homme le plus obligeant de France pour pouvoir ensuite en faire cadeau à la France, ou plutôt pour pouvoir la racheter à l'aide de l'argent français, car, en tant que chef de la société du 10 Décembre, il faut qu'il achète ce qui doit lui appartenir. Et tout sert à acheter, toutes les institutions d'État, le Séant, le Conseil d'État, le Corps législatif, la Légion d'honneur, la médaille militaire, les lavoirs, les travaux publics, les chemins de fer, l'état-major de la garde nationale sans soldats, les biens confisqués de la maison d'Orléans. Chaque poste dans l'armée et dans la machine gouvernementale devient un moyen d'achat. Mais le plus important dans cette affaire, où l'on prend à la France pour lui donner ensuite ce qu'on lui a volé, ce sont les pourcentages qui, pendant le trafic, tombent dans les poches du chef et des membres de la société du 10 Décembre. Le mot d'esprit par lequel la comtesse L., la maitresse de M. de Morny, caractérisa la confiscation des biens de la maison d'Orléans : "C'est le premier vol de l'aigle *", s'applique à tous les vols de cet aigle, qui est d'ailleurs plus un corbeau qu'un aigle. Lui-même et ses partisans se répètent tous les jours ce que ce chartreux italien disait à l'avare qui énumérait fastueusement les biens qu'il avait encore pour des années à dévorer : Tu fai il conto sopra i béni, bisogna prima far il conto sopra gli anni. (Au lieu de compter tes biens, tu ferais mieux de commencer à compter les années qui te restent à vivre.) Pour ne pas se tromper dans le comte des années, ils comptent par minutes. A la cour, dans les ministères, à la tête de l'administration et de l'armée, se presse une foule de drôles, dont on peut dire du meilleur qu'on ne sait d'où il vient, toute une bohème bruyante, mal famée, pillarde, qui rampe dans ses habits galonnés avec la même dignité grotesque que les grands dignitaires de Soulouque ${ }^{36}$. On se représentera facilement cette couche supérieure

\footnotetext{
En français dans le texte.

En français dans le texte.

En français dans le texte.

En français dans le texte.
}

36 SoUlOUQUE (1782-1867) : président de la République nègre d'Haïti qui, imitant Napoléon Ier, se fit en 1849 empereur d'Haïti, s'entoura de tout un état-major de maréchaux et de généraux nègres, organisa sa cour sur 
de la société du 10 Décembre si l'on songe qu'elle a pour moraliste Véron-Crevel et comme penseur Granier de Cassagnac. Lorsque Guizot, à l'époque de son ministère, employait ce Granier dans une petite feuille contre l'opposition dynastique, il avait coutume de le vanter en disant : «C'est le roi des drôles ${ }^{(*)}$. » On aurait tort de rappeler la Régence ou Louis XV à propos de la cour et de la clique de Bonaparte. Car «... la France a déjà connu un assez grand nombre de gouvernements de maitresses, mais jamais encore un gouvernement d'hommes entretenus ».

Pressé par les exigences contradictoires de sa situation, et contraint, d'autre part, tel un prestidigitateur, de tenir par quelque tour surprenant les yeux du public constamment fixés sur lui comme le «succédané » de Napoléon et, par conséquent, de faire tous les jours un coup d'État en miniature, Bonaparte met sens dessus dessous toute l'économie bourgeoise, touche à tout ce qui avait paru intangible à la révolution de 1848, rend les uns résignés à la révolution et les autres désireux d'une révolution, et crée l'anarchie au nom même de l'ordre, tout en enlevant à la machine gouvernementale son auréole, en la profanant, en la rendant à la fois ignoble et ridicule. Il renouvelle à Paris le culte de la Sainte Tunique de Trèves ${ }^{37}$ sous la forme du culte impérial napoléonien. Mais le jour où le manteau impérial tombera enfin sur les épaules de Louis Bonaparte, la statue d'airain de Napoléon s'écroulera du haut de la colonne Vendôme.

le modèle français. Le peuple saisit avec esprit cette ressemblance en donnant à Louis Bonaparte le sobriquet de « Soulouque français ».

37 Relique sacrée conservée à la cathédrale de Trèves. D’après la légende, cette tunique était un cadeau fait par l'impératrice Hélène, mère de Constantin le Grand, à l'évêque de Trèves. En 1844, l'évêque Arnoldi exposa publiquement cette relique, ce qui provoqua l'indignation d'un grand nombre de catholiques et contribua à la formation du mouvement catholique allemand dirigé par Ronge. Ce dernier protesta vigoureusement dans une lettre adressée à Arnoldi, contre un tel fanatisme et une telle superstition. 